\title{
Halogens and their role in polar boundary-layer ozone depletion
}

\author{
W. R. Simpson ${ }^{1}$, R. von Glasow ${ }^{2}$, K. Riedel ${ }^{3}$, P. Anderson ${ }^{4}$, P. Ariya ${ }^{5}$, J. Bottenheim ${ }^{6}$, J. Burrows ${ }^{7}$, L. J. Carpenter ${ }^{8}$, \\ U. Frieß $^{9}$, M. E. Goodsite ${ }^{10}$, D. Heard ${ }^{11}$, M. Hutterli ${ }^{4}$, H.-W. Jacobi ${ }^{17}$, L. Kaleschke ${ }^{12}$, B. Neff ${ }^{13}$, J. Plane ${ }^{11}$, U. Platt ${ }^{9}$,

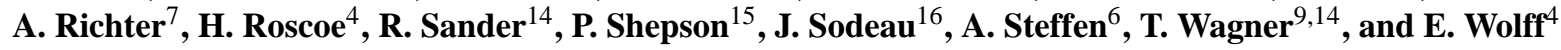 \\ ${ }^{1}$ Geophysical Institute and Department of Chemistry, University of Alaska Fairbanks, Fairbanks, AK, 99775-6160, USA \\ ${ }^{2}$ School of Environmental Sciences, University of East Anglia, Norwich, NR4 7TJ, UK \\ ${ }^{3}$ National Institute of Water and Atmospheric Research, Private Bag 14-901, Wellington, New Zealand \\ ${ }^{4}$ British Antarctic Survey, High Cross, Madingley Road, Cambridge CB3 0ET, UK \\ ${ }^{5}$ McGill University, Canada \\ ${ }^{6}$ Environment Canada, Toronto, Canada \\ ${ }^{7}$ Institute of Environmental Physics, University of Bremen, Bremen, Germany \\ ${ }^{8}$ Dept. of Chemistry, University of York, York YO10 5DD, UK \\ ${ }^{9}$ Institute for Environmental Physics, University of Heidelberg, Germany \\ ${ }^{10}$ University of Southern Denmark, Department of Chemistry and Physics, Campusvej 55 DK5230 Odense M, Denmark \\ ${ }^{11}$ School of Chemistry, University of Leeds, Leeds, LS29JT, UK \\ ${ }^{12}$ Center for Marine and Atmospheric Research, Institute of Oceanography, University of Hamburg, Bundesstrasse 53, 20146 \\ Hamburg, Germany \\ ${ }^{13}$ NOAA/Earth System Research Laboratory, Boulder CO, USA \\ ${ }^{14}$ Air Chemistry Department, Max-Planck Institute of Chemistry, PO Box 3060, 55020 Mainz, Germany \\ ${ }^{15}$ Purdue Climate Change Research Center, 503 Northwestern Ave. West Lafayette, IN 47907, USA \\ ${ }^{16}$ Department of Chemistry, University College Cork, Ireland \\ ${ }^{17}$ Alfred Wegner Institute (AWI) for Polar and Marine Research, Bremerhaven, Germany
}

Received: 5 March 2007 - Published in Atmos. Chem. Phys. Discuss.: 29 March 2007

Revised: 30 July 2007 - Accepted: 16 August 2007 - Published: 22 August 2007

\begin{abstract}
During springtime in the polar regions, unique photochemistry converts inert halide salt ions (e.g. $\mathrm{Br}^{-}$) into reactive halogen species (e.g. $\mathrm{Br}$ atoms and $\mathrm{BrO}$ ) that deplete ozone in the boundary layer to near zero levels. Since their discovery in the late 1980s, research on ozone depletion events (ODEs) has made great advances; however many key processes remain poorly understood. In this article we review the history, chemistry, dependence on environmental conditions, and impacts of ODEs. This research has shown the central role of bromine photochemistry, but how salts are transported from the ocean and are oxidized to become reactive halogen species in the air is still not fully understood. Halogens other than bromine (chlorine and iodine) are also activated through incompletely understood mechanisms that are probably coupled to bromine chemistry. The main consequence of halogen activation is chemical destruction of ozone, which removes the primary precursor of atmospheric oxidation, and generation of reactive halogen atoms/oxides that become the primary oxidizing species. The different re-
\end{abstract}

Correspondence to: W. R. Simpson

(ffwrs@uaf.edu) activity of halogens as compared to $\mathrm{OH}$ and ozone has broad impacts on atmospheric chemistry, including near complete removal and deposition of mercury, alteration of oxidation fates for organic gases, and export of bromine into the free troposphere. Recent changes in the climate of the Arctic and state of the Arctic sea ice cover are likely to have strong effects on halogen activation and ODEs; however, more research is needed to make meaningful predictions of these changes.

\section{Introduction, history, and chemical mechanisms}

\subsection{Introduction}

The Arctic and Antarctic, geographically remote as they may be, have a significant impact on the global atmosphere. They play an important role in the atmospheric and oceanic circulation and are regions where unusual chemical processes take place. The glacial ice in polar regions represents an exceptional archive of atmospheric composition histories, which

Published by Copernicus Publications on behalf of the European Geosciences Union. 


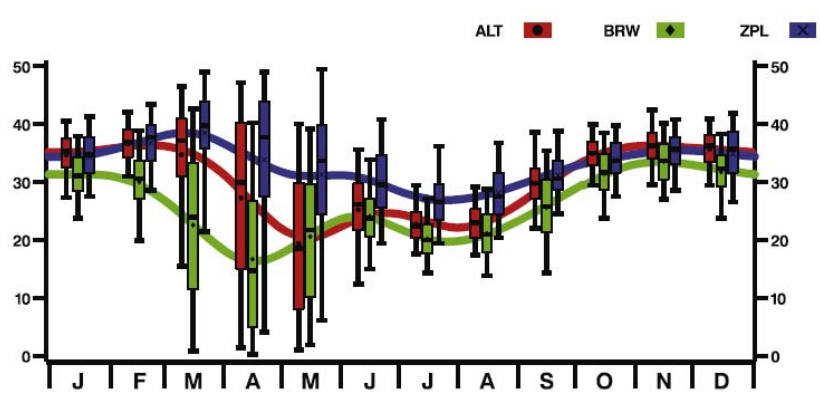

Fig. 1. Box and whisker plots showing 9 years of observations of $\mathrm{O}_{3}$ mole fractions in $(\mathrm{nmol} / \mathrm{mol})$ at Alert (red), Barrow (green), and Zeppelinfjellet (also called Ny-Ålesund in this paper) (blue). The smoothing curves were generated by LOWESS, a nonparametric technique used here to illustrate the seasonal cycles for the three stations (Cleveland and Devlin, 1988; Peña et al., 2000). Lower and upper whiskers are the 5th and 95th percentiles, while the bottom and top of boxes are the 25 th and 75 th percentiles, respectively. Horizontal lines inside the boxes are monthly median values for the 9-year period, and the symbols are monthly means. Reprinted from Bottenheim and Chan (2006) with permission from the American Geophysical Union (AGU).

can be extracted by ice coring. The Arctic, in particular, is influenced by pollution affecting the biosphere and indigenous people, for example by deposition of mercury and persistent organic pollutants (POPs).

The atmospheres of the Arctic and Antarctic are unique. Dominated by cold temperatures, stable stratification of the boundary layer and unusual light conditions, they are an exceptional natural laboratory to study atmospheric processes. The Antarctic atmosphere is pristine, dry and isolated from the rest of the atmosphere by the surrounding Southern Ocean and the polar vortex. The Arctic, however, is strongly influenced by seasonal atmospheric transport and anthropogenic emissions due to its proximity to landmasses and highly industrialized countries. Lifetimes of chemical species are long in polar environments, especially during the dark months of winter with a lack of photochemistry. The winter/spring Arctic pollution phenomenon, known as Arctic haze (e.g. Mitchell, 1957; Schnell, 1983; Barrie et al., 1989; Shaw, 1995; Stohl, 2006), is enhanced by inefficient dispersal of pollutants and slow removal rates (Barrie, 1986).

Large areas in the polar regions are perennially covered by ice, providing an invaluable paleoarchive in the form of glacial ice cores (Legrand, 1997; Legrand and Mayewski, 1997; EPICA community members, 2004). Understanding polar atmospheric chemistry is essential for the interpretation of ice cores and to reconstruct past variations in atmospheric composition.

Interest in Antarctic atmospheric chemistry intensified after it was postulated that industrially produced halocarbons (particular chlorofluorocarbons, CFCs) could cause se- vere depletion in stratospheric ozone (Molina and Rowland, 1974). In the mid 1980s, the springtime stratospheric ozone hole over Antarctica was discovered (Farman et al., 1985). The ozone hole involves heterogeneous reactions on polar stratospheric clouds that lead to chlorine activation (Solomon et al., 1986).

Like the discovery of stratospheric ozone depletion, the observation of ozone depletion events within the polar boundary layer in the mid-1980s came as a surprise. Episodes of low surface ozone concentrations were measured at Barrow, Alaska $\left(71^{\circ} \mathrm{N}, 157^{\circ} \mathrm{W}\right.$, Oltmans, 1981; Oltmans and Komhyr, 1986) and at Alert, northern Canada $\left(82.5^{\circ} \mathrm{N}\right.$, $62.3^{\circ} \mathrm{W}$, Bottenheim et al., 1986; Barrie et al., 1989) in late winter/early spring. Ozone levels drop from typical levels of $>30 \mathrm{nmol} / \mathrm{mol}$ to below $10 \mathrm{nmol} / \mathrm{mol}$, or even below detection limit (Oltmans, 1981; Barrie et al., 1988). These episodes were called "ozone depletion events" (ODEs, Oltmans et al., 1989). After being discovered in the Arctic, ODEs were also observed in the Antarctic boundary layer (Kreher et al., 1996, 1997; Wessel et al., 1998) prompting a variety of new field programs and satellite investigations in the Antarctic. Interestingly, ozone depletions were measured in 1958 at Halley, but the data were not interpreted until the late 1990s. For an historic overview, see Sect. 1.2.

Early on, halogens were found to be involved in the ozone depletion process, since strong ozone depletion events coincided with high levels of filterable bromine (f-Br) (Barrie et al., 1988). A bromine radical-catalyzed cycle involving $\mathrm{Br}$ and $\mathrm{BrO}$ was suggested (Barrie et al., 1988; Fan and Jacob, 1992; McConnell et al., 1992; Hausmann and Platt, 1994) with $\mathrm{BrO}+\mathrm{BrO} \rightarrow 2 \mathrm{Br}+\mathrm{O}_{2}$ as the central reaction (for a detailed discussion of the chemical mechanism see Sect. 1.3). In contrast, stratospheric ozone depletion is dominated by chlorine chemistry $\left(\mathrm{ClO}\right.$ self reaction forming the $\mathrm{Cl}_{2} \mathrm{O}_{2}$ dimer) and halogen oxide cross reactions (Yung et al., 1980; McElroy et al., 1999).

Because ozone is the precursor for most atmospheric oxidizers, it generally controls the atmospheric oxidation potential. However, during ozone depletion events, ozonedominated oxidation pathways become less important and unique halogen-dominated oxidation pathways become most important. These new pathways alter lifetimes of species and change their fates in the environment. A key example of this effect is that halogens efficiently oxidize gas-phase mercury and cause it to be transferred from the atmosphere to the snow, probably enhancing its bioavailability. This important topic is briefly discussed in Sect. 4.1 and in more detail in an accompanying article (Steffen et al., 2007). Another example is volatile organic compounds (VOCs) that get very efficiently oxidized by the $\mathrm{Cl}$ atom (see Sects. 2.2 and 4.2).

Ozone depletion episodes are most commonly observed during springtime, March to May in the Arctic (Tarasick and Bottenheim, 2002; Bottenheim and Chan, 2006) and August to October in the Antarctic (Kreher et al., 1997; Roscoe et al., 2001; Frieß et al., 2004; Jones et al., 2006), when sunlight re- 
turns to the high latitudes, but temperatures are still low (below $-20^{\circ} \mathrm{C}$ ). Most observations of ODEs have been recorded from coastal sites when the ocean is frozen and snow covered, although leads and polynyas dynamically open exposing salt water and freeze over again. A statistical analysis of the ozone seasonal cycle at Alert, Barrow, and Ny-Ålesund $\left(79^{\circ} \mathrm{N}, 12^{\circ} \mathrm{E}\right)$ is shown in Fig. 1. For a map of all sites described in this paper and their geographic coordinates, see the electronic supplement (http://www.atmos-chem-phys.net/7/ 4375/2007/acp-7-4375-2007-supplement.pdf). In this figure, ODEs appear as decreases in the smooth seasonal cycle during March, April, and May and enhanced variability during these months. Typical unaveraged data show either high ( 30-40 nmol/mol) ozone or near zero values, depending upon whether the site is experiencing a background or an ODE air mass.

The most severe and temporally extensive ODEs have been observed over the frozen Arctic Ocean. Measurements performed on ice floes in the Arctic during ice camp SWAN northwest of Ellesmere Island (Hopper et al., 1994) and Narwhal, $160 \mathrm{~km}$ North of Alert (Hopper et al., 1998) found that ozone levels were regularly very close to zero. Ship-borne measurements performed in the Arctic in 2005 confirm this observation (Jacobi et al., 2006). Hopper et al. (1994) reported that ozone was undetectable $(<0.4 \mathrm{nmol} / \mathrm{mol})$ during $40 \%$ of the time at polar sunrise during ice camp SWAN. During the flight campaign TOPSE, Ridley et al. (2003) observed large areas over the Arctic with low ozone levels and Zeng et al. (2003) estimate that $20 \%$ of the area of the northern high latitudes are influenced by ODEs. This finding is in agreement with satellite measurements that show large and persistent areas of elevated $\mathrm{BrO}$ in spring over the Arctic (Richter et al., 1998c; Wagner and Platt, 1998a). Recent analysis of historic ozone data from 1958 showed depleted ozone also in the Antarctic boundary layer in the middle of winter (Roscoe and Roscoe, 2006), suggesting a different chemical mechanism since no sunlight is available for photolytic reactions.

The main source of reactive bromine species $(\mathrm{Br}$ and $\mathrm{BrO})$ is bromide from sea salt that is released via a series of photochemical and heterogeneous reactions known as the bromine explosion (see Sect. 1.3). Biogenic oceanic sources have been discussed from the early days (Barrie et al., 1988) but are probably of smaller importance as bromine source for polar regions. Biogenic halogen sources may be of more importance to upper tropospheric chemistry, as has been recently considered (Yang et al., 2005; Salawitch, 2006). Considering boundary-layer halogen activation, it is still unclear how bromide from sea salt is released to the gas phase. Interactions between snow/ice surfaces and the atmosphere probably play an important role. Sea-ice surfaces, aerosol, brine, and frost flowers - delicate ice crystals that grow out of the vapor phase and transport concentrated brines of young seaice - have raised a lot of interest as bromine source in recent investigations. However, the question remains unsolved so far and is discussed in detail in Sect. 3.1 of this article.

Ozone depletion events occur mostly over the frozen ocean, as supported by aircraft (Ridley et al., 2003), ground based ice camp (Hopper et al., 1994, 1998), and ship-borne observations (Jacobi et al., 2006). Satellite observations of $\mathrm{BrO}$ also indicate that it is present mostly over the frozen ocean, thus indirectly indicating $\mathrm{O}_{3}$ depletion over frozen oceans (Richter et al., 1998c; Wagner and Platt, 1998a; Wagner et al., 2001). However, depleted air masses can also be transported to lower latitudes or over land. When discussing ODEs, it is important to distinguish between advection of ozone depleted air masses to a measuring site (meteorology controlled), local chemical ozone depletion (chemistry controlled) and a combination of the two.

Section 3.2 contains further discussion of the relationship between boundary layer structure and ozone depletion episodes. Transport-controlled ODEs can be very rapid in their onset (timescale of minutes, Morin et al., 2005), associated with significant $\mathrm{O}_{3}$ loss and wind speed and direction changes (Jones et al., 2006), while chemically controlled ODEs appear normally much more gradual and are not as intense (Jones et al., 2006). However, some fast $\mathrm{O}_{3}$ depletions $(\sim 7 \mathrm{~h})$ have been linked to local chemistry (Jacobi et al., 2006). The duration of ODEs at coastal sites is typically between 1-3 days, depending on meteorology. During ALERT2000, a 9-day period with basically no ozone occurred, one of the longest ODEs ever recorded at Alert (Bottenheim et al., 2002; Strong et al., 2002). In April 1992 during ice camp SWAN, Hopper et al. (1994) detected ODEs most of the time with ozone at or below the detection limit $(0.4 \mathrm{nmol} / \mathrm{mol})$ more than $40 \%$ of the 18 day measurement period. From the analysis of historical ozonesonde records, Tarasick and Bottenheim (2002) concluded that springtime surface temperatures below $-20^{\circ} \mathrm{C}$ seem to be required for the occurrence of ODEs. However, observations of $\mathrm{BrO}$ at above freezing temperatures over salt lakes and lake beds indicate that cold temperatures are not a prerequisite for halogen activation (e.g. Hebestreit et al., 1999, see also Sect. 2.1.3). The mechanism by which halogen activation occurs at salt lakes may be subtly different from that of polar halogen activation, which does seem to be enhanced by cold temperatures (Tarasick and Bottenheim, 2002). The end of an ODE is largely determined by meteorology since vertical or horizontal mixing with $\mathrm{O}_{3}$-rich air is required to replenish $\mathrm{O}_{3}$. Chemical $\mathrm{O}_{3}$ production is generally not sufficient for a recovery (due to low $\mathrm{NO}_{\mathrm{x}}$ ).

The frequency of ODEs at Arctic and some Antarctic stations was analyzed from historical ozonesonde records by Tarasick and Bottenheim (2002). ODEs occurred frequently at Alert, Resolute, and Eureka (Barrow was not considered in this study, but also shows frequent ODEs). Other Arctic stations such as $\mathrm{Ny}$-Ålesund and Churchill experienced fewer ODEs probably due to less nearby sea ice coverage and warmer conditions.

Vertically, most ODEs extend from the surface to 100- 
Table 1. Major field campaigns related to ODEs in the Arctic and Antarctic. The following are acronyms in the table: Arctic Gas and Aerosol Sampling Program (AGASP), Polar Sunrise Experiment (PSE), Tropospheric Ozone Production during the Spring Equinox (TOPSE), NItrogen Cycle and Effects on the oxidation of atmospheric trace species at high latitudes (NICE), Out On The Ice (OOTI), Chemistry of the Antarctic Boundary Layer and the Interface with Snow (CHABLIS). ARCTOC was an ozone depletion campaign in Ny-Ålesund, and LEADX involved experiments at an open lead near Barrow. Some campaigns do not yet have an overview paper and thus do not have a reference.

\begin{tabular}{cccl}
\hline Campaign & Location & year & Reference \\
\hline AGASP-II & Arctic Ocean & 1986 & Mickle et al. (1989) \\
PSE 88 & Alert, Canada & 1988 & Bottenheim et al. (1990) \\
AGASP-III & Barrow, Alaska & 1989 & Sturges and Shaw (1993) \\
PSE 92 & Alert, Canada & 1992 & Barrie et al. (1994) \\
AGASP-IV & Arctic Ocean & 1992 & Davidson and Schnell (1993) \\
PSE 94 & Alert, Canada & 1994 & Hopper et al. (1998) \\
ARCTOC & Ny-Ålesund, Svalbard & 1995,1996 & Platt and Lehrer (1996); Barrie and Platt (1997) \\
PSE 98 & Alert, Canada & 1998 & \\
ALERT2000 & Alert, Canada & 2000 & Bottenheim et al. (2002) \\
TOPSE & North American Arctic & 2000 & Atlas et al. (2003) \\
NICE & Ny-Ålesund, Svalbard & 2001 & Beine et al. (2003) \\
OOTI & Alert, Canada & 2004,2005 & Morin et al. (2005) \\
LEADX & Barrow, Alaska & 2004,2005 & \\
CHABLIS & Halley, Antarctica & 2004 & Jones et al. (2007) \\
\hline
\end{tabular}

1 Jones, A. E., W., W. E., Salmon, R. A., and Bauguitte, S. J.-B.: Chemistry of the Antarctic Boundary Layer and the Interface with Snow: An overview of the CHABLIS campaign, Atmos. Chem. Phys. Discuss., in preparation, 2007.

$400 \mathrm{~m}$ (Mickle et al., 1989; Leaitch et al., 1994; Anlauf et al., 1994; Gong et al., 1997; Tarasick and Bottenheim, 2002; Bottenheim et al., 2002; Strong et al., 2002; Tackett et al., 2007), but the depth can increase during the season, from $100-200 \mathrm{~m}$ in early spring to as high as $1-2 \mathrm{~km}$ altitude in late spring (Bottenheim et al., 2002; Ridley et al., 2003). Solberg et al. (1996) found that during some episodes in the Norwegian Arctic ozone was nearly completely depleted up to $2 \mathrm{~km}$ altitude. DOAS measurements at Alert (Hönninger and Platt, 2002), Hudson Bay (Hönninger et al., 2004b), and Neumayer, Antarctica (Frieß et al., 2004) showed that BrOenriched air is often found at the surface but can be lifted to elevations of up to $4 \mathrm{~km}$ (Frieß et al., 2004).

This review article presents our current knowledge on tropospheric ozone depletion in the Arctic and Antarctic. It combines a historical review of the discovery of the phenomenon (in Sect. 1.2) with the most recent laboratory, modeling, remote sensing, and field results. Chemical reaction mechanisms for bromine, chlorine and iodine are discussed in Sect. 1.3. Methods involved in the study of ODEs are discussed in Sect. 1.4, while observations of halogens and their roles in ODEs are discussed in Sect. 2. The influence of sea ice, boundary layer meteorology and photochemistry on ODEs is discussed in Sect. 3, while the impacts of ODEs on mercury deposition, ice cores, the free troposphere and other aspects of polar chemistry are described in Sect. 4. Open questions and future scenarios of ozone depletion events are highlighted in Sect. 5 of this article.

\subsection{Historic overview of the discovery of ODEs}

The first reports on surface ozone depletion in the Arctic date from the 1980s. In a paper on surface ozone measurements in clean air, Oltmans (1981) noted that the greatest day-to-day changes in $\mathrm{O}_{3}$ occurred at Barrow during the spring. Similarly, Bottenheim et al. (1986) reported a significant (and quite variable) decrease in $\mathrm{O}_{3}$ levels at Alert without being able to explain these observations. The key to the understanding of the Arctic surface ozone depletion came shortly afterwards. During the second AGASP campaign (Arctic Gas and Aerosol Sampling Program; see Table 1 for an overview of major field campaigns related to ODEs) in 1986, ozone was sampled together with Br collection on cellulose filters. Atmospheric bromine was chosen to be studied because of another curious observation in spring, the occurrence of "excess of filterable bromine" (f-Br), bromine that could not be explained from windblown dust, sea salt, or automobile fuel additives (Berg et al., 1983; Sturges, 1990). Ozone and f-Br data from spring 1986 at Alert (Fig. 2) show the now classical strong negative correlation (Barrie et al., 1988). Barrie et al. (1988) hypothesized that the chemical mechanism of $\mathrm{O}_{3}$ depletion involves a bromine-catalyzed chain reaction and that photolysis of bromoform $\left(\mathrm{CHBr}_{3}\right)$ could be the source of $\mathrm{Br}$ atoms. They speculated that heterogeneous chemistry on ice surfaces could be involved. In subsequent years knowledge advanced through intensive field campaigns as well as laboratory and modeling studies. A chronology of major field campaigns in the Arctic follows (Table 1). 
The first field campaign dedicated to the study of ODEs was the Polar Sunrise Experiment 1988, PSE88, see Bottenheim et al. (1990) at Alert, Canada. The PSE88 campaign involved studies that investigated the bromoform photolysis hypothesis proposed by Barrie et al. (1988). Indeed, during PSE88 a strong negative correlation between $\mathrm{O}_{3}$ and $\mathrm{CHBr}_{3}$ was observed, results that were confirmed during the second Polar Sunrise Experiment at Alert in 1992 (PSE92, Yokouchi et al., 1994). Similar correlations were observed at Barrow during the AGASP-III experiment in 1989 (Sturges and Shaw, 1993). However, $\mathrm{CHBr}_{3}$ photochemistry as cause for $\mathrm{O}_{3}$ depletion was ruled out after absorption spectra of $\mathrm{CHBr}_{3}$ were obtained and spectroscopic data were analysed (Moortgat et al., 1993). Using this cross section, the photolytic lifetime of bromoform under Arctic springtime conditions is $\sim 100$ days (Simpson et al., 2002), indicating that very little of the reactive bromine could come from the relatively low observed concentrations of bromoform (Yokouchi et al., 1996). Nevertheless, a truly satisfactory explanation for the strong $\mathrm{CHBr}_{3}-\mathrm{O}_{3}$ correlation was not found. It has been proposed that reactive halogen chemistry during ODEs could in fact be producing halocarbon gases (Carpenter et al., 2005b), possibly explaining high halocarbon gas abundances during ODEs (see Sect. 3.3.2). Based on trajectory calculations and satellite images Sturges and Shaw (1993) deduced that high levels of $\mathrm{CHBr}_{3}$ were due to recent passage $(<24 \mathrm{~h})$ of the air over open leads in the ice. This implied that $\mathrm{O}_{3}$ depletion also must have occurred within the same time period. Another important result from AGASP-III, which was largely an aircraft campaign, was that $\mathrm{O}_{3}$ depletion in the marine boundary layer was observed commonly over the Arctic Ocean (Sheridan et al., 1993). They also confirmed that $\mathrm{f}-\mathrm{Br}$ was mostly particlulate $\mathrm{Br}$, and not gas-phase $\mathrm{HBr}$ (Sturges and Shaw, 1993; Sturges et al., 1993).

During PSE92 (Barrie et al., 1994), long-path DOAS measurements confirmed for the first time the role of BrO (Hausmann and Platt, 1994) and Jobson et al. (1994) showed that $\mathrm{Cl}$ atom chemistry, although not driving $\mathrm{O}_{3}$ depletion, was taking place, confirming speculations by Kieser et al. (1993).

During an 18-day study at ice camp SWAN, $\mathrm{O}_{3}$ was depleted over the Arctic ocean for most of the time and only increased due to turbulent mixing of ozone-rich air from aloft (Hopper et al., 1994). Ingenious methods were designed and employed to measure "photolysable bromine" (Impey et al., 1997b) and in-situ BrO (Mihele and Hastie, 1998). Furthermore, continuing efforts were made to determine low molecular weight carbonyl compounds (formaldehyde $\mathrm{HCHO}$, acetaldehyde $\mathrm{CH}_{3} \mathrm{CHO}$, acetone $\mathrm{CH}_{3} \mathrm{COCH}_{3}$ ), as they were thought to play an important role in the cycling of reactive bromine (Barrie et al., 1988). During PSE92, de Serves (1994) made on-site measurements and found HCHO levels much higher than predicted by Barrie et al. (1988), based on a gas phase production mechanism. Studies using the DNPH (2,4-Dinitrophenylhydrazine) technique (Shepson et al., 1996) yielded similar high concentrations, which were

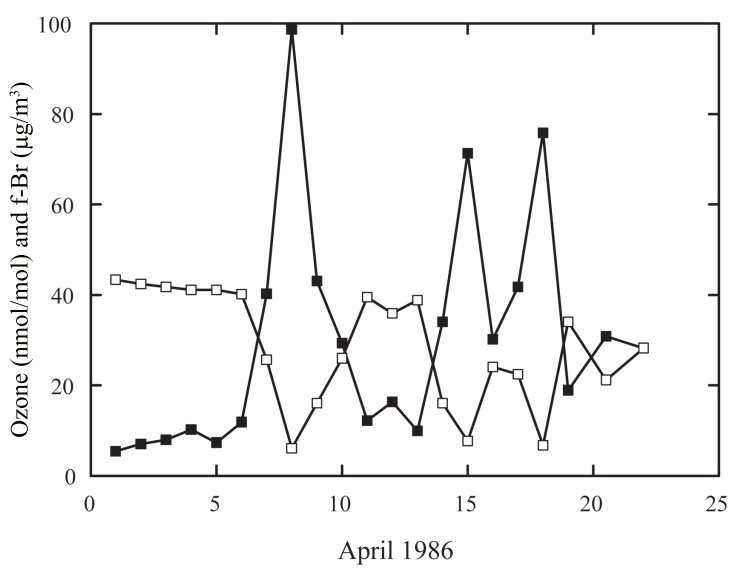

Fig. 2. The first published observation of the anticorrelation between ozone and filterable bromine, measured at Alert. Filled squares show filterable $\mathrm{Br}(\mathrm{f}-\mathrm{Br})$ in $\mathrm{ng} / \mathrm{m}^{3}$, from $24 \mathrm{~h}$ filter pack, open squares show daily averaged ozone in nmol/mol (ppbV). Reprinted by permission from Macmillan Publishers LTD: Nature, Barrie et al. (1988), copyright 1988.

explained during PSE98, when it was discovered that gas phase HCHO was emitted from the snow (Fuhrer et al., 1996; Hutterli et al., 1999; Sumner and Shepson, 1999). At the same time, Honrath et al. (1999) discovered at Summit that $\mathrm{NO}_{\mathrm{x}}$ was produced in sunlit snow. These unexpected discoveries of active snow pack chemistry became a major topic of research, giving rise to summer projects at Summit in 1999, 2000, 2001, 2002, 2003, 2004, and 2006, the ALERT2000 campaign, and the South Pole campaigns in 1998, 2000, and 2003 (for further information see the accompanying snow photochemistry review, Grannas et al., 2007). It was shown that $\mathrm{O}_{3}$, once in the snow pack, is short lived (Bottenheim et al., 2002), that molecular halogens $\left(\mathrm{Br}_{2}, \mathrm{BrCl}\right)$ are produced in the snow (Foster et al., 2001) along with several other species like $\mathrm{NO}_{\mathrm{x}}$, HONO and VOCs, and that oxidized mercury $(\mathrm{Hg}$ (II)) can be photo-reduced in the snow leading to re-emission of elemental $\mathrm{Hg}$ into the atmosphere (see also the accompanying mercury review, Steffen et al. (2007).

While many discoveries have first been made in the Arctic, these processes have subsequently been observed to varying degrees in the Antarctic. Boundary layer $\mathrm{O}_{3}$ depletion in the Antarctic was first observed in the mid-1990s (Kreher et al., 1996, 1997; Wessel et al., 1998) also reporting the presence of BrO (Kreher et al., 1997). Since then, many more Antarctic field (Rankin et al., 2002; Wolff et al., 2003; Frieß et al., 2004; Jones et al., 2006; Kalnajs and Avallone, 2006) and satellite studies (Wagner and Platt, 1998a; Richter et al., 1998c; Hegels et al., 1998a; Kaleschke et al., 2004) have been performed. Analysis of historical surface ozone data from Halley has shown that ozone depletion events were observed as early as 1957/8 during the International Geophysical Year (Roscoe and Roscoe, 2006). 


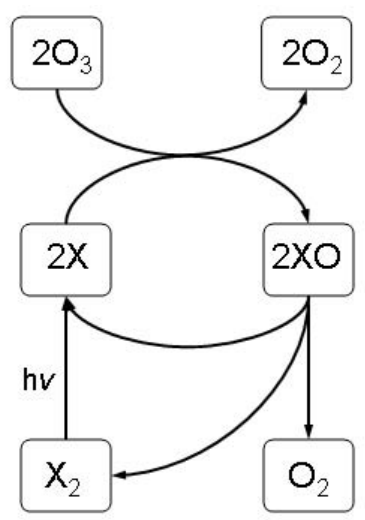

Fig. 3. Key reactions for the XO self reaction ozone destruction reaction cycle.

\subsection{Key reactions and cycles}

In this section, we discuss key chemical reactions and reaction cycles involved in ozone depletion chemistry. This discussion is not meant to be a complete discussion of all halogen chemistry; the interested reader is referred to recent reviews on this topic (Wayne et al., 1995; Platt and Janssen, 1995; Platt and Moortgat, 1999; Platt and Hönninger, 2003; von Glasow and Crutzen, 2003, 2007). The overall catalytic ozone destruction mechanism involves halogen atoms (denoted by $\mathrm{X}, \mathrm{Y}$, where $\mathrm{X}, \mathrm{Y}=\mathrm{Cl}, \mathrm{Br}$, or I) that cycle between their atomic forms and their oxides, $\mathrm{XO}$. Halogen atoms are formed from precursors such as $\mathrm{Br}_{2}, \mathrm{BrCl}, \mathrm{HOBr}$, etc., as discussed below. The typical fate of an atomic halogen radical is to react with ozone, forming a halogen oxide molecule.

$\mathrm{X}+\mathrm{O}_{3} \rightarrow \mathrm{XO}+\mathrm{O}_{2}$

Typical conversion times (at $40 \mathrm{nmol} / \mathrm{mol} \mathrm{O}_{3}$ ) via Reaction (R1) for $\mathrm{Cl}$ are around $0.1 \mathrm{~s}$ and of the order of $1 \mathrm{~s}$ for $\mathrm{Br}$ and I atoms. Halogen atoms are regenerated in a series of reactions including photolysis of $\mathrm{XO}$, which is of importance for $\mathrm{X}=\mathrm{I}, \mathrm{Br}$ and to a minor extent $\mathrm{Cl}$,

$\mathrm{XO}+h v \rightarrow \mathrm{X}+\mathrm{O}$

For this reaction, typical springtime Arctic daytime values of Eq. (J2) are $\sim 3 \times 10^{-5} \mathrm{~s}^{-1}, \sim 4 \times 10^{-2} \mathrm{~s}^{-1}$, and $0.2 \mathrm{~s}^{-1}$ for $\mathrm{X}=\mathrm{Cl}, \mathrm{Br}$, I, respectively. Often the photolysis of halogen oxides is the fastest decay of those species, thus the partitioning of $\mathrm{X} / \mathrm{XO}$ is controlled by a balance of Reactions (R1) and (J2). Because of this rapid cycling, the sum of $\mathrm{Br}+\mathrm{BrO}$ is called the $\mathrm{BrO}_{\mathrm{x}}$ family. For bromine, during the day and at high ozone, $\mathrm{BrO}$ is the prevalent $\mathrm{BrO}_{\mathrm{x}}$ species; however at low ozone $(<1 \mathrm{nmol} / \mathrm{mol})$, calculations suggest that $\mathrm{Br}$ can become more abundant than $\mathrm{BrO}$.
For catalytic destruction of ozone to occur, the XO must recycle to $\mathrm{X}$ atoms without production of ozone. The primary reactions that destroy ozone are the reactions with other halogen oxides or $\mathrm{HO}_{2}$. In polar regions, the halogen oxide reactions are most important, so we consider them first. The self reaction of halogen oxides reforms halogen atoms or dihalogens, which rapidly photolyse leading again to two $\mathrm{X}$ atoms,

$$
\begin{aligned}
\mathrm{XO}+\mathrm{XO} & \rightarrow 2 \mathrm{X}+\mathrm{O}_{2} \\
& \rightarrow \mathrm{X}_{2}+\mathrm{O}_{2}
\end{aligned}
$$

In the case of $\mathrm{XO}=\mathrm{BrO}$ the rate constant $k_{3}=3.2 \times 10^{-12} \mathrm{~cm}^{3} \mathrm{molec}^{-1} \mathrm{~s}^{-1}$ (Atkinson et al., 2006). The reaction sequence that combines (R1) and (R3) using $\mathrm{X}=\mathrm{Br}$ was proposed by Barrie et al. (1988) to explain Arctic ozone depletion episodes (Fig. 3),

$$
\begin{gathered}
2 \times\left(\mathrm{Br}+\mathrm{O}_{3} \rightarrow \mathrm{BrO}+\mathrm{O}_{2}\right) \\
\mathrm{BrO}+\mathrm{BrO} \rightarrow 2 \mathrm{Br}+\mathrm{O}_{2} \\
\hline \text { net: } 2 \mathrm{O}_{3} \rightarrow 3 \mathrm{O}_{2}
\end{gathered}
$$

Returning to the general discussion, XO may also react with a different halogen oxide, YO.

$$
\begin{aligned}
\mathrm{XO}+\mathrm{YO} & \rightarrow \mathrm{X}+\mathrm{Y}+\mathrm{O}_{2} \\
& \rightarrow \mathrm{XY}+\mathrm{O}_{2} \\
& \rightarrow \mathrm{OXO}+\mathrm{Y}
\end{aligned}
$$

If $\mathrm{XY}$ is formed, it is rapidly photolysed to $\mathrm{X}+\mathrm{Y}$. The combination of (R1) with (R4) forms a catalytic cycle destroying ozone based upon recycling of the halogens by the cross Reaction (R4). Cross reactions, e.g. $\mathrm{ClO}+\mathrm{BrO}$ (LeBras and Platt, 1995) and IO+BrO (Solomon et al., 1994), are about one order of magnitude faster than the reaction $\mathrm{BrO}+\mathrm{BrO}$. The cross reaction between $\mathrm{BrO}$ and $\mathrm{ClO}$ is important in stratospheric polar halogen chemistry but there is no clear evidence for the presence of significant amounts of $\mathrm{ClO}$ in the polar boundary layer (although $\mathrm{ClO}$ detection limits are relatively high, see Sect. 2.2). Recently, very high concentrations of IO have been observed at Halley in the Antarctic, so that the reaction $\mathrm{BrO}+\mathrm{IO}$ might play a key role under these conditions (see Sect. 2.3). The channel leading to OXO generally leads to short-lived products with little chemical impact, possibly except for the case of iodine (see discussion at end of this section).

Another ozone destruction scheme involves reactions of halogen oxides with $\mathrm{HO}_{2}$ and follows the sequence:

$$
\begin{aligned}
\mathrm{X}+\mathrm{O}_{3} & \rightarrow \mathrm{XO}+\mathrm{O}_{2} \\
\mathrm{XO}+\mathrm{HO}_{2} & \rightarrow \mathrm{HOX}+\mathrm{O}_{2} \\
\mathrm{HOX}+h v & \rightarrow \mathrm{X}+\mathrm{OH} \\
\mathrm{OH}+\mathrm{CO}+\mathrm{O}_{2} & \rightarrow \mathrm{CO}_{2}+\mathrm{HO}_{2}
\end{aligned}
$$




$$
\text { net: } \mathrm{CO}+\mathrm{O}_{3} \rightarrow \mathrm{CO}_{2}+\mathrm{O}_{2}
$$

In this scheme, a key reaction is $\mathrm{XO}+\mathrm{HO}_{2}$, which is very fast (several times $10^{-11} \mathrm{~cm}^{3}$ molec $^{-1} \mathrm{~s}^{-1}$, Knight and Crowley, 2001). An analogous reaction of $\mathrm{XO}+\mathrm{CH}_{3} \mathrm{O}_{2}$ is also likely to ultimately produce HOX (Aranda et al., 1997). The above sequence oxidizes $\mathrm{CO}$ to $\mathrm{CO}_{2}$, but other reactions similar to R7 involving hydrocarbons may be substituted for Reaction (R7).

All three of these types of reaction cycles, self reaction $(\mathrm{XO}+\mathrm{XO})$, cross reaction $(\mathrm{XO}+\mathrm{YO})$, and $\mathrm{XO}+\mathrm{HO}_{2}$ catalytically destroy ozone at times when halogen atoms and halogen oxides are present in the atmosphere. However, these cycles do not increase the reactive stock of halogen atoms and halogen oxides ( $\mathrm{X}$ and $\mathrm{XO}$ ). A special sequence of chemical reactions, often known as the "bromine explosion" reaction sequence, can theoretically produce reactive halogen gases. This sequence is thought be the source of the majority of reactive halogens during ozone depletion events (Fan and Jacob, 1992; McConnell et al., 1992; Platt and Lehrer, 1996; Tang and McConnell, 1996; Wennberg, 1999). The bromine explosion reaction sequence is

$$
\begin{aligned}
\mathrm{HOBr}+\mathrm{Br}^{-}+\mathrm{H}^{+} & \stackrel{m p}{\rightarrow} \mathrm{H}_{2} \mathrm{O}+\mathrm{Br}_{2} \\
\mathrm{Br}_{2}+h v & \rightarrow 2 \mathrm{Br} \\
\mathrm{Br}+\mathrm{O}_{3} & \rightarrow \mathrm{BrO}+\mathrm{O}_{2} \\
\mathrm{BrO}+\mathrm{HO}_{2} & \rightarrow \mathrm{HOBr}+\mathrm{O}_{2}
\end{aligned}
$$

$$
\text { net: } \mathrm{H}^{+}+\mathrm{Br}^{-}+\mathrm{HO}_{2}+\mathrm{O}_{3} \stackrel{\mathrm{mp}, \mathrm{h} v}{\rightarrow} \mathrm{Br}+\mathrm{H}_{2} \mathrm{O}+2 \mathrm{O}_{2}
$$

In this sequence, graphically depicted in Fig. 4, reactive bromine is produced by $\mathrm{HO}_{2}$ oxidizing bromide $\left(\mathrm{Br}^{-}\right)$, most often from sea salt and present in solution or on ice surfaces. The multiphase reaction involvement is shown in Reaction (R8) by the shorthand "mp", highlighting its importance. If we consider the reactions to be occurring in liquid brine solution, then Reaction (R8) would consist of three sub-steps, $\mathrm{HOBr}$ gas uptake, reaction in brine solution, and degassing of dissolved $\mathrm{Br}_{2}$ gas. The sequence is autocatalytic, meaning that the product is a reactive halogen species that then acts as a catalyst, further speeding up the reaction. It is important to remember that this reaction consumes $\mathrm{HO}_{\mathrm{x}}$, bromide $\left(\mathrm{Br}^{-}\right)$and protons (acidity), all of which are critical to subsequent discussions in this paper.

Another equivalent method to consider the bromine explosion chemistry is to not view the net reaction above, but instead consider an inventory of inactive (e.g. $\mathrm{Br}^{-}$) and reactive bromine species. Reaction (R8) consumes one reactive bromine species $(\mathrm{HOBr})$ but produces $\mathrm{Br}_{2}$, the precursor of two reactive bromine species (two $\mathrm{Br}$ atoms). Therefore, effectively, one $\mathrm{BrO}_{\mathrm{x}}$ molecule is converted into two by oxidizing bromide at the surface e.g. of brine or dry sea salt on sea ice or aerosol. This process leads to an exponential growth of the $\mathrm{BrO}$ concentration in the atmosphere, which led to the term bromine explosion (Platt and Janssen, 1995;

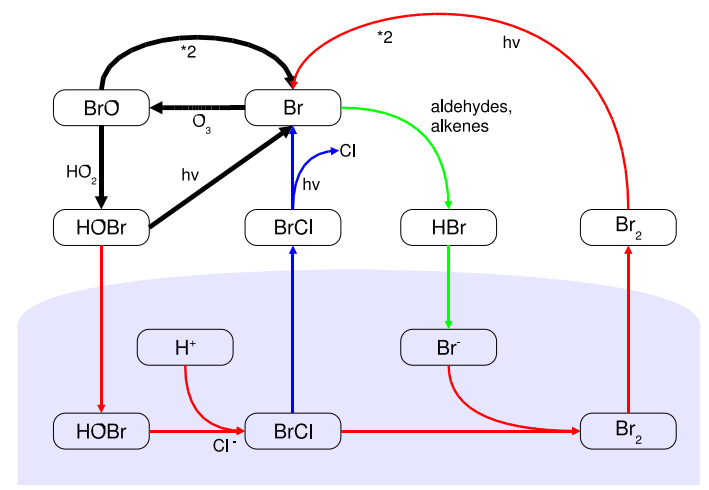

Fig. 4. A simplified set of bromine explosion reactions. The blue area at the bottom is meant to represent the condensed phase (liquid brine or ice surface).

Platt and Lehrer, 1996; Wennberg, 1999). Recent laboratory investigations have shown that the above heterogeneous reaction is efficient and thus this sequence can produce $\mathrm{BrO}_{\mathrm{x}}$ in the troposphere (e.g. Kirchner et al., 1997; Abbatt, 1994; Abbatt and Nowak, 1997; Fickert et al., 1999; Huff and Abbatt, 2000, 2002; Adams et al., 2002).

The actual mechanism of R8 has been the subject of a number of laboratory studies (Fickert et al., 1999; Huff and Abbatt, 2000, 2002; Adams et al., 2002). These studies considered the source of the halides $\left(\mathrm{Cl}^{-}\right.$and $\left.\mathrm{Br}^{-}\right)$to be sea salt. In sea salt the $\mathrm{Cl}^{-} / \mathrm{Br}^{-}$ratio is about 650 , but in experiments the $\mathrm{Cl}^{-} / \mathrm{Br}^{-}$ratios were varied to elucidate the mechanism. When the concentration of $\mathrm{Br}$ is decreased below the sea salt ratio, an increasing fraction of $\mathrm{BrCl}$ is produced, while at high relative $\mathrm{Br} / \mathrm{Cl}$ ratios, $\mathrm{Br}_{2}$ is the preferred product (Adams et al., 2002). The following sequence was first suggested by Vogt et al. (1996) and later laboratory experiments (Fickert et al., 1999) were consistent with this mechanism.

$$
\begin{array}{r}
\mathrm{HOBr}+\mathrm{Cl}^{-}+\mathrm{H}^{+} \stackrel{\text { mp }}{\rightarrow} \mathrm{H}_{2} \mathrm{O}+\mathrm{BrCl} \\
\mathrm{BrCl}+\mathrm{Br}^{-} \stackrel{\text { aq }}{=} \mathrm{Br}_{2} \mathrm{Cl}^{-} \\
\mathrm{Br}_{2} \mathrm{Cl}^{-} \stackrel{\text { aq }}{=} \mathrm{Br}_{2}+\mathrm{Cl}^{-}
\end{array}
$$

net: $\mathrm{HOBr}+\mathrm{Br}^{-}+\mathrm{H}^{+} \stackrel{\mathrm{mp}}{\rightarrow} \mathrm{H}_{2} \mathrm{O}+\mathrm{Br}_{2}$

Field evidence supporting this scheme comes from the observation that both $\mathrm{BrCl}$ and $\mathrm{Br}_{2}$ are produced from the snow pack (Foster et al., 2001). Additionally, the $\mathrm{Br}^{-} / \mathrm{Cl}^{-}$ratio in snow has been found to be very variable possibly due to these reactions removing bromide from snow and gas-phase $\mathrm{HBr}$ adding $\mathrm{Br}^{-}$back (Simpson et al., 2005). When all bromide is used up and the forward Reaction (R11) cannot proceed, $\mathrm{BrCl}$ can escape from the surface. It is then photolysed to produce reactive chlorine atoms, which then typically react 


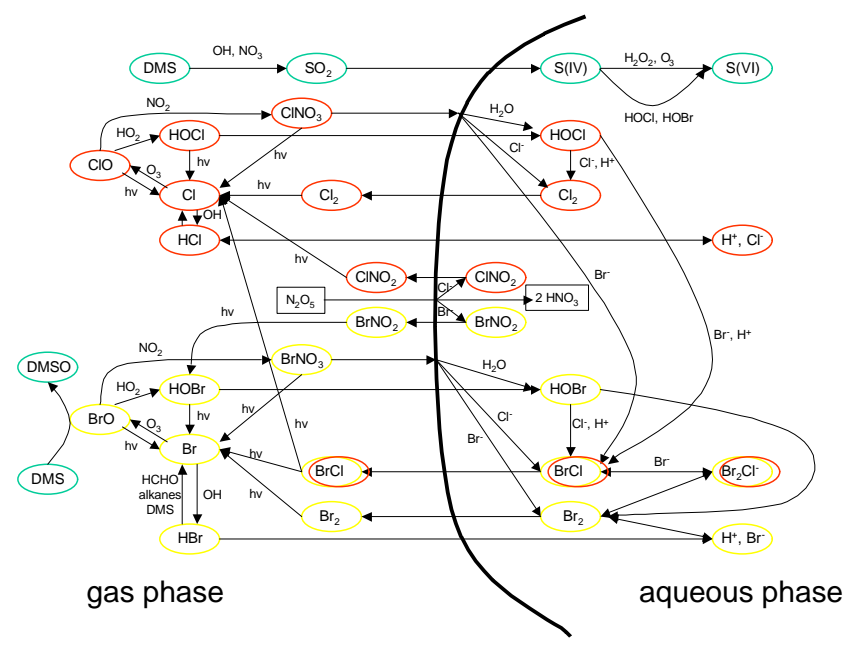

Fig. 5. Schematic diagram of the major halogen-related reactions in the gas and aqueous phase. Refer to Atkinson et al. (2006) or Sander et al. (2003b) for reaction rate coefficients. The aqueousphase reaction $\mathrm{XY}+\mathrm{Z}^{-} \leftrightharpoons \mathrm{XYZ}^{-}$leads to very efficient halogen interconversion reactions often leading to the release of $\mathrm{Br}_{2}$. Uptake of $\mathrm{HOBr}$ and reaction with $\mathrm{Br}^{-}$leads to the release of $\mathrm{Br}_{2}$, the socalled bromine explosion. Reprinted from Treatise on Geochemistry, Vol. 4, von Glasow and Crutzen (2003), "Tropospheric halogen chemistry", 21-64, Copyright (2003), with permission from Elsevier.

with hydrocarbons, reducing their impact on tropospheric ozone destruction,

$\mathrm{Cl}+\mathrm{RH} \rightarrow \mathrm{HCl}+\mathrm{R}$.

The relevance of reactive chlorine is discussed further in Sect. 2.2. The high abundance of hydrocarbons in the troposphere (e.g. methane) and the high reactivity of $\mathrm{Cl}$ atoms means that $\mathrm{Cl}$ atoms are to $\mathrm{HCl}$ by Reaction (R13) with a $50 \%$ probability per $\mathrm{Cl}$ atom reaction.

The concept of lifetimes and fates of various $\mathrm{XO}_{\mathrm{x}}$ species is very useful when considering the relative importance of the various halogen atoms in ozone depletion chemistry. The lifetime of XO is short during sunlit periods, due to photolysis (J2). For typical springtime noon conditions, the IO lifetime is a few seconds, the $\mathrm{BrO}$ lifetime is around 2 minutes, and the $\mathrm{ClO}$ lifetime is roughly an hour. When high levels of halogen oxides are present (e.g. $30 \mathrm{pmol} / \mathrm{mol}$ of $\mathrm{BrO}$ found in the polar boundary layer), the lifetime of XO can drop to minutes and self or cross reactions can be the most efficient in converting $\mathrm{XO}$ to $\mathrm{X}$. Once halogen atoms are released they are, however, quite likely to reform $\mathrm{XO}$ by reaction with $\mathrm{O}_{3}$ (Reaction R1), the probability ranges from $>99 \%$ for I to up to $99 \%$ for $\mathrm{Br}$ to $\sim 50 \%$ for $\mathrm{Cl}$. This gas-phase recycling of $\mathrm{X}$ to $\mathrm{XO}$ leads to an effective lifetime of $\mathrm{XO}_{\mathrm{x}}$ given by

$\tau_{\mathrm{XO}_{\mathrm{x}}}=\tau_{\mathrm{XO}} \frac{\text { rate of } \mathrm{X}+\mathrm{O}_{3}}{\text { rate of } \mathrm{X}+\operatorname{not}\left(\mathrm{O}_{3}\right)}$.
For $\mathrm{ClO}_{\mathrm{x}}$ this translates to daytime lifetimes between about two hours (at low levels of $\mathrm{BrO}$ ) to several minutes (at $30 \mathrm{pmol} / \mathrm{mol}$ of $\mathrm{BrO}$ ), since $\mathrm{Cl}$ atoms react with the ubiquitous methane, as mentioned above. On the other hand, $\mathrm{Br}$ atoms only react with aldehydes, olefins, or $\mathrm{HO}_{2}$ radicals, thus re-conversion to $\mathrm{BrO}$ (via Reaction $\mathrm{R} 1$ and causing $\mathrm{O}_{3}$ depletion) is most likely at normal ozone levels, consequently $\mathrm{BrO}_{\mathrm{x}}$ lifetimes are quite long despite rapid photolysis of $\mathrm{BrO}$. In fact $\mathrm{BrO}_{\mathrm{x}}$ lifetimes typically reach several hours, with relatively little influence from XO levels. On the other hand, in polar regions the time to destroy ozone is of the order of one day, thus $\mathrm{BrO}_{\mathrm{x}}$ needs to be recycled from bromide on surfaces about 10 times during a typical ozone depletion event (Platt and Lehrer, 1996; Platt and Hönninger, 2003; Lehrer et al., 2004). Based upon the autocatalytic mechanism's ability to convert nonreactive salt bromide into reactive bromine, it is currently assumed that most of the reactive bromine comes from sea salt that is activated by this mechanism. Early ideas that the majority of the reactive bromine might come from organobromine gases (e.g. $\mathrm{CHBr}_{3}$, Barrie et al., 1988) or coupling with reactive nitrogen gases (e.g. $\mathrm{N}_{2} \mathrm{O}_{5}$, Finlayson-Pitts et al., 1990) have now been discounted because they are not a sufficiently strong bromine source to explain the rate of ozone destruction or observed $\mathrm{BrO}$ levels. However, the bromine explosion chemistry requires a source of "seed" reactive halogens that initiate the explosion. There may be a role for these or other relatively weak sources of reactive halogen species in providing the "seed" for the explosion. Other possible initiators of bromine chemistry are interhalogen reactions, discussed in recent halogen chemistry review articles (e.g. von Glasow and Crutzen, 2003, 2007). The complexity of these reactions and interactions is illustrated in Fig. 5, which highlights interhalogen couplings. More recent investigations have shown that iodine must also be included in the scheme (see Sects. 2.3 and 2.4).

Recent laboratory studies of gas-phase halogen chemistry have focused on iodine oxide chemistry, in order to quantify the efficiency of $\mathrm{O}_{3}$ destruction (Vogt et al., 1999) and to understand the formation of new particles (O'Dowd and Hoffmann, 2005). The IO self-reaction produces OIO ( 40\%) and IOIO $(\sim 55 \%)$ at atmospheric pressure. The IOIO product is unstable and most likely rapidly thermally decomposes to yield OIO, so that the overall yield of OIO from the IO self-reaction is high. The photolysis of OIO to $\mathrm{O}\left({ }^{3} \mathrm{P}\right)+\mathrm{IO}$ is very unlikely to occur, it has an upper limit for the quantum yield of $7 \times 10^{-3}$ (Ingham et al., 2000). OIO has a series of strong absorption bands between 480 and $620 \mathrm{~nm}$, where photolysis to yield $\mathrm{I}+\mathrm{O}_{2}$ is possible and would make OIO formation through the $\mathrm{IO}$ self reaction a major $\mathrm{O}_{3}$-depleting cycle (Ashworth et al., 2002). Although two recent studies report upper limits to the I atom quantum yield of $<0.05$ $(560-580 \mathrm{~nm})$ and $<0.24(532 \mathrm{~nm})$ (Joseph et al., 2005; Tucceri et al., 2006), a small probability of photolysis at wavelengths $>470 \mathrm{~nm}$, integrated over the entire OIO absorption band would still lead to significant photochemical conversion 
Table 2. Satellite measurements of $\mathrm{BrO}$.

\begin{tabular}{cccl}
\hline Instrument & Hemisphere & Time period (MM.YYYY) & Reference \\
\hline GOME & $\mathrm{SH}$ & Sep 1996 & Wagner and Platt (1998a) \\
GOME & $\mathrm{NH}$ & Feb 1997-July 1997 & Richter et al. (1998c) \\
GOME & $\mathrm{NH}$ & April 1997, May 1997 & Chance (1998) \\
GOME & $\mathrm{NH}$ & April 1997 & Burrows et al. (1999) \\
GOME & $\mathrm{NH}+\mathrm{SH}$ & Jan 1997-Dec 1997 & Wagner et al. (2001) \\
GOME & $\mathrm{NH}+\mathrm{SH}$ & July 1999-June 2000 & Richter et al. (2002) \\
GOME & $\mathrm{NH}$ & March 2000-April 2000 & Zeng et al. (2003) \\
GOME & $\mathrm{NH}+\mathrm{SH}$ & Feb 1996-Oct 2001 & Hollwedel et al. (2004) \\
GOME & $\mathrm{SH}$ & Aug 1999, Sep 1999, Aug 2000, Sep 2000 & Frieß et al. (2004) \\
GOME & $\mathrm{NH}+\mathrm{SH}$ & Aug 1997, March 2001 & Kaleschke et al. (2004) \\
SCIAMACHY & $\mathrm{NH}$ & March 2003 & Jacobi et al. (2006) \\
GOME & $\mathrm{NH}$ & Feb 2000-May 2000 & Zeng et al. (2006) \\
\hline
\end{tabular}

of $\mathrm{OIO}$ to I and consequent $\mathrm{O}_{3}$ loss.

\subsection{Observational, modeling, and laboratory methods}

\subsubsection{Observations}

Most direct observations of halogen compounds in the polar troposphere rely on optical absorption measurements. Halogen oxides have narrow band absorption structures at $\mathrm{UV}$ and visible wavelengths, and $\mathrm{BrO}, \mathrm{IO}$, and tentatively also $\mathrm{ClO}$ have been observed by active Differential Optical Absorption Spectroscopy (long-path DOAS) measurements using a strong light source and an open path (e.g. Hausmann and Platt, 1994; Martinez et al., 1999; Saiz-Lopez et al., 2007b). The technique can also be used for $\mathrm{OIO}, \mathrm{OClO}$, and $\mathrm{I}_{2}$, but no results have been reported so far for polar regions. The same species can be detected using atmospherically scattered light with passive DOAS instruments, and polar measurements have been reported for $\mathrm{BrO}$ and $\mathrm{IO}$ (e.g. Kreher et al., 1997; Wittrock et al., 2000; Frieß et al., 2001; Hönninger and Platt, 2002; Hönninger et al., 2004b). Later observations use the multiple axis DOAS (Hönninger et al., 2004c) technique, which has the advantage of being able to separate clearly the tropospheric and stratospheric portions of the atmospheric column, and even derive a crude vertical profile. An overview of these ground-based measurements can be found in the electronic supplement (http://www.atmos-chem-phys. net/7/4375/2007/acp-7-4375-2007-supplement.pdf).

Global maps of the total BrO column density (the sum of troposheric and stratospheric columns) can be retrieved with the DOAS technique from satellite measurements by instruments such as GOME, SCIAMACHY or OMI (e.g. Wagner and Platt, 1998a; Richter et al., 1998c) (Table 2). First observations of IO from SCIAMACHY around coastal Antarctica have recently been reported by Saiz-Lopez et al. (2007a) and Schönhardt et al. (2007). Satellite data provide good coverage but have to be corrected for stratospheric XO, the vertical distribution of $\mathrm{XO}$, and cloud effects in the troposphere, introducing substantial uncertainties.

In-situ measurements of $\mathrm{BrO}$ and potentially also $\mathrm{ClO}$ are possible using the atomic fluorescence method (e.g. Avallone et al., 2003) and can determine the vertical profile of $\mathrm{BrO}$ in the lowest several meters. The atomic fluorescence technique, originally developed for stratospheric measurements, is less accurate when measuring tropspheric $\mathrm{BrO}$ due to increased quenching of the resonance signals at higher pressures and large pumps needed to decrease the pressureinduced quenching. With another in-situ method, atmospheric pressure chemical ionization mass spectrometry, $\mathrm{Br}_{2}$, $\mathrm{BrCl}$, and $\mathrm{Cl}_{2}$ can be observed (Foster et al., 2001; Spicer et al., 2002). Indirect evidence for the presence of enhanced levels of chlorine atoms can be obtained from measurements of hydrocarbons, chosen to have rate constants that are similar for reaction with $\mathrm{Cl}$ but different for $\mathrm{OH}$ or vice versa (this method is known as the hydrocarbon clock method; see Jobson et al., 1994). The analysis of halogenated VOCs, formed by the reaction of ethene and propene with $\mathrm{Cl}$ and $\mathrm{Br}$ atoms, provides a valuable method to determine $[\mathrm{Br}] /[\mathrm{Cl}]$ ratios (Keil and Shepson, 2006). The sum of photolysable bromine compounds can also be measured by conversion to bromoacetone and subsequent GC analysis (Impey et al., 1999). See Sect. 2.2 for more details on these techniques.

\subsubsection{Models}

Numerical models have been developed to examine and quantify the processes involved in bromine explosions and ODEs as well as the consequences for the chemistry of the atmosphere. They have significantly improved our understanding of the reaction cycles and the interdependencies of different elemental cycles. Models have, for example, helped to realize that fast multiphase reactions are necessary to maintain the bromine explosion (e.g. Fan and Jacob, 1992). Most of these studies use box models focusing on the chemical 
reaction mechanism. Some include parameterizations of varying complexity for heterogeneous reactions (McConnell et al., 1992; Tang and McConnell, 1996), some explicitly include heterogeneous reactions (Fan and Jacob, 1992; Sander et al., 1997; Michalowski et al., 2000; Evans et al., 2003). Similarly, the treatment of photochemical processes in the snow pack has explicitly only been done by Michalowski et al. (2000). These processes are discussed in detail in the snow photochemistry companion paper (Grannas et al., 2007). One-dimensional model studies have investigated the vertical structure of ODEs (Lehrer et al., 2004; Piot and von Glasow, 2007; Saiz-Lopez et al., 2007c) Three-dimensional models have so far only used very simple approaches regarding the chemical processes, like estimating ozone destruction based on satellite-derived vertical $\mathrm{BrO}$ columns (Zeng et al., 2003).

One benefit of models is that the whole life cycle of ODEs and the shift in elemental speciation and oxidants can be investigated. Field measurements often only give brief observations of the chemical composition with a poorly determined history of the air mass. A great deal can be learned from these model studies which highlight the often puzzling chemical interactions under the highly non-linear chemical conditions of ODEs. Shifts in bromine speciation play a key role in speeding up or slowing down the development of ODEs (e.g. Sander et al., 1997; Piot and von Glasow, 2007). An innovative way of comparing model results with measurements was used by Evans et al. (2003) who used $\mathrm{O}_{3}$ as "chemical coordinate" to be able to compare their results to the rather randomly measured various stages of ODEs encountered during the TOPSE campaign.

One common problem of all models is that many processes, especially the source of the bromine for the bromine explosions and the triggering of these events, are still not understood and therefore have to be prescribed/parameterized in the models. The proper description of processes in and on the snow seems to be key to further progress in this field. However, incorporation of snow pack processes in models is very challenging due to the lack of a quantitative physical and chemical understanding of these processes. Progress in these fields will strongly increase our ability to simulate ODEs and lead to a better understanding of polar chemistry in general.

\subsubsection{Laboratory methods}

Laboratory measurements have contributed significantly to improve our understanding of the chemical processes behind the bromine explosion and snow and ice chemistry. One of the main advantages of laboratory experiments is that good control of conditions is possible, which leads to ready and systematic variation of suspected key features.

The techniques that are typically used for the investigation of rate coefficients, products/mechanisms, photolysis cross sections and quantum yields of gas phase reactions are, flow reactors, flash or pulse photolysis, or smog chambers with a multitude of techniques to measure the products, like UV/VIS/IR spectroscopy, mass spectroscopy, cavity ring down spectroscopy (see e.g. Finlayson-Pitts and Pitts, 2000, for an overview).

A special challenge is posed by reactions on surfaces like snow and ice or liquid or solid aerosol particles, all of which play a major role in ODEs. One example of the involved complications is that at typical polar temperatures, hundreds to thousands of monolayers of ice desorb per second. This desorption is balanced by adsorption of water vapor onto the surface, resulting in a very dynamic equilibrium at the surface. The ice surfaces in the environment are very complex, and include natural snow, slush, solid ice and quasiliquid layers (QLL) on their surfaces. Artificial snow, with its amorphous and crystalline characteristics, may not be always representative of the true solid/slush/QLL conditions found in the environment. However, several successful attempts have been made to investigate frost flowers (Martin et al., 1995, 1996; Nghiem et al., 1997; Hutterli et al., 2006), snow (Jacobi and Hilker, 2007) and sea-ice (Richardson, 1976; Adams et al., 2002; Papadimitriou et al., 2003) in the laboratory.

Other laboratory experiments focus on the kinetics and mechanisms of gas-phase halogen release from surfaces. They can be divided into three main types: (1) Flow tubes; these experiments provide information on gas-solid partitioning including reactive and non-reactive uptake. (2) Surface probes; these techniques provide characterization of surface and bulk species can be made using a wide range of spectroscopic techniques. (3) Bulk analyses; these techniques examine the net reactivity of ice and gases in contact with them and can be monitored by a variety of approaches including mass spectrometry. The frozen solids are often analyzed by methods including X-ray diffraction (XRD) and Raman spectroscopy. Much of the bulk analysis is performed on thawed material, which is problematic for interpretation because the effective surface concentrations of ions and molecules at ice surfaces may be very different from the melted analysis. For example, the $\mathrm{pH}$ of the melt might be quite different from the effective $\mathrm{pH}$ of molecules on the surface of ice. Two recent reviews are particularly useful for a more in-depth discussion of this subject (Huthwelker et al., 2006; Abbatt, 2003).

When ice freezes, ions separate from ice, leading to freezeconcentrated solutions that have different reactivity from the unfrozen solution (see Sect. 3.1). Freeze-concentration effects have been used to explain the effect of cooling on a variety of acidified and neutral, nitrite ion and bromide- or chloride-containing mixtures. In laboratory studies, several trihalide ions were formed, including $\mathrm{I}_{2} \mathrm{Cl}^{-}, \mathrm{I}_{2} \mathrm{Br}^{-}, \mathrm{ICl}_{2}^{-}$ and $\mathrm{IBr}_{2}^{-}$(O'Driscoll et al., 2006). A mechanism to explain the observations was given in terms of reaction steps involving INO and the nitroacidium ion, $\mathrm{H}_{2} \mathrm{ONO}^{+}$, within liquid 
"micropockets". These and similar reactions in liquid inclusions of ice are likely to be critical to understanding air-ice chemistry that relates to halogen activation and ozone depletion events.

\section{Halogens and their roles in ODEs}

\subsection{Bromine}

As already discussed in Sect. 1, bromine is the key halogen species for polar ODEs. In this subsection, we give more details on these measurements and other bromine compounds, including biogenic bromine, discuss satellite observations of $\mathrm{BrO}$, and mention similarities to other regions. The electronic supplement to this paper (http://www.atmos-chem-phys.net/7/4375/2007/ acp-7-4375-2007-supplement.pdf) contains an extensive list of measurements.

\subsubsection{Ground based measurements of bromine compounds}

The key first measurements of inorganic bromine compounds in the polar boundary layer were those of "filterable bromine" published by Barrie et al. (1988) (see Fig. 2 and Sect. 1.2). Since then, a multitude of further gas phase and aerosol measurements have been made. The Arctic sites where the majority of these observations have been made are Barrow, Alert, Ny-Ålesund, and the Hudson Bay. Halley and Neumayer stations have been the locations of key Antarctic studies. See the electronic supplement (http://www.atmos-chem-phys.net/7/4375/2007/ acp-7-4375-2007-supplement.pdf) for a complete listing of the sites and maps of their location.

With the direct detection of BrO by active DOAS at Alert, (see Sect. 1.4.1 and Fig. 6) (Hausmann and Platt, 1994), the first evidence for the chemical mechanisms described in Sect. 1.3 was made. Since then active and passive DOAS techniques (Tuckermann et al., 1997; Kreher et al., 1997; Martinez et al., 1999; Hönninger and Platt, 2002; Frieß et al., 2004; Hönninger et al., 2004b; Saiz-Lopez et al., 2007b) as well as radical amplifiers (Impey et al., 1999) and atomic fluorescence techniques (Avallone et al., 2003) have been used to identify $\mathrm{BrO}$ in both polar regions at Alert, Barrow, $\mathrm{Ny}-$ Ålesund, the Hudson Bay, Neumayer, and Arrival Heights. Typical mixing ratios of $\mathrm{BrO}$ are a few to several tens of $\mathrm{pmol} / \mathrm{mol}$.

The MAX-DOAS measurements of Hönninger and Platt (2002) at Alert show that the vertical extent of BrO layers is about $1 \mathrm{~km}(500-2000 \mathrm{~m})$. Under under some circumstances elevated layers might be present (Hönninger et al., 2004b). Frieß et al. (2004) showed that enhanced BrO vertical columns were present at Neumayer, Antarctic, when part of the probed airmass was previously in contact with sea ice surfaces (see Fig. 7). The recent ship-based MAX-DOAS measurements of $\mathrm{BrO}$ around the Antarctic by Wagner et al.

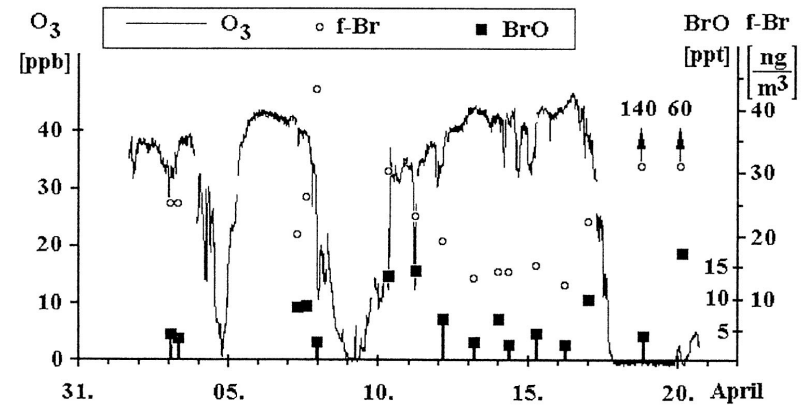

Fig. 6. Comparison of in situ ozone, filterable bromine (f-Br), and $\mathrm{BrO}$ at Alert. Reprinted from Hausmann and Platt (1994) with permission from the American Geophysical Union (AGU).

(2007) gives indications for an elevated $\mathrm{BrO}$ layer at the top of the boundary layer. Furthermore they showed that shipbased measurements of $\mathrm{BrO}$ show high boundary layer $\mathrm{BrO}$ values up to one month before they were detected by satellite, due to the higher sensitivity of MAX-DOAS to near-surface $\mathrm{BrO}$ compared to satellite observations.

Most measurements of $\mathrm{BrO}$ are made during polar spring. However, data from Alert showed the presence of $\mathrm{BrO}$ at smaller mixing ratios in fall as well (G. Hönninger, personal communication, 2003). The first seasonal variation of $\mathrm{BrO}$ was measured by Saiz-Lopez et al. (2007b) in the Antarctic at Halley during the CHABLIS campaign (January 2004February 2005). BrO was detected whenever the solar zenith angle was less than $\sim 92^{\circ}$ i.e. also before direct sunlight reached the surface at mixing ratios up to $4 \mathrm{pmol} / \mathrm{mol}$ but not during the polar night. BrO showed a distinct maximum of $20 \mathrm{pmol} / \mathrm{mol}$ in October/November (spring), followed by a decrease towards the summer and a possible secondary maximum in fall. The smaller radical concentrations between November and April could be a consequence of the less frequent appearance of frost flowers, a lower salinity of sea-ice surfaces, or faster mixing due to a less stable boundary layer (see Sect. 3.1).

Impey et al. (1997b,a) developed a method for determination of the total photolysable chlorine and bromine $\left(\mathrm{X}_{2}\right.$ and $\mathrm{HOX}$ ), calibrated and determined "as $\mathrm{Cl}_{2}$ " and "as $\mathrm{Br}_{2}$ ". The mixing ratios represent $\mathrm{Cl}_{2}$ and $\mathrm{Br}_{2}$ equivalents, e.g. in terms of the rate of photolytic production of chlorine and bromine atoms. For bromine they were able to give mixing ratios for $\mathrm{HOBr}$ and $\mathrm{Br}_{2}$ separately. This method was applied during the 1994 Polar Sunrise Experiment at Alert. Total photolysable bromine (TPB) typically ranged from $\sim 5-$ $30 \mathrm{pmol} / \mathrm{mol}$, and remained at these levels under full sunlight conditions. The highest values of $\mathrm{HOBr}(\sim 240 \mathrm{pmol} / \mathrm{mol})$ detected by Impey et al. (1999) occured at the end of an ODE when $\mathrm{O}_{3}$ was already increasing. They also measured $\mathrm{Br}_{2}$ of up to $24 \mathrm{pmol} / \mathrm{mol}$ during an ODE.

There are strong indications for a snow pack source for 


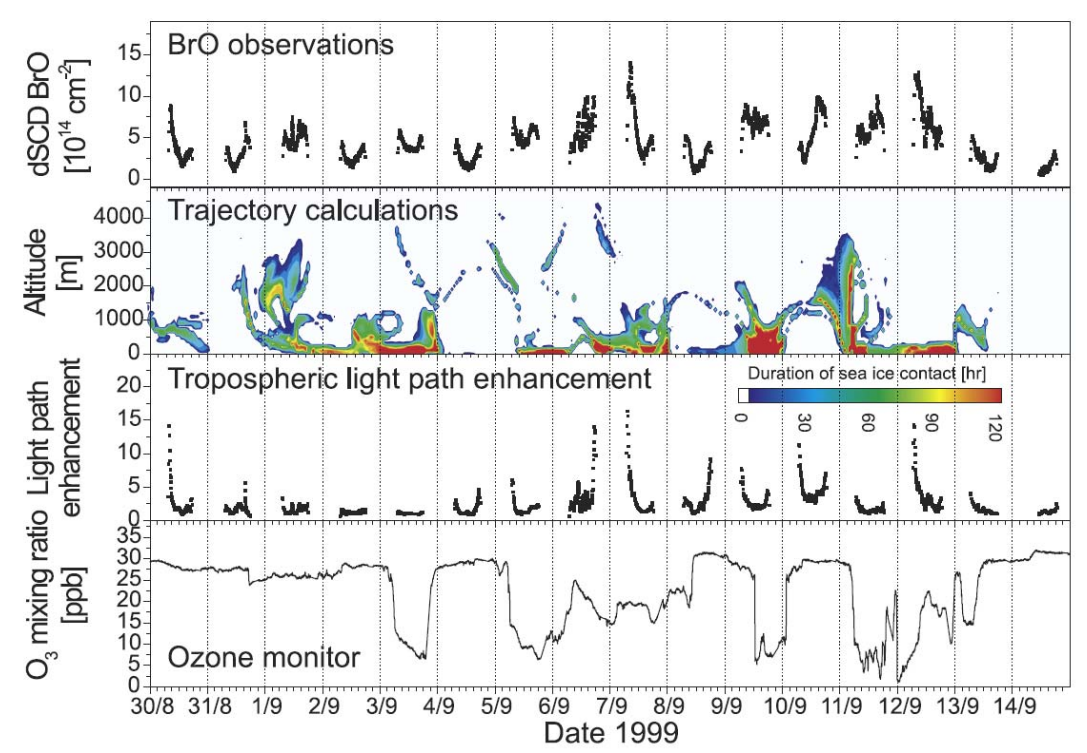

Fig. 7. Observations of enhanced BrO from 30 August to 15 September 1999, Neumayer, Antarctica. The stacked plots show the BrO differential slant column density (dSCD), duration of sea ice contact (shown in colors on the altitude - time plot), light path enhancement factor (a measurement of the light scattering in the atmosphere), and surface ozone mixing ratio. Reprinted from Frieß et al. (2004) with permission from the American Geophysical Union (AGU).

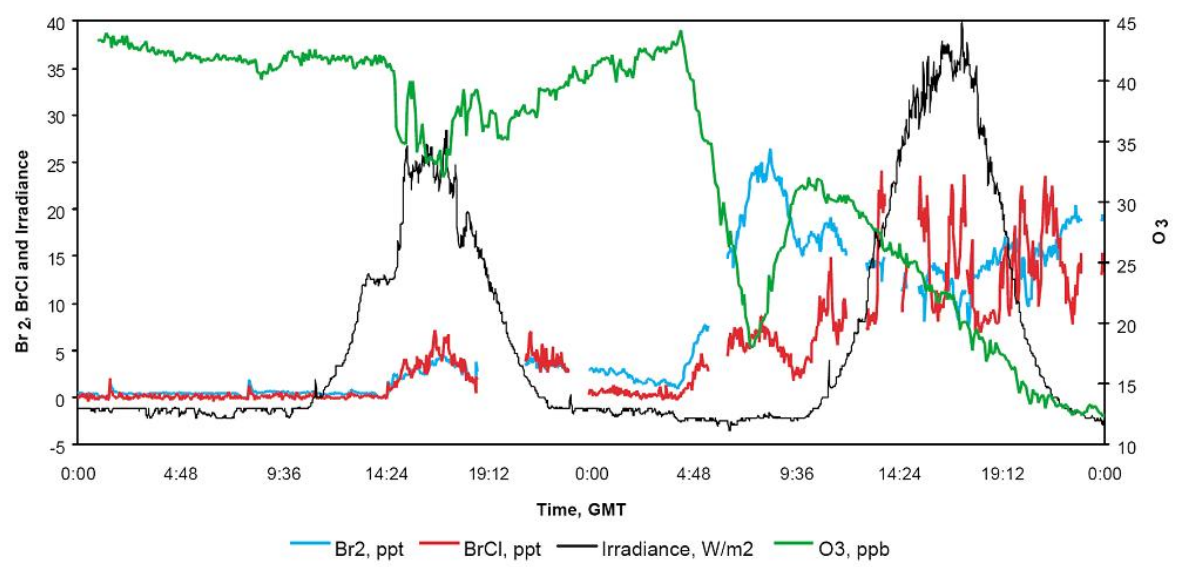

Fig. 8. Time series of $\mathrm{O}_{3}, \mathrm{Br}_{2}, \mathrm{BrCl}$, and global irradiance at Alert for 10-11 March 2000 (note that the global irradiance results have not been adjusted for a negative offset). Reprinted from Spicer et al. (2002), copyright 2002, with permission from Elsevier.

bromine compounds (especially $\mathrm{Br}_{2}$ and $\mathrm{BrCl}$ ). This evidence includes $\mathrm{Br}_{2}$ - wind sector comparisons from Alert (Impey et al., 1997b), strong vertical gradients in $\mathrm{BrO}$ in the lowest meters observed at Ny-Ålesund and Alert (Avallone et al., 2003), and especially direct measurements of $\mathrm{Br}_{2}$ and $\mathrm{BrCl}$ by mass spectrometry in the vicinity and within the snow pack (see Fig. 8 and Foster et al., 2001; Spicer et al., 2002). Both $\mathrm{Br}_{2}$ and $\mathrm{BrCl}$ were measured before direct sunlight reached the site, possibly indicating a role of $\mathrm{O}_{3}$ reactions in the dark activation of bromine. Organic bromine compounds and their relevance will be discussed in Sect. 3.3.2. 
2.1.2 BrO and IO satellite observations: spatial and temporal scale

With the launch of the Global Ozone Monitoring Experiment (GOME) in April 1995 (Burrows et al., 1999), it became possible, for the first time, to detect globally the spectroscopic signatures of many tropospheric trace gases in the spectra of backscattered sunlight. These observations include $\mathrm{BrO}$ (Chance, 1998; Eisinger et al., 1997; Hegels et al., 1998a,b; Perner et al., 1998; Richter et al., 1998b,c; Wagner et al., 1998a; Wagner and Platt, 1998a) as well as IO (Saiz-Lopez et al., 2007a, Schönhardt et al., 2007²) and other trace gases. Such UV/Visible nadir satellite observations (which have since also been performed by the SCanning Imaging Absorption SpectroMeter for Atmospheric CHartographY instrument, SCIAMACHY, the Ozone Monitoring Instrument, OMI, and the second Global Ozone Monitoring Experiment, GOME-2 allow the assessment of the spatial dimension and temporal variation of "trace gas clouds" (see also Table 2 for an overview of satellite measurements of $\mathrm{BrO}$ ).

After the first detection of plumes of enhanced $\mathrm{BrO}$ in GOME data (Wagner and Platt, 1998a; Wagner et al., 1998b; Wagner and Platt, 1998b) it rapidly became clear that they are a frequent phenomena in both hemispheres in polar spring, covering large areas mainly over sea ice and along the coasts (Chance, 1998; Richter et al., 1998c,a). It could be shown that the enhanced $\mathrm{BrO}$ concentrations detected by satellite were well correlated with depleted $\mathrm{O}_{3}$ concentrations measured from ground based instruments (Wagner and Platt, 1998a; Wagner et al., 2001) and also related with the depletion of gaseous mercury (Lu et al., 2001; Ebinghaus et al., 2002; Sommar et al., 2007). As the satellite record grew, it also became clear that the phenomenon of enhanced boundary layer $\mathrm{BrO}$ concentrations occurs very regularly for several months in both hemispheres (Van Roozendael et al., 1999, 2002; Wagner et al., 2001; Richter et al., 2002), indicating that it probably is a natural phenomenon. From the investigation of the spatio-temporal variation a strong correlation with the occurrence of first-year sea ice was found (Wagner, 1999; Wagner et al., 2001, see also Fig. 9), indicating that the source is related to the enrichment of sea salt on the surface of freezing sea ice. From a detailed comparison study (Kaleschke et al., 2004) it was found in particular that enhanced $\mathrm{BrO}$ concentrations were observed under conditions where the existence of frost flowers was possible (see Sect. 3.1). Several satellite studies address issues like a potential trend of the areas covered by enhanced $\mathrm{BrO}$ concentrations (Hollwedel et al., 2004) or the existence of a global free tropospheric $\mathrm{BrO}$ mixing ratio of the order of $1 \mathrm{pmol} / \mathrm{mol}$ (Van Roozendael et al., 1999; Wagner,

\footnotetext{
${ }^{2}$ Schönhardt, A., Richter, A., Wittrock, F., Kirk, H., Oetjen, H., Roscoe, H. K., and Burrows, J. P.: Observations of iodine monoxide (IO) columns from satellite, Atmos. Chem. Phys. Discuss., submitted, 2007.
}
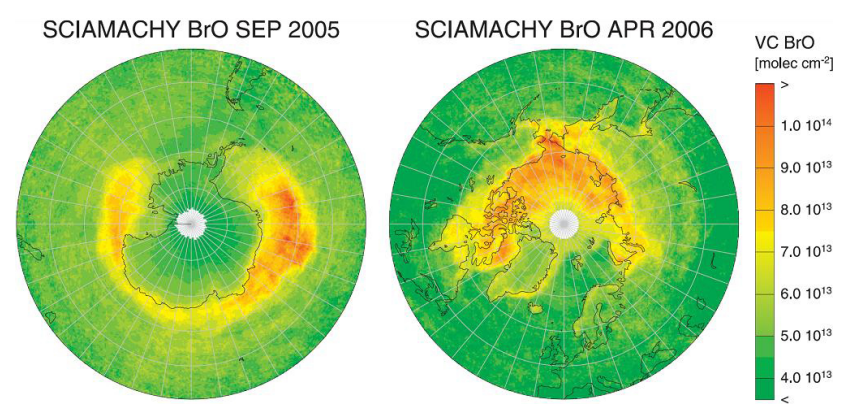

Fig. 9. Vertical columns for $\mathrm{BrO}$ for both hemispheres in spring. Data from SCIAMACHY, courtesy of A. Richter.

1999; Theys et al., 2004). It was in particular speculated that the free tropospheric $\mathrm{BrO}$ might be at least partly caused by transport of $\mathrm{BrO}$ enriched air masses from polar regions (Hollwedel, 2005, see Sect. 4.4). Short-lived halocarbon gases may also be sources of free-tropsopheric $\mathrm{BrO}$ (Salawitch, 2006). In many aspects, the enhanced $\mathrm{BrO}$ concentrations in the boundary layer during polar spring are an ideal target for the observation with space-borne sensors. First, the high albedo of ice and snow in polar regions causes a high sensitivity for trace gases located very close to the surface (even in the presence of some clouds). Second, the typical spatial extension (several hundreds of kilometers) and lifetime (about one day) of boundary layer BrO fit very well to the temporal and spatial resolution and coverage of GOME. However, some uncertainties remain with respect to the separation of stratospheric and tropospheric columns, cloud effects, and the amount of $\mathrm{BrO}$ over low reflectivity surfaces such as the oceans. The improved spatial and temporal coverage and resolution of the latest and future satellite instruments will provide the opportunity to monitor tropospheric $\mathrm{BrO}$ chemistry in greater detail.

Very recently IO was identified from SCIMACHY along the coastline of Antarctica (Saiz-Lopez et al., 2007a; Schönhardt et al., 2007). There are indications that IO is below the detection limit in the Arctic and that there is a clear seasonal variation in the Antarctic with maxima in September and October and a second maximum in austral autumn (Schönhardt et al., 2007²).

\subsubsection{The link to other places}

Reactive bromine chemistry has been found to be of importance in many other regions, namely the coastal and open oceans, salt lakes, volcanic plumes, polluted cities (under certain circumstances), and the free troposphere. For an overview see, e.g., von Glasow and Crutzen (2007). Of particular interest in this regard are salt lakes (e.g. Hebestreit et al., 1999; Stutz et al., 2002; Hönninger et al., 2004a) as the release mechanisms are likely related to the ones in polar regions due to the presence of large salt deposits on the 
surface for both salt lakes and regions with new sea ice in high latitudes. This observation shows that low temperatures are not a prerequisite for the chemical cycles to be efficient in bromine release even though many of the involved reactions are temperature dependent so that one can expect important differences. This point, however, does not exclude the possibility that other - possibly physical - processes in polar regions might be dependent on cold temperatures. Specifically, the freezing of sea water, which causes brine to be pushed to the surface of the newly forming sea ice, is caused by cold temperatures and is likely involved in providing a saline surface on which halogen activation can occur (see Sect. 3.1 and its subsections). In Sect. 4.4 we discuss the possibility of transport of boundary layer air to the free troposphere and consequences for the chemistry in the free troposphere.

\subsection{Chlorine}

Chlorine was the second halogen (in inorganic form) that was detected in polar regions. As chlorine is present in small concentrations only, its direct role in ozone destruction is probably very minor. For a typical $[\mathrm{Br}]$ to $[\mathrm{Cl}]$ ratio of 800 (see Sect. 2.4), chlorine atoms would account for only $2 \%$ of ozone depletion. Chlorine does play an important role, however, in the oxidation of volatile organic compounds (VOCs, see also Sect. 4.2) and possibly in the activation of bromine via $\mathrm{BrCl}$ (see Sects. 1.3 and 2.4). Furthermore, the concentration of $\mathrm{HO}_{\mathrm{x}}$ is increased by oxidation of VOCs by chlorine, as detailed in Sect. 4.2. A multitude of measurements is compiled in the electronic supplement (http://www.atmos-chem-phys.net/7/4375/2007/ acp-7-4375-2007-supplement.pdf). With the exception of one measurement of $\mathrm{HCl}$ all data for inorganic chlorine so far are from the Arctic.

Jobson et al. (1994) were the first to develop an indirect technique to measure chlorine atoms in the polar troposphere. Their technique involved a kinetic analysis of the relative rates of hydrocarbon destruction. They showed that the time integrated chlorine concentration in the observed air mass at Alert was $\sim 3-7 \times 10^{9}$ molecules s $/ \mathrm{cm}^{3}$ which corresponds, based on estimated reaction times of 1-20 days, to chlorine atom concentrations ranging from $\sim 3 \times 10^{3}-6 \times 10^{4}$ molecules $/ \mathrm{cm}^{3}$.

Muthuramu et al. (1994) studied the decay of a series of alkyl nitrates at Alert and found that the relative alkyl nitrate decays were also consistent with the known chlorine atom rate constants. Kinetic analysis of the data led to a value of $6.5 \times 10^{9}$ molecules $\mathrm{s} / \mathrm{cm}^{3}$, i.e. the same result as obtained for light alkanes by Jobson et al. (1994). Muthuramu et al. (1994) discuss that $\mathrm{Cl}$ atom oxidation of alkyl nitrates may be an important mechanism for recycling $\mathrm{NO}_{\mathrm{x}}$ in the Arctic lower atmosphere. Several other investigators (Solberg et al., 1996; Ariya et al., 1998; Ramacher et al., 1999; Rudolph et al., 1999) have used the VOC relative oxidation rate method, producing comparable values for $[\mathrm{Cl}]$. Boudries and Bottenheim (2000) used the absolute decay rate for alkanes during a rapid ozone depletion event at Alert, Nunavut to derive a value $[\mathrm{Cl}]=7.5 \times 10^{4}$ molecules $/ \mathrm{cm}^{3}$. The chlorine atom is responsible for all the consumption of a variety of VOCs, such as the alkanes studied by Jobson et al. (1994), and alkyl nitrates (Muthuramu et al., 1994) over the Arctic Ocean during these events, see more details in Sect. 4.2.

As part of ARCTOC, Perner et al. (1999) conducted measurements of $\mathrm{ClO}_{\mathrm{x}}$ at $\mathrm{Ny}$-Ålesund, and measured a maximum [ClO] of $2 \mathrm{pmol} / \mathrm{mol}$, leading again to the conclusion that ozone destruction is dominated by $\mathrm{Br}$ atoms. Tuckermann et al. (1997) found average mixing ratios of $\mathrm{ClO}$ of about $21 \mathrm{pmol} / \mathrm{mol}$ during ODEs in 1995 at Ny-Ålesund which implies $\mathrm{Cl}$ atom concentrations much higher than those calculated with the hydrocarbon clock methods. However, Tuckermann et al. (1997) report an average of only $3.3 \mathrm{pmol} / \mathrm{mol}$ $\mathrm{ClO}$ during ODEs for 1996. The high mixing ratios observed in 1995 stand out as very unusual and seem to be inconsistent also with what was observed at other locations. These observations highlight the need for independent methods for measurement of $[\mathrm{Cl}]$.

The measurements by Impey et al. (1997b) of total photolysable chlorine (TPC) at Alert during the 1995 Polar Sunrise Experiment showed mixing ratios typically ranging from $\sim 5-15 \mathrm{pmol} / \mathrm{mol}$, with the highest concentrations found in the dark. After polar sunrise, TPC decreased to below the detection limit. This work showed that there is a dark production mechanism for chlorine atom precursors.

As already mentioned above, Foster et al. (2001) and Spicer et al. (2002) conducted the first direct measurements of $\mathrm{Br}_{2}$ and $\mathrm{BrCl}$, at Alert (see Fig. 8). Interestingly, while $\mathrm{BrCl}$ is present in quantities comparable to $\mathrm{Br}_{2}$, as discussed by Spicer et al. (2002), $\mathrm{Cl}_{2}$ was not detected.

A recent study by Tackett et al. (2007) addresses the question of the vertical scale impact of surface-derived halogenatom precursors. They conducted measurements of VOCs, $\mathrm{Hg}(0)$, and $\mathrm{O}_{3}$ in the lowest $300 \mathrm{~m}$ above the surface snow pack at Barrow, Alaska. From these measurements they concluded that both $\mathrm{Br}$-atom and $\mathrm{Cl}$-atom chemistry was most active in the lowest $\sim 100-200 \mathrm{~m}$ above the surface. As an example, shown in Fig. 10 are plots of [methyl ethyl ketone]/[nbutane] as a function of altitude. As discussed in the paper, $\mathrm{MEK} /$ butane is a sensitive function of $\mathrm{Cl}$-atom chemistry.

It is clear that chlorine atom chemistry is active and important in polar marine boundary layers, and over snow packs inland. This chlorine atom chemistry can play a dominant role in the processing of VOCs, and also in radical chemistry that in turn influences bromine atom chemistry. However, the nature of the chlorine atom precursors is not necessarily well understood and more measurement data for chlorine atom precursors and chlorine atoms themselves is needed to test and develop our understanding. 


\subsection{Iodine}

Most modeling studies that include iodine chemistry have been performed for the marine boundary layer (e.g. Vogt et al., 1999; McFiggans et al., 2000). They show that IO mixing ratios on the order of $1 \mathrm{pmol} / \mathrm{mol}$ already have a strong impact on ozone concentration, with destruction rates of up to $1 \mathrm{nmol} / \mathrm{mol}$ per day and that under these conditions, $\mathrm{O}_{3}$ destruction by iodine radicals is faster than by the $\mathrm{O}_{3}+\mathrm{HO}_{2}$ reaction (Vogt et al., 1999). They also showed that a strong chemical coupling between reactive $\mathrm{Cl}$ and $\mathrm{Br}$ compounds with iodine compounds exists and this coupling accelerates the autocatalytic release of these compounds from sea salt aerosol as discussed in the study of Vogt et al. (1999). In the box model study of Sander et al. (1997) the presence of about $1 \mathrm{pmol} / \mathrm{mol}$ of IO leads to an increase in the $\mathrm{O}_{3}$ destruction rate of about $20 \%$ mainly via the reaction $\mathrm{BrO}+$ IO. Model studies by Calvert and Lindberg (2004a) focused on the role of iodine in the chemistry during polar tropospheric ozone depletion events. They have shown that additional halogen atom formation from reactions of $\mathrm{IO}$ with $\mathrm{BrO}$ and $\mathrm{ClO}$ cause significant enhancements in polar ozone depletion when only small amounts of iodine-containing compounds, such as $\mathrm{CH}_{2} \mathrm{I}_{2}, \mathrm{IBr}$ or $\mathrm{ICl}$, are present in an air mass. Furthermore, their model studies suggest that the coupling between iodine and bromine radical chemistry leads to an enhanced depletion of gaseous mercury during bromine explosion events (Calvert and Lindberg, 2004b). The study of Saiz-Lopez et al. (2007c) aims to reproduce measured IO and $\mathrm{BrO}$ concentrations in the coastal Antarctic. They show that the rate of $\mathrm{O}_{3}$ depletion is increased about threefold by the presence of IO and BrO in roughly equal amounts compared to $\mathrm{BrO}$ alone. The main source for reactive iodine in the marine boundary layer is the photodegradation of iodinated organic compounds (such as $\mathrm{CH}_{3} \mathrm{I}, \mathrm{CH}_{2} \mathrm{I}_{2}, \mathrm{CH}_{2} \mathrm{IBr}$ and $\mathrm{CH}_{2} \mathrm{ICl}$ ) produced by macroalgae and phytoplankton in the ocean. The atmospheric lifetime of these compounds is very short, ranging from $5 \mathrm{~min}$ for $\mathrm{CH}_{2} \mathrm{I}_{2}$ to 5 days for $\mathrm{CH}_{3} \mathrm{I}$. For mid-latitude coastal regions $\mathrm{I}_{2}$ has been shown to be the main source for iodine atoms (Saiz-Lopez and Plane, 2004), which has a lifetime of about $10 \mathrm{~s}$. See Sect. 3.3.2 for more details.

First indications for the presence of reactive iodine in the polar boundary layer were found by Wittrock et al. (2000), who detected tropospheric IO in late spring and early summer 1995-1998 with a zenith sky DOAS instrument in NyÅlesund. However, no IO could be positively observed above the detection limit with a long-path DOAS at $\mathrm{Ny}$ Ålesund (Tuckermann et al., 1997). First long-term observations of IO in polar regions by zenith sky DOAS, performed at Neumayer Station, Antarctica, were reported by Frieß et al. (2001). Based on the interpretation of the diurnal variation of IO (see Fig. 11 using radiative transfer calculations, they concluded that the observed IO is located in the lower troposphere. Mixing ratios of roughly 5-10 $\mathrm{pmol} / \mathrm{mol}$
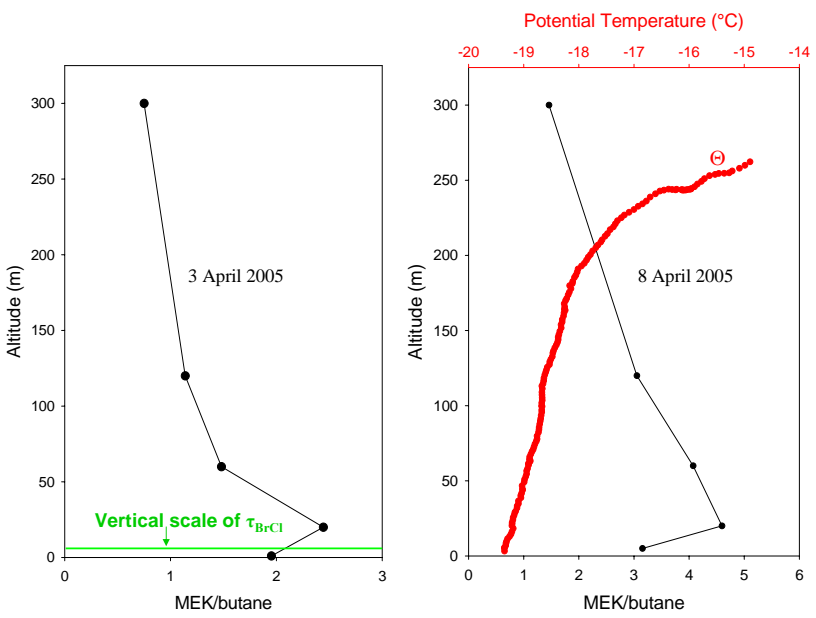

Fig. 10. Observations of organic gas vertical profiles from tethered balloon observations at Barrow, Alaska. The left panel shows a vertical profile of the ratio of methyl ethyl ketone (MEK) divided by butane from 3 April 2005. The right panel shows the same ratio for 8 April, 2005 along with potential temperature $(\theta)$. Reprinted from Tackett et al. (2007) with permission from the American Geophysical Union (AGU).

during summer were estimated under the assumption that IO is entirely located in the boundary layer. The IO measurements at Neumayer showed a pronounced seasonal cycle with a maximum during summer. This finding was explained by a more efficient photodissociation of organic precursors, a shorter distance to the open sea owing to the retreating sea ice as the likely source for organoiodine compounds, and/or a higher biological activity during summer. Based on multi-axis DOAS measurements during May 2000 in Alert, Canada, Hönninger (2002) estimated IO mixing ratios of $0.73+/-0.23 \mathrm{pmol} / \mathrm{mol}$ in the Arctic boundary layer, significantly lower than the Antarctic values.

The first positive detection of IO in the polar boundary layer by active DOAS was made by Saiz-Lopez et al. (2007b) in the Antarctic at Halley during the CHABLIS campaign (January 2004-February 2005). Both its seasonal cycle and its mixing ratios were very similar to those of $\mathrm{BrO}$ measured at the same time (see Section 2.1.1). IO was detected whenever the solar zenith angle was less than $92^{\circ}$, i.e. it was also present before direct sunlight reached the ground at mixing ratios up to $4 \mathrm{pmol} / \mathrm{mol}$ but not during the polar night. Its maximum with about $20 \mathrm{pmol} / \mathrm{mol}$ was also observed in October/November (spring) followed by a decrease towards the summer and a possible secondary maximum in fall.

The observed high levels of IO in Antarctica might lead to the formation of new aerosol particles as had been observed in a mid-latitude coastal location, (O'Dowd and Hoffmann, 2005; Saiz-Lopez et al., 2007b) and thus could explain the ultrafine particle events that have been observed in coastal Antarctica (Davison et al., 1996). 


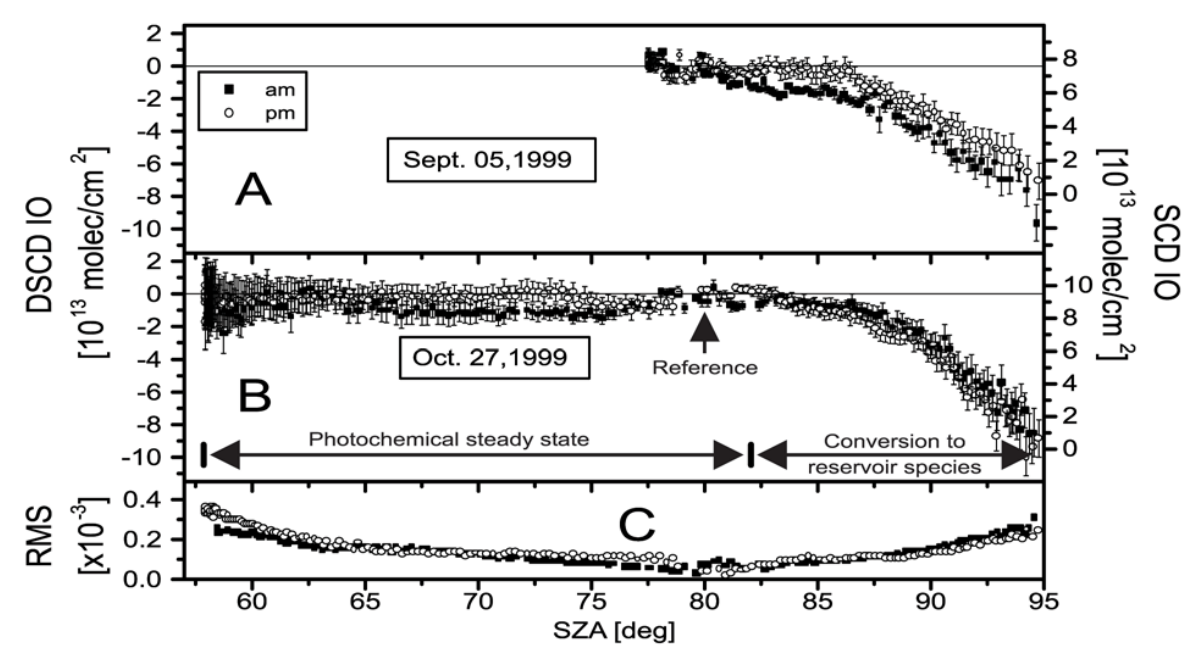

Fig. 11. Upper panel: Diurnal variation of the IO slant column density observed at Neumayer Station, Antarctica by zenith sky DOAS in spring 1999. Left-hand axis: inferred IO differential slant column density with unknown offset; Right-hand axis: absolute IO slant column density under the assumption that photochemistry leads to a complete removal of IO from the atmosphere at a solar zenith angles above $95^{\circ}$. Lower Panel: RMS residual of the spectral retrieval on 27 October. Adapted from Frieß et al. (2001) with permission from the American Geophysical Union (AGU).

\subsection{Interhalogen interactions}

Preceding sections have introduced the concept that there are a number of interactions between the various halogen compounds. As explained in Sect. 1.3, laboratory studies have shown that the halogen activating reaction, $\mathrm{HOBr}+\mathrm{X}^{-}+\mathrm{H}^{+}$, where $\mathrm{X}^{-}$is a halide ion $\left(\mathrm{Cl}^{-}, \mathrm{Br}^{-}\right)$is efficient at activating both $\mathrm{Br}^{-}$and $\mathrm{Cl}^{-}$(Fickert et al., 1999; Adams et al., 2002; Huff and Abbatt, 2000, 2002). Typically, when $\mathrm{Cl}^{-}$is the initial reaction partner, the product $\mathrm{BrCl}$ reacts with $\mathrm{Br}^{-}-$ yielding $\mathrm{Br}_{2}$ and $\mathrm{Cl}^{-}$, however, the efficiency of this conversion reaction depends upon bromide being present in the reacting mixture.

A number of studies have investigated the bromine to chlorine ratios in the gas phase. The techniques used most often so far is the VOC relative oxidation rate method (Jobson et al., 1994; Solberg et al., 1996; Ariya et al., 1998; Ramacher et al., 1999; Rudolph et al., 1999, for more details see Sect. 2.2). Typical $\mathrm{Br}$ to $\mathrm{Cl}$ ratios derived in these studies range from several hundred to over a thousand. Boudries and Bottenheim (2000) used the absolute decay rate for alkanes during a rapid ODE at Alert, Nunavut to derive a ratio $[\mathrm{Br}] /[\mathrm{Cl}] \sim 190$ for that event. Recently, Keil and Shepson (2006) developed a method for measurement of the ratio $[\mathrm{Br}] /[\mathrm{Cl}]$, through measurements of the products (haloaldehydes) of bromine and chlorine atom reaction with ethene and propene. This method was applied in the Barrow, Alaska, region, where there are relatively elevated concentrations of these alkenes, yet where there are also active ozone and $\mathrm{Hg}$ depletion events. An advantage of the Keil and Shepson method is that it is very sensitive to halogen chemistry, and chlorine and bromine atoms can be detected in the absence of a significant ozone depletion event. They reported $[\mathrm{Br}] /[\mathrm{Cl}]$ atom ratios ranging from $80-990$ for partial ozone-depleted conditions. Analysis of their data indicated that the measured haloaldehydes were produced locally, and that the precursors were derived from chemistry occurring in the snow pack.

Direct field observations of $\mathrm{Br}_{2}$ and $\mathrm{BrCl}$ from snow at Alert showed a variable ratio of the $\mathrm{Br}_{2}$ and $\mathrm{BrCl}$ yields (Foster et al., 2001). The ratio of $\mathrm{Br}^{-}$to $\mathrm{Cl}^{-}$in the ice is important for halogen reactions, and this ratio has been shown to be highly variable in snow (Simpson et al., 2005). Impey et al. (1997b) found that total photolysable chlorine (TPC) showed the highest concentrations in the dark, by full sunlight TPC was below the detection limit. In contrast, total photolysable bromine (TPB) remained at the same values during darkness and sunlight. This and the fact that the back trajectories for airmasses with high TPC and TPB are quite different led Impey et al. (1997b) to conclude that the mechanisms for production of chlorine and bromine atoms are also quite different. A steady state analysis led to an estimated $[\mathrm{Br}] /[\mathrm{Cl}]$ ratio of 100-300 during ozone depletion events.

From these direct and indirect observations it might be concluded, and has been discussed in several of the above papers, that the high variability in the ratio of $\mathrm{Br}$ to $\mathrm{Cl}$ atoms of under one hundred to over a thousand (both in the presence and absence of ODEs) is likely caused by the surface (i.e. snow pack) being the source or "recycler" for the halogens and the high variability of these halogen's anions in snow and aerosols. Also it might mean that different release/recycling processes are dominant under different conditions. 
We want to stress again, however, that despite a lack of a clear correlation of $\mathrm{Br}$ and $\mathrm{Cl}$ atoms there is a clear connection between chlorine and bromine chemistry, beyond the chemical reaction that produces $\mathrm{BrCl}$ (see Reaction $\mathrm{R} 10$ ). Specifically, the chemistry that produces $\mathrm{Br}_{2}$ and $\mathrm{BrCl}$ and the "bromine explosion" requires production of $\mathrm{HOBr}$ which is produced in the reaction of $\mathrm{BrO}$ with $\mathrm{HO}_{2}$ (R5) and $\mathrm{HO}_{2}$ can be produced to a substantial amount by chlorine chemistry as detailed in Sect. 4.2.

In the Antarctic, there is evidence of substantial amounts of reactive iodine (Frieß et al., 2001), which could be coupled to bromine chemistry. During the CHABLIS campaign, a correlation between $\mathrm{BrO}$ and IO was observed at Halley, Antarctic (Saiz-Lopez et al., 2007b). Both showed a diurnal cycle, tracking the solar radiation and peaking at local noon. This observation indicates that both species are produced photochemically, and have a boundary layer lifetime of less than $\sim 2 \mathrm{~h}$. IO and $\mathrm{BrO}$ showed a correlation with the air mass origin predicted by back trajectory calculations, with elevated concentrations of both radicals when the wind was from the open ice front sector. However, even in continental air masses which had not been close to the ocean over the preceding 5 days, $\mathrm{IO}$ and $\mathrm{BrO}$ were still usually observed at mixing ratios up to $\sim 6 \mathrm{pmol} / \mathrm{mol}$ during sunlit periods. This implies that substantial halogen activation must be widespread in the Antarctic boundary layer, not restricted to close proximity to the ice front. Under the conditions encountered during CHABLIS the reaction of IO with $\mathrm{BrO}$ would increase $\mathrm{O}_{3}$ destruction by about $20 \%$ (Saiz-Lopez et al., 2007b).

However, in the Arctic, substantially lower levels of reactive iodine have been detected, indicating no linkage between iodine and bromine chemistry for the Arctic. This finding seems to be confirmed by recent satellite studies of IO in both hemispheres that could only detect IO above the detection limit in the southern hemisphere (Schönhardt et al., $2007^{2}$ ). It remains an important question if this link has so far been overlooked or if indeed important differences between the Arctic and Antarctic in terms of halogen interactions exist.

\section{Key environmental processes and their effects on ODEs}

\subsection{The role of sea ice}

Many of the early studies of Arctic tropospheric ozone depletion identified marine influences on ozone depleted air masses. As explained in Sect. 1, it was soon clear that sea salt is likely the major source for bromine. The observation of depleted ozone levels during the majority of the time at ice camps on the frozen Arctic Ocean reinforced the picture of ocean-derived salts as key in the process (Hopper et al., 1994). GOME satellite observations showed that re- gions of enhanced $\mathrm{BrO}$ were largely present over young sea ice but not over multi-year sea ice (Wagner et al., 2001), giving strong indications for the relevance of young sea ice in halogen activation. The match of the tropospheric $\mathrm{BrO}$ features to areas of first-year sea ice is probably related to the higher salinity of first-year ice as compared to multi-year ice (Wagner et al., 2001). Frieß et al. (2004) and Simpson et al. (2007) also showed, using trajectory analysis, that areas of first-year sea ice are correlated to high BrO levels. The processes behind transformation of salt from the oceans to reactive halogens is crucial for understanding the dependence of halogen activation and ozone depletion on environmental properties, particularly sea ice extent. As discussed in Sect. 5.1, in the context of a rapidly changing Arctic marine environment, sensible predictions of changes in halogen activation require detailed mechanistic understanding of the role of sea ice.

In this section, we consider sea ice and how salts, initially in the ocean, are transported through the ice. This transport is probably related to sea-ice structures, such as leads (cracks in the ice, typically linear and variable in location), polynyas (reoccurring, larger areas of open water), and other sea-ice forms. The process of freezing sea ice has a complex thermodynamics due to separation of ice from the concentrated salt solutions (i.e. brine). Additionally, forms of ice and snow that occur in the sea ice environment may have key roles in the halogen activation process. For example, when an open lead begins to freeze over, it often forms dendritic vapor-deposited ice crystals that wick brine from the freezing ice (Perovich and Richter-Menge, 1994; Rankin et al., 2002). These ice forms, known as frost flowers, will be considered as possible sources of salt aerosols and possible sites of halogen activation. Figure 12 shows a photograph of frost flowers growing on sea ice.

As sea water cools, ice begins to form and rejection of salts from the freezing water creates highly saline brine. As the brine cools with the ice, some forms of salts reach solubility limits and precipitate, altering the chemical composition of the residual unfrozen brine. The precipitation process may affect chemistry and impart signatures on salt aerosols or snow contaminated by their aerosols. Some important processes are the precipitation of mirabilite $\left(\mathrm{Na}_{2} \mathrm{SO}_{4} \bullet 10 \mathrm{H}_{2} \mathrm{O}\right)$, which starts at $-8^{\circ} \mathrm{C}$, and the precipitation of calcium carbonate $\left(\mathrm{CaCO}_{3} \bullet 6 \mathrm{H}_{2} \mathrm{O}\right)$ at $-2^{\circ} \mathrm{C}$ (Richardson, 1976). Both of these precipitation processes would be expected to occur at temperatures commonly encountered during the freezing of sea ice. Hydrohalite $\left(\mathrm{NaCl} \bullet 2 \mathrm{H}_{2} \mathrm{O}\right)$ precipitation may occur if sea ice is cooled below $-21^{\circ} \mathrm{C}$ and is likely to occur in brine aerosols that encounter low air temperatures. Even at temperatures down to $-30^{\circ} \mathrm{C}$, some salts remain in liquid solution (Koop et al., 2000). Figure 13 shows the properties of the unmelted brine resulting from freezing of sea ice as a function of temperature. Precipitation temperatures of various salt hydrates are also shown on the plot. 


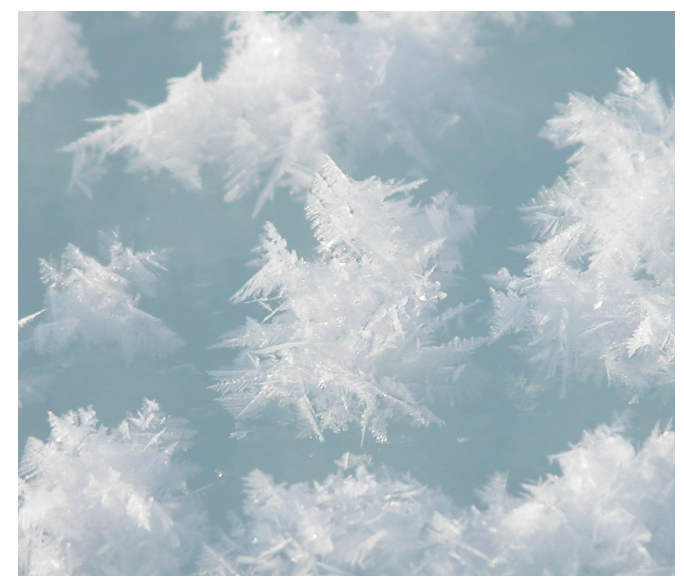

Fig. 12. A photograph of frost flowers growing on newly forming sea ice. The width of the figure is $12 \mathrm{~cm}$. Courtesy of T. A. Douglas.

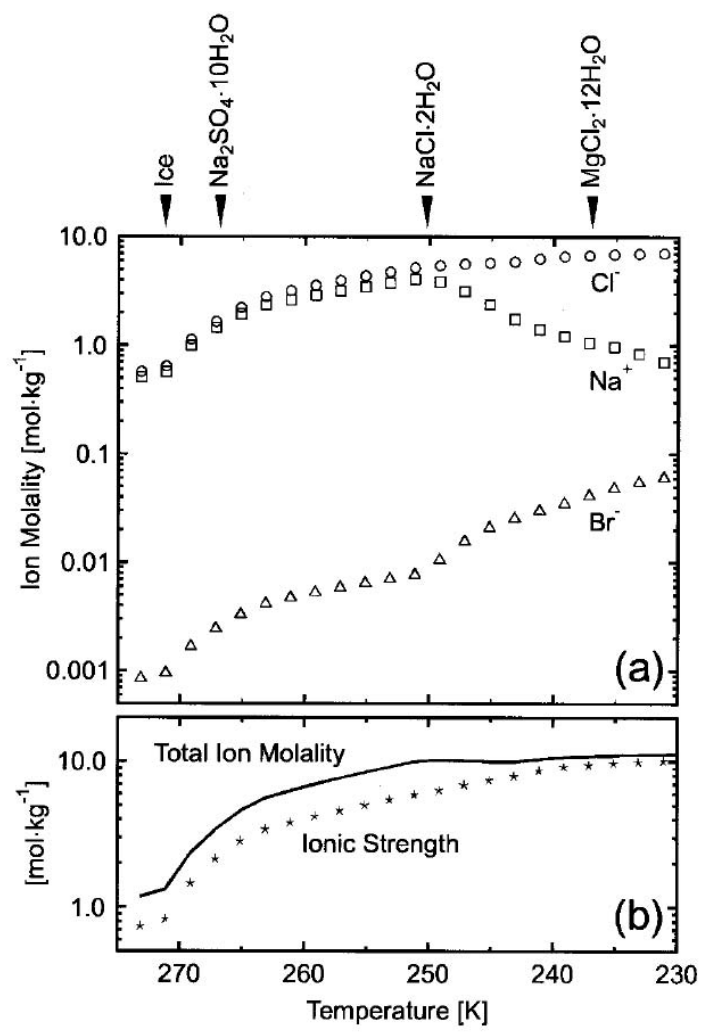

Fig. 13. Properties of sea ice as a function of temperature. Panel (a) shows molalities for specific ions in the residual brine. Precipitation temperatures of various salt hydrates are shown on the top of the plot. Panel (b) shows total ion molality and ionic strength of the un-frozen brine as a function of temperature. Reprinted from Koop et al. (2000) with permission from the American Geophysical Union (AGU).

\subsubsection{Brine formation and aerosol production}

New sea ice formation is linked to these precipitation processes, although similar phase transitions occur in sea-salt aerosol particles, or on the surface of snow contaminated by salts. Ice begins to form in sea water at around $-1.7^{\circ} \mathrm{C}$, and as ice grows, it produces a network of ice crystals interleaved by volumes of unfrozen brine. Soon the brine forms channels in the young ice. As the ice cools, the channels constrict and some brine is pushed to the surface, while other brine sinks through the ice down into the water column. The brine that is pushed to the surface then experiences colder temperatures, and precipitation processes may begin to occur. When mirabilite precipitates, sodium and sulfate are removed from the brine. Because the sulfate concentration is much smaller than the sodium concentration, the fraction of sulfate that may be removed is higher than for sodium. Measurements of aerosol composition in the Antarctic (Wagenbach et al., 1998; Rankin et al., 2002; Rankin and Wolff, 2003; Wolff et al., 2003; Hara et al., 2004) showed a decrease in the sulfate to sodium ratio compared to sea water (negative non-sea salt sulfate), indicating fractionation processes before release of the particles. As discussed above, this depletion is caused by the precipitation of mirabilite below $-8^{\circ} \mathrm{C}$. Rankin and Wolff (2003) estimate that at least $60 \%$ of sea-salt aerosol arriving at Halley is derived from sulfate-depleted brine. Because frost flowers transport brine at temperatures colder than the mirabilite precipitation temperature, aerosol derived from frost flowers would be expected to be sulfate depleted. Chemical analysis of frost flowers indicate that most frost flowers are depleted in sulfate (Rankin and Wolff, 2003; Simpson et al., 2005). Therefore, most observations of sulfate depleted aerosol are discussed as indications of frost flowers as the source of the fractionated brine, although other fractionated brine processes could still be responsible. Dominé et al. (2004) considered how wicking of brine up snow on sea ice may produce salty snow, which could later be blown and form aerosol particles (see Fig. 14). Overall, these experimental studies indicate that sulfate-depleted brine, probably derived from frost flowers, is the most common source of sea-salt aerosol particles in the polar atmosphere during winter/springtime.

\subsubsection{Precipitation processes, modification of $\mathrm{pH}$, and sur- face reactivity}

Another effect of salt precipitation processes is modification of the brine's composition. A potentially important precipitation process in this regard is that of carbonate, which may affect the $\mathrm{pH}$ of the residual brine (as proposed by Sander et al., 2006). The $\mathrm{pH}$ of the brine is important because of the $\mathrm{pH}$ dependence of the key step of the bromine explosion mechanism, the heterogeneous reaction of $\mathrm{HOBr}$ with $\mathrm{Cl}^{-}$ or $\mathrm{Br}^{-}$(Reactions $\mathrm{R} 8$ and $\left.\mathrm{R} 10\right)$. In liquid solution, these reactions have been shown to have a strong $\mathrm{pH}$ dependence 
(Fickert et al., 1999), with efficient reaction at acid pH, but lower efficiency at high $\mathrm{pH}$. Sea water is basic enough to shut off the reaction. Some later laboratory studies indicate that freezing of the salt solution may reduce or even eliminate the $\mathrm{pH}$ dependence of this reaction (Huff and Abbatt, 2000, 2002; Adams et al., 2002). The alkalinity of sea water derives from the presence of bicarbonate and carbonate (which are in equilibrium) in the water. Precipitation of calcium carbonate, which is predicted to occur soon after initial freezing of sea water, depletes carbonate and bicarbonate through their equilibrium and diminishes the buffering capacity of sea-salt aerosol. This effect could assist the bromine explosion, as has been shown in the model calculations of Sander et al. (2006). In another model study, Piot and von Glasow (2007) showed that the presence of a polluted airmass as in an Arctic Haze event would have the same effect on the development of an ODE as carbonate precipitation. However, a detailed analysis of the effects of the carbonate system in this context requires the knowledge of all thermodynamic data (Henry's law for $\mathrm{CO}_{2}$, solubility products, carbonic acid dissolution constants) at sub-zero temperatures and activity corrections to the thermodynamic parameters are likely to be necessary to account for the effect of salinities in the remaining brine (Richardson, 1976; Marion, 2001).

Analysis of the $\mathrm{pH}$ of melted frost flowers and snow in Antarctica showed that the $\mathrm{pH}$ of the frost-flower melt water was too alkaline to support bromine explosion chemistry (in liquid solution), while the $\mathrm{pH}$ of melted snow was favorable for bromine activation (Kalnajs and Avallone, 2006). These results are consistent with the idea that carbonate precipitation in the brine can reduce the buffer capacity of the aerosol source and thus allow the aerosol to be acidified more easily. However, if precipitation of carbonate had happened in the frost flowers, their surface $\mathrm{pH}$ may have been different from the bulk $\mathrm{pH}$ analysis employed in this study. In addition to the question of the effective $\mathrm{pH}$ of frost flowers, ice, and snow, laboratory experiments and molecular modeling studies indicate that all halide ions except for fluoride are segregated to the surface of aqueous solutions and crystals (Ghosal et al., 2000, 2005; Knipping et al., 2000; Jungwirth and Tobias, 2001, 2002; Finlayson-Pitts, 2003). Jungwirth and Tobias (2002) explained this effect with the polarizability of the halides that increases with the size of the ion. The presence of halide ions on the surface was proposed to allow heterogeneous oxidation of halides by hydroxyl radicals (Knipping et al., 2000; Laskin et al., 2003). These ideas, which were developed in the context of unfrozen aerosol systems, may have parallels in frozen systems relevant to polar halogen activation. If similar reactions occur for bromide and lead to $\mathrm{Br}_{2}$ or $\mathrm{BrCl}$, it might play a role in initiation of bromine explosions or possibly in the observations of Foster et al. (2001) and Spicer et al. (2002) of $\mathrm{Br}_{2}$ and $\mathrm{BrCl}$ before polar sunrise.

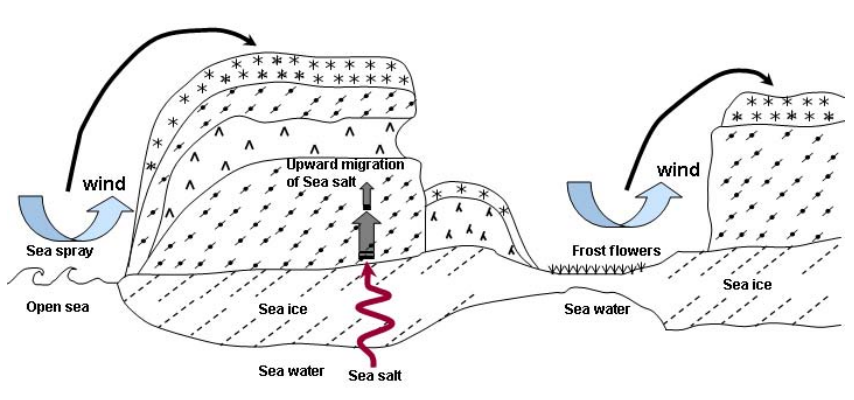

Fig. 14. Illustration of the main three processes suspected of supplying sea salt ions to marine snow: wind-transport of sea spray, upward migration from sea ice, and wind-blown frost flowers. Reprinted from Dominé et al. (2004) with the permission of the authors.

\subsubsection{Sources of reactive halogens}

The realization that sulfate-depleted brine, possibly arising from frost flowers, was likely a major source of sea-salt aerosol particles led to the idea that frost flowers are involved in halogen activation (Rankin et al., 2002). The precise means of their involvement is still an active question of research. Frost flowers may directly release gas phase bromine to the atmosphere, or they may produce aerosol particles that carry bromide ions into the atmosphere, where they then undergo halogen activation and produce reactive halogen radicals. Brine-derived aerosol particles, or brine wicking may contaminate snow with halide ions that are then activated and emitted to the atmosphere (e.g. as $\mathrm{Br}_{2}$ and $\mathrm{BrCl}$ ). It is likely that several of these processes occur; therefore the real discussion is: What are the relative roles of these mechanisms? Here we consider each limiting case separately.

\subsubsection{Frost flowers as a direct halogen source}

Frost flowers may be a direct source of reactive bromine. Frost flowers are vapor deposited crystals, and thus have sharp angular features and enhanced surface area. Early estimates of their surface area were very high, leading to the idea that bromine is released to the atmosphere from frost flowers (Rankin et al., 2002). However, due to difficulties in making detailed chemical observations near frost flowers, direct evidence of their involvement is sparse. One recent study has shown rapid ozone depletion $(\sim 7 \mathrm{~h})$ in the marginal ice zone, which has been interpreted as due to in-situ chemical loss (Jacobi et al., 2006). Difficulties with interpretation of ozone temporal loss rates are discussed in Sect. 3.3, but if one assumes that these loss rates are due to chemical loss, it might indicate that frost flowers produce bromine. Jones et al. (2006) found that ozone depletion events detected at Halley were correlated with airmass motions that brought air in contact with a large coastal polynya that often produces 
frost flowers. However, a number of other lines of evidence can be considered with regard to direct release of bromine from frost flowers. Measurements of the specific surface area (SSA) of frost flowers (Domine et al., 2005) found values less than $200 \mathrm{~cm}^{2} / \mathrm{g}$ for fresh frost flowers ( $<1$ day old), approximately two orders of magnitude smaller than the early estimates, making frost flowers appear less likely as direct bromine sources. At first glance, it appears that depletion of bromide in frost flowers as compared to a sea salt tracer (e.g. $\mathrm{Na}^{+}$) could be used to calculate the amount of volatilized bromide. Such measurements of bromide to sodium ratios have been made and showed that bromide is not measurably depleted as compared to sodium in frost flowers (Simpson et al., 2005). However, the concentration of bromide in frost flowers is so large that even a few percent removal of bromide (smaller than analytical precisions of this study) could provide an atmospheric column of bromine of the magnitude measured by BrO DOAS spectroscopy (e.g. Hausmann and Platt, 1994; Tuckermann et al., 1997; Hönninger and Platt, 2002). Therefore, the direct observations of bromide ions in frost flowers do not provide definitive information on their possible direct role in halogen activation. Arguments based upon the $\mathrm{pH}$ of melted frost flowers, discussed above, indicate that the $\mathrm{pH}$ of frost flowers may be too alkaline to support bromine explosion chemistry (Kalnajs and Avallone, 2006) at the surface. However, carbonate precipitation may allow aerosols and snow to be more easily acidified, promoting halogen activation chemistry (Sander et al., 2006). However, the effective $\mathrm{pH}$ of frost flower surfaces in their native state is not known and could also be affected by carbonate precipitation as discussed in Sect. 3.1.2. Frost flowers could also be indirect source of reactive bromine through aerosol production, as discussed in the following section.

\subsubsection{Frost flower-derived aerosol as a halogen source}

Aerosol produced from frost flowers contains relatively high concentrations of sea salt, and thus could be the predominant surface on which the $\mathrm{HOBr}+\mathrm{X}^{-}$reactions occur ( $\mathrm{Re}$ actions R8 and R10). Many modeling studies have found that reactions on aerosol surfaces are important in sustaining halogen activation events (McConnell et al., 1992; Fan and Jacob, 1992; Tang and McConnell, 1996; Sander et al., 1997; Michalowski et al., 2000; Evans et al., 2003). Evidence for aerosol involvement in halogen activation comes from ground-based MAX-DOAS BrO profile observations (Hönninger et al., 2004b) done in coincidence with surfacelevel $\mathrm{BrO}$ concentration measurements that have shown that $\mathrm{BrO}$ layers can be aloft. Because the lifetime of $\mathrm{BrO}_{\mathrm{x}}$ is only a few hours in the absence of recycling (see Sect. 1.3), layers observed aloft would need to be either lofted quite recently or $\mathrm{BrO}_{\mathrm{x}}$ would have to recycle on lofted aerosol. Therefore, this observation shows aerosol is probably capable of sustaining halogen activation. Very high column densities of $\mathrm{BrO}$ observed from a high-altitude aircraft were also interpreted as due to $\mathrm{BrO}$ being lofted to elevations above the boundary layer and transporting long distances (McElroy et al., 1999). Additionally, there is satellite-based evidence for outflow of $\mathrm{BrO}$ events from the Arctic, which last multiple days, and must be sustained on aerosol surfaces (Hollwedel, 2005). Most measurements of aerosol bromide enrichment factors show that they are enhanced in bromide (Berg et al., 1983; Barrie et al., 1988; Toom-Sauntry and Barrie, 2002; Ianniello et al., 2002; Sander et al., 2003a). Enhancement in bromide would occur by scavenging of $\mathrm{HBr}$, the chain termination product of bromine activation, by the particle. This particulate bromine could be reactivated to recycle gas-phase bromine. Although there is significant evidence for aerosol involvement in halogen activation, the early observation that most ozone depletion episodes are based at the ground argues for some ground-based flux of halogens or their precursors and thus against a dominant role of aerosol particles in halogen activation (Bottenheim et al., 2002; Zeng et al., 2003).

\subsubsection{Satellite remote sensing of frost flowers}

Satellite-based synthetic aperture radar (SAR) images are capable of detecting frost flowers, through their high brightness (Kaleschke et al., 2001). Radar images have been used to examine the relationship between frost flowers and aerosol (Rankin et al., 2002). Kaleschke et al. (2004) have exploited multiple satellite-derived data sets to predict regions of possible frost flower formation. In this method, potential frost flowers (PFF) are calculated by using a physical model of their formation (Martin et al., 1995, 1996) that is based upon the combination of open water fraction, the regions that soon freeze over forming new ice, and the ambient air temperature, a factor that takes into account the observation that cold air temperatures are needed to form frost flowers. With this physical model, PFF can be calculated from satellite-derived sea-ice fraction maps (from SSM/I or AMSR-E passive microwave images) and meteorological reanalysis of temperature fields. Kaleschke et al. (2004) showed that the areas of high PFF fraction, when advected by one day using a trajectory model matched spatial patterns of satellite derived enhanced vertical columns of BrO. Figure 15 shows an example of this spatial match. This correlation shows evidence that frost flowers, or the conditions that are prone to form them, appear in coincidence with bromine explosion events. Later work by Kaleschke and co-workers considered the annual cycle in PFF fraction to try to explain the annual cycle of BrO, as discussed in Sect. 3.2.2 (Kaleschke et al., 2005). Recently, Bottenheim and Chan (2006) showed that younger sea ice areas, particularly areas known for polynya formation, appear to be sources of ozone depleted airmasses. However, a recent trajectory study showed that PFF contact was not as good a predictor of $\mathrm{BrO}$ in airmasses impacting Barrow, Alaska, as was simple first year ice contact (Simpson et al., 2007). Further work in this area is needed to determine if it is actually frost flowers that are causing this correlation, and if 
the release of bromine is from the frost flowers directly, from aerosol produced, or from snow contaminated by the aerosol.

\subsubsection{Saline surfaces as a halogen source}

Saline surfaces, particularly snow pack in coastal areas and snow/ice on the sea ice contaminated with sea salts, are ubiquitous in polar regions during springtime, making them possible sites for halogen activation. As discussed in Sect. 3.1.1, snow is contaminated by salts by wind-transport of sea spray, upward migration from sea ice, and wind-blown frost flowers. The surface-based nature of ozone depletion episodes, discussed in Sect. 3.1.5, also provides indirect evidence that the snow pack may be providing the halogen flux. Direct measurements of $\mathrm{Br}_{2}$ and $\mathrm{BrCl}$ above snow by mass spectroscopy have shown the most clear evidence for the role of snow pack in halogen activation (Foster et al., 2001; Spicer et al., 2002). In these direct studies, in-snow measurements also showed that snow was the source of the halogen gases. In-situ measurements of $\mathrm{BrO}$ by resonance fluorescence showed high $\mathrm{BrO}$ concentrations near the snow surface, also providing evidence for snow as a source of reactive halogen gases (Avallone et al., 2003). Additional indirect evidence for the role of snow in the processing of bromine are measurements of the coastal gradient in bromide enrichment factors that showed that many snow samples were significantly depleted in bromide, indicating that they had released bromine to the atmosphere (Simpson et al., 2005). Snow pack may also be related to halogen activation via photochemistry, as is discussed in the companion review paper on snow photochemistry. In a recent model study, Piot and von Glasow (2007) found that they could reproduce an ODE in a one-dimensional model only when, in addition to the bromine source in form of frost flower aerosol, the re-release of deposited bromine from the snow pack as $\mathrm{Br}_{2}$ and $\mathrm{BrCl}$ was assumed. A major ODE developed only 3-4 days after emission of the salt aerosols in the model. They also note that their results are not restricted to the source of salt aerosols being from frost flowers, any other process related to salty aerosols being emitted from brine would have led to the same results. Direct degassing of gas-phase bromine from a frost flowers field only leads to ODEs under unrealistic conditions.

\subsection{The role of meteorology and boundary layer physics}

\subsubsection{Polar boundary layer description}

The boundary layer in polar regions is unique and may play a dominant role in ODE chemistry by limiting the dispersion of reactive chemicals produced from Earth's surface. For a detailed description of the polar boundary layer, see the accompanying review article, Anderson and Neff (2007). In discussions of the meteorology of atmosphere-ice interactions, it is important to distinguish between temperature inversions and boundary layers (BL). Inversions describe the

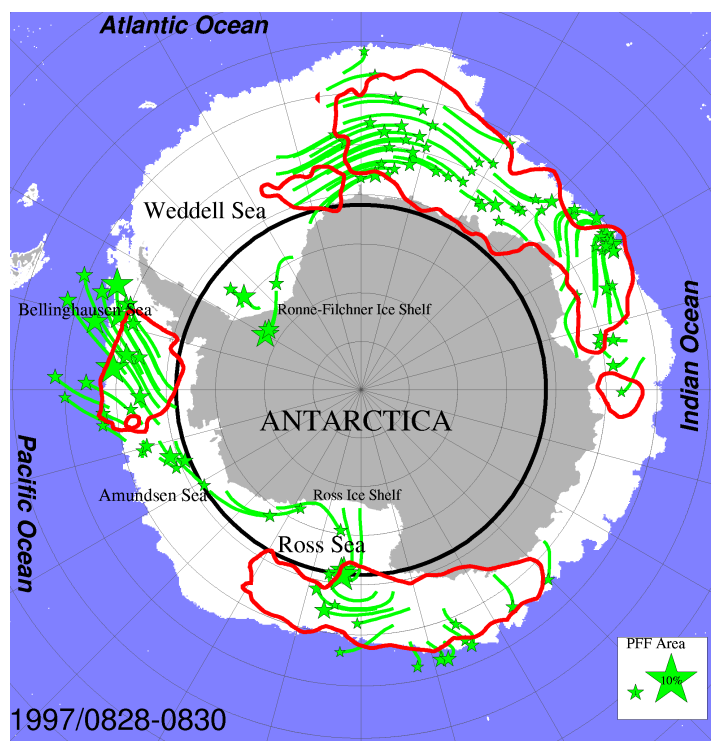

Fig. 15. The spatial match between potential frost flowers (PFF), shown by stars and regions of enhanced $\mathrm{BrO}$ (shown in red isocontours). Reprinted from Kaleschke et al. (2004) with permission from the American Geophysical Union (AGU).

atmospheric temperature structure, and hinder vertical mixing, while the boundary layer can be most simply defined as the layer of the atmosphere directly influenced by the Earth's surface in the exchange of heat, momentum, and moisture. From the perspective of chemistry occurring at Earth's surface, it would be the layer of the atmosphere through which primary emissions from the surface would be mixed vertically. This concept allows a quantitative definition of BL height. For example, the top of the BL can be defined as the point where some quantity (e.g. heat flux, concentration etc.) falls off to some fraction of its surface value (e.g. 10\%). It can also be observed using remote sensing such as sodar (e.g. Neff et al., 2007; Jones et al., 2006) or lidar systems (e.g. Zeng et al., 2003). It can also be deduced from series of ozonesondes (e.g. Shepson et al., 2003) although because of the long lifetime of ozone (or conversely its slow recovery rate after depletion) its vertical profile may not coincide with short term variations in the boundary depth (Neff et al., 2007). In this respect, chemical as well as temperature profiling often reflect the history of boundary layer processes, not necessarily the boundary layer's current state.

As described by Anderson and Neff (2007), boundary layers fall into three general classes: stable, neutral, or unstable (convective). In the stable BL, the turbulence produced by friction of the air flow over a rough surface has to work against the effect of buoyancy, eroding into the overlying air. In the neutral BL, no work needs to be done to overcome buoyancy and the BL simply grows or diminishes in response to changes in surface friction and the rate of dissipation of 
turbulent energy (a molecular process). In the unstable, or convective, BL, turbulence is produced by heated parcels rising from a warmer surface into cooler air aloft. In these cases, the "heated surface" can arise from the absorption of radiation (e.g. direct sunlight), development of a heat and moisture source such as the relatively warm water in an open lead (Serreze et al., 1992; Alam and Curry, 1995), or result from an air mass change where a cold air mass moves over a warmer surface. In polar regions, each of these "classical" BLs can occur within an otherwise stable atmosphere. For an example of complex vertical mixing and layering, see the trajectory calculations of Frieß et al. (2004) shown in Fig. 7. Complicating this picture are other buoyancy effects such as wave motions that may transfer momentum but not heat and the effects of the heterogeneous surfaces characteristic of coastal areas. This last effect is sometimes present in ground-based observations of ODEs from coastal sites, and often adds complication to the observations and modeling (Zeng et al., 2003; Jones et al., 2006).

Ozone depletion episodes have been observed to be sporadic at locations like Alert, Barrow, or Ny-Ålesund, indicating that rapid changes in atmospheric conditions affect the beginning and ending of these events. Some of these changes could be associated with complicating coastal topography. Limited ice camp observations (Hopper et al., 1994) and satellite observations of $\mathrm{BrO}$ (e.g. Wagner and Platt, 1998a; Richter et al., 1998c) show that at higher latitudes the conditions of ODEs are the most common situation in spring (see Sect. 1).

\subsubsection{Meteorological influences on ozone destruction events and seasonality}

The relationship between ozone depletion events and the meteorological situation during their detection has been studied since the initial observations of this phenomenon (e.g. Oltmans and Komhyr, 1986; Bottenheim et al., 1986; Hopper et al., 1994). These investigations, however, have been difficult to interpret because of the specific meteorology of the limited number of stations where observations have been made. Generally, ozone depletion episodes are correlated with air mass contact with sea-ice and stable boundary layer structures, which typically occur during low wind speeds and clear sky conditions (Wagner et al., 2001; Frieß et al., 2004; Jones et al., 2006). To observe ODEs at sites elevated from the sea ice or significantly inland (e.g. Alert), winds are necessary to bring the ozone depleted air mass up to the station. Therefore, the events may be detected during relatively high wind events (Hausmann and Platt, 1994; Hönninger and Platt, 2002). The complication that observation of ODEs at topographically complex coastal sites (e.g. Alert) usually requires specific meteorological conditions to transport the proper air masses to the field site has also caused difficulty in interpretation of the rate of ozone destruction. Many of the observations have shown extremely rapid temporal $\mathrm{O}_{3}$ de- crease rates: decrease of more than $30 \mathrm{nmol} / \mathrm{mol}$ to less than $1 \mathrm{nmol} / \mathrm{mol}$ within several hours (Bottenheim et al., 1986; Tuckermann et al., 1997; Morin et al., 2005; Jones et al., 2006; Jacobi et al., 2006). An example of particularly rapid $\mathrm{O}_{3}$ temporal loss and recovery is shown in Fig. 16. Most of these events can be clearly attributed to a change in air masses, where air parcels with reduced $\mathrm{O}_{3}$ concentrations were quickly transported to the measuring sites. For this reason, it is generally considered that the temporal rate of ozone decrease at a fixed site is not a good measure of the chemical ozone destruction rate. Most modeling studies also indicate that the chemical rate of ozone destruction is on the order of at least a day (e.g. Fan and Jacob, 1992; McConnell et al., 1992; Sander et al., 2006), or rather on a 3-5 day timescale as shown in studies where it was attempted to reproduce ODEs from the release of halogens from the snowpack (Michalowski et al., 2000) or from frost flower-related aerosol and recycling on snow (Piot and von Glasow, 2007). One field study that was made in the marginal ice zone of the frozen Arctic Ocean has interpreted their observation as being due to rapid local chemical processing (Jacobi et al., 2006).

The earliest observations of ozone depletion events showed that they occurred in the spring but not in the fall (Oltmans and Komhyr, 1986), and this apparent seasonal asymmetry has been a point for discussion ever since. In fact, earlier observations of bromine aerosol (Berg et al., 1983) showed that bromine peaks in springtime and not in the fall. Most interpretations of this asymmetry relate to the asymmetry of the annual cycle of temperature and snow/ice as compared to the solar input. The solar input is symmetric about the summer solstice, while the temperature and snow/ice cycles are lagged, with significantly lower temperatures and snow and sea ice during the springtime and warmer temperatures and increased open water during fall. This seasonal change in surface properties also causes stronger surface temperature inversions, reduced vertical mixing, and a shallower atmospheric boundary layer in the springtime. Lehrer et al. (2004) argued that the combination of a shallow boundary layer, availability of salts on the sea ice surface, and solar radiation, which drives the photochemistry, is only proper for halogen activation in the springtime. Kaleschke et al. (2005) extended their work on potential frost flowers (Kaleschke et al., 2004), discussed in Sect. 3.1.6, to a hemispheric scale and showed that the hemispheric-averaged $\mathrm{BrO}$ has a similar annual cycle to the product of the solar flux times PFF. If PFF is a good predictor of frost flowers or other processes leading to the release/activation of $\mathrm{Br}^{-}$to photolysable bromine, this work could indicate that the higher probability of cold conditions and new ice formation (prerequisites for PFF) in springtime than during fall is the cause of the seasonal asymmetry. 

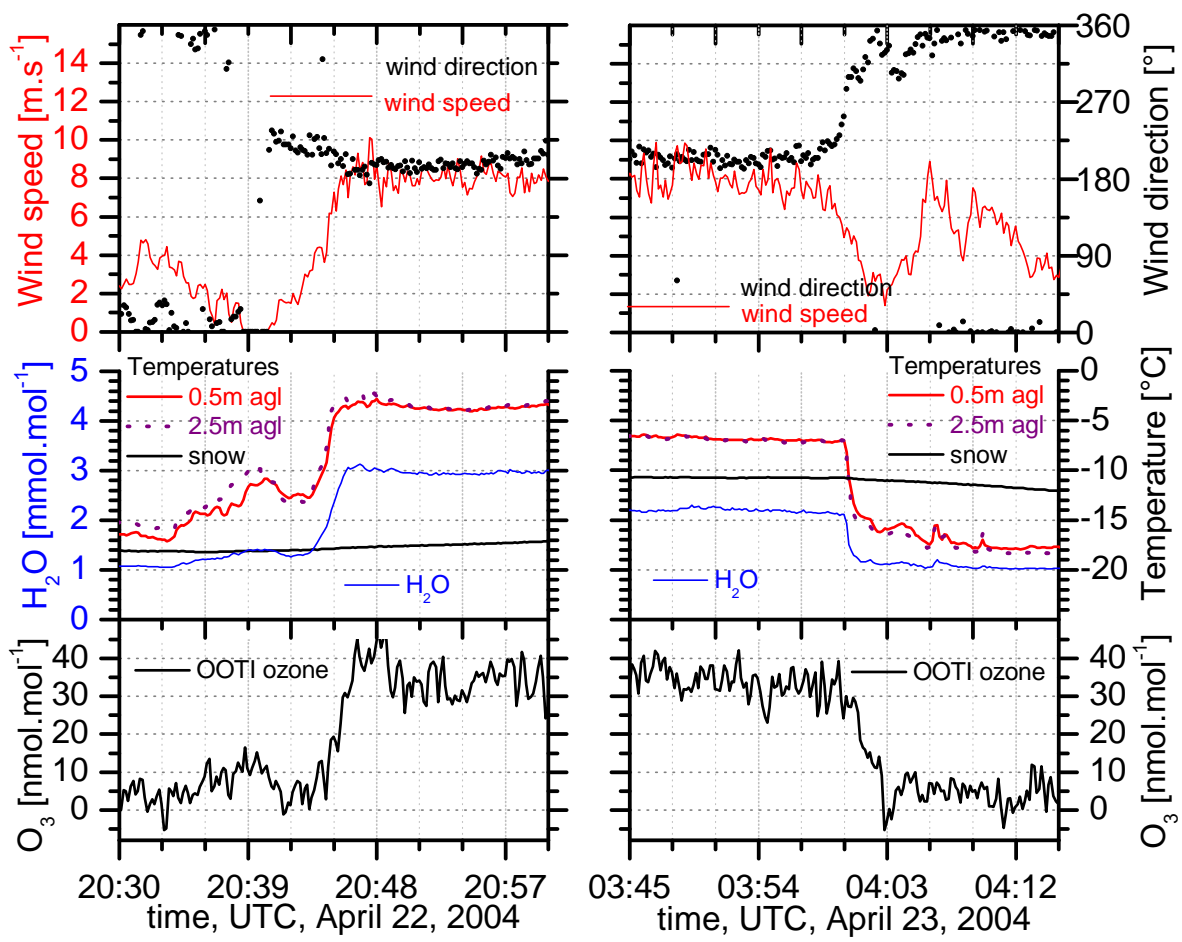

Fig. 16. Close-up on the onset and end of the wind episode over the Arctic Ocean near Alert that recovered normal ozone levels. From OOTI 2004 measurements. Reprinted from Morin et al. (2005) with permission from the American Geophysical Union (AGU).

\subsubsection{Termination of ozone depletion events}

Little is understood about the termination of ozone depletion chemistry; however the sporadic nature of observed ozone depletion events indicates that for a termination, mixing of ozone rich airmasses back into the boundary layer must occur. Removal of reactive bromine could terminate the chain reaction through conversion to $\mathrm{HBr}$ or particulate bromine, which is deposited with the respective particles and has therefore a lifetime on the order of hours to about one week. Similarly, gas phase bromine is deposited to the ground. As discussed in Sects. 1.3 and 3.3, bromine that has been deposited to snow surfaces can easily be re-released to the atmosphere. Therefore, deposition to the unfrozen ocean or burial in the snow pack beyond ventilation depth may be necessary to truly remove bromine. It is likely that the termination is associated with extensive vertical mixing which occurs more often in fall, which may be one reason that ODEs are not observed in that season (Lehrer et al., 2004). Rapid changes in air masses are usually related to the passing of synoptic systems. Often the passing of fronts is associated with the break-up of the inversion capping the boundary layer and strong vertical mixing leading to the entrainment of free tropospheric air into the boundary layer. Under ODE conditions this most importantly means the entrainment of $\mathrm{O}_{3}$ and the transport of bromine to the free troposphere. Indications for this upward transport have been found in satellite images (Hollwedel, 2005).

\subsection{The role of surface fluxes and snow photochemistry}

\subsection{1 $\mathrm{HO}_{\mathrm{x}}$ and $\mathrm{NO}_{\mathrm{x}}$ fluxes}

As was described in Sect. 1.3, bromine can be released from salty ice surfaces in an autocatalytic chemical mechanism that oxidizes bromide in the salt to bromine that is released to the atmosphere. In these reactions, $\mathrm{HO}_{\mathrm{x}}$ and acidity $\left(\mathrm{H}^{+}\right)$ are consumed to drive the oxidation, coupling the bromine explosion chemistry to $\mathrm{HO}_{\mathrm{x}}$ chemistry. Many studies have shown that the snow pack is a photochemical reactor that produces $\mathrm{HO}_{\mathrm{x}}$ precursors, such as $\mathrm{HONO}$, (e.g. Zhou et al., 2001; Dominé and Shepson, 2002) indicating ties between snow pack chemistry and ozone depletion chemistry in the overlying atmosphere. Additionally, snow pack photochemistry is likely to produce small organic molecules (Sumner and Shepson, 1999; Michalowski et al., 2000; Boudries et al., 2004) that can be sinks for reactive halogen species, such as $\mathrm{HCHO}$, also modulating the efficiency of ozone depletion. $\mathrm{NO}_{\mathrm{x}}$ is also produced by snow pack photochemistry and interacts with halogen oxide cycling (Honrath et al., 1999, 2000; Jones et al., 1999, 2000). The surface chemistry producing the $\mathrm{HO}_{\mathrm{x}}$ and $\mathrm{NO}_{\mathrm{x}}$ and field observations are discussed in detail in the accompanying snow photochemistry review 
paper (Grannas et al., 2007). Here we focus on couplings between $\mathrm{HO}_{\mathrm{x}}$ and $\mathrm{NO}_{\mathrm{x}}$ precursors and halogen species.

In the pristine polar environment, it is expected that $\mathrm{OH}$ levels, and hence the rate of chemical oxidation of VOCs, are low. However, summertime measurements at South Pole (Mauldin et al., 2004) and at Summit (Sjostedt et al., 2007) show several times $10^{6}$ molecule $\mathrm{cm}^{-3} \mathrm{OH}$ radicals, higher than expected for production via ozone photolysis and the subsequent $\mathrm{O}\left({ }^{1} \mathrm{D}\right)+\mathrm{H}_{2} \mathrm{O}$ reaction. At the South Pole, photolysis of $\mathrm{H}_{2} \mathrm{O}_{2}$ and $\mathrm{HCHO}$ produced from the snow pack cause much of the $\mathrm{OH}$ enhancement, with the additional factor of relatively high levels of snow pack-produced $\mathrm{NO}$ altering the partitioning of $\mathrm{HO}_{\mathrm{x}}$ to favor OH. At Summit, ozone photolysis is a key producer of $\mathrm{OH}$ with snow pack $\mathrm{H}_{2} \mathrm{O}_{2}$ also contributing. The photolysis of nitrate ions in the snow appears to be the initiating step in production of $\mathrm{NO}_{\mathrm{x}}$ precursors see the accompanying snow photochemistry review (Grannas et al., 2007). This type of modification of the atmospheric composition as compared to snow pack-free chemical models was discussed in a review article (Dominé and Shepson, 2002) and references therein. Box models have also shown an increase in $\mathrm{OH}$ and decrease in $\mathrm{HO}_{2}$ concentrations during ODEs reflecting the shift in $\mathrm{HO}_{\mathrm{x}}$ speciation due to halogen chemistry (e.g. Sander et al., 1997). Model calculations trying to reproduce halogen oxide measurements during the recent CHABLIS campaign (Saiz-Lopez et al., 2007c) and other studies indicate there may be substantial photochemical production of reactive halogen species from the snow pack, with rapid conversion to reservoir species aloft. The resulting sharp vertical gradients in halogen oxides would then produce significant vertical gradients in $\mathrm{OH}$ and $\mathrm{HO}_{2}$ concentrations above the snow pack, with implications for placing of inlets for field instruments. Other studies have shown that ozone may be destroyed in the snow pack (Peterson and Honrath, 2001; Boudries et al., 2004), as is described in the accompanying snow photochemistry review article (Grannas et al., 2007).

\subsubsection{Haloorganic fluxes}

The concept that haloorganic molecules are the main source of the reactive halogen species (Barrie et al., 1988) has been replaced by the view that the majority of the reactive halogen species come from sea salt (see Sect. 1). However they might be the major source for iodine and there may still be a role for haloorganic fluxes in initiation or termination of the reactive halogen chemistry. In this section, we consider observations of haloorganic molecules in the polar regions and their implications for halogen activation/ozone depletion chemistry and as source for reactive iodine.

Sturges et al. (1992) and Sturges and Shaw (1993) demonstrated that Arctic and Antarctic sea ice algae were a source of bromoform $\left(\mathrm{CHBr}_{3}\right)$ and observed venting of bromoform from cracks in the sea ice. Schall and Heumann (1993) reported the first measurements of bromo and iodo halocar- bons in the Arctic. They measured a variety of compounds including $\mathrm{CH}_{3} \mathrm{I}, \mathrm{CH}_{2} \mathrm{I}_{2}, \mathrm{CH}_{2} \mathrm{ClI}$ with mixing ratios in the range $0.7-2 \mathrm{pmol} / \mathrm{mol}$ and $\mathrm{CH}_{2} \mathrm{Br}_{2}, \mathrm{CHBr}_{3}, \mathrm{CH}_{2} \mathrm{BrCl}$, and $\mathrm{CHBr}_{2} \mathrm{Cl}$ between 0.1 and $0.5 \mathrm{pmol} / \mathrm{mol}$. Most of the organic bromine compounds are thought to be produced biologically, by macro and micro algae and esp. by ice algae (e.g. Reifenhäuser and Heumann, 1992a; Schall et al., 1994). Wever et al. (1991) even measured the direct release of HOBr from seaweed in incubation studies indicating a potentially larger role for seaweed in ODEs than one might expect from the release of only organic bromine compounds. The production of halocarbons by different types of macroalgae in the south polar sea was investigated by Schall et al. (1994), who have found that organoiodines are mainly emitted as $\mathrm{CH}_{2} \mathrm{I}_{2}(4.1 \mathrm{ng} / \mathrm{g}$ of wet algae in case of Laminaria saccarina), followed by $\mathrm{CH}_{3} \mathrm{I}$ and $\mathrm{CH}_{2} \mathrm{ClI}$. Volatilisation of these compounds occurs if the ocean becomes supersaturated, which is the case for iodinated hydrocarbons with mean sea water concentrations of $2.5 \mathrm{ng} / \mathrm{l}$ for $\mathrm{CH}_{3} \mathrm{I}$ and $0.15 \mathrm{ng} / \mathrm{l}$ for $\mathrm{CH}_{2} \mathrm{ClI}$ in the south polar sea (Reifenhäuser and Heumann, 1992b). There is only limited knowledge about the production of biomass and the related release rates of iodinated organic compounds into the atmosphere. The primary production of biomass in the Southern Ocean per area and year was estimated by Lønne (1999) to $645 \mathrm{~g}(\mathrm{C}) / \mathrm{m}^{2} / \mathrm{yr}$, which is more than twice as much as the average production rate for all oceans $\left(282 \mathrm{~g}(\mathrm{C}) / \mathrm{m}^{2} / \mathrm{yr}\right.$ Longhurst et al., 1995). Very little is known about the release of iodinated compounds during winter, and only rough estimates exist on the biomass production of the sea ice covered polar ocean. The total primary biological production associated with the Antarctic sea has been estimated to $2.14 \times 10^{14} \mathrm{~g}(\mathrm{C}) / \mathrm{yr}$ (Legendre et al., 1992). Thus, $33 \%$ of the total primary production takes place below, in, or on the surface of the sea ice, with the majority $\left(1.41 \times 10^{14} \mathrm{~g}(\mathrm{C}) / \mathrm{yr}\right)$ being produced in the water column in ice edge blooms. While the biological activity is more uniformly distributed over the whole water column during summer, it is concentrated on the surface in the ice covered ocean during winter/spring.

Incubation studies (Moore et al., 1996) showed that a number of cold-water diatoms were capable of production of short-lived polyhalomethanes including $\mathrm{CHBr}_{3}$, $\mathrm{CH}_{2} \mathrm{I}_{2}$ and $\mathrm{CH}_{2} \mathrm{ICl}$. Concentrations of bromo- and bromochloromethanes in Arctic air have been observed to peak over a broad winter period and apparently did not directly correspond to blooms of marine biota (Yokouchi et al., 1996), however their seasonal variations will also be affected by variations in prevailing winds and in chemical loss rates, and have not been definitively assigned to any one cause. Spring blooms of sea ice algae tend to occur rather earlier than those of phytoplankton, and indeed the sea ice communities that detach from the ice during polar spring may seed the subsequent phytoplankton blooms (Lizotte, 2001).

There is also evidence for abiotic sources of halocarbons in the polar regions. Swanson et al. (2002) measured the alkyl halides $\mathrm{CH}_{3} \mathrm{Br}, \mathrm{CH}_{3} \mathrm{I}$ and $\mathrm{C}_{2} \mathrm{H}_{5} \mathrm{I}$ in the near-surface 
Arctic snow pack and found their concentrations to be 310 times higher in the snow pack than in ambient air. The authors suggested a photochemical source from reaction of alkyl radicals produced from photolysis of carbonyl compounds, which comprise part of the high levels of total organic carbon found in snow (Couch et al., 2000; Yang et al., 2002). More recently, the shorter-lived di- and trihalomethanes (e.g. $\mathrm{CHBr}_{3}, \mathrm{CH}_{2} \mathrm{I}_{2}, \mathrm{CH}_{2} \mathrm{IBr}, \mathrm{CH}_{2} \mathrm{ICl}$ ) have been observed in high concentrations in air that had passed over the frozen Hudson Bay during polar sunrise (Carpenter et al., 2005a, and see Fig. 17). The absence of local leads in the Bay coupled with the extremely short atmospheric lifetime of $\mathrm{CH}_{2} \mathrm{I}_{2}$ indicated that production occurred in the surface of the sea-ice/overlying snow pack rather than from algal emissions through leads. Carpenter et al. (2005a) proposed an abiotic mechanism for the production of polyhalogenated iodo- and bromocarbons, via reaction of HOI and/or $\mathrm{HOBr}$ with organic material in the quasi-liquid layer to explain this phenomenon, but so far this has yet to be confirmed by studies within the snow pack. Such a link between organic and inorganic halogen release may, however, offer an explanation for observations that $\mathrm{CHBr}_{3}$ is inversely correlated to $\mathrm{O}_{3}$ and positively correlated to inorganic $\mathrm{Br}$ during polar sunrise (Bottenheim et al., 1990; Li et al., 1994; Carpenter et al., 2005a). The observations and suggestions by Swanson et al. (2002) and Carpenter et al. (2005a) might be an explanation for the airborne measurements of $\mathrm{CHBr}_{3}$ by Wingenter et al. (2003) that showed elevated concentrations over the Canadian Arctic during boundary layer ODEs. However, no other organic gas measured during these flights showed a similar anticorrelation which might be due to the different lifetimes of these gases.

Although the direct chemical impact of bromoform on ODEs is thought to be negligible, recent modeling studies (Calvert and Lindberg, 2004a,b) indicate that reactive organic iodocarbons such as $\mathrm{CH}_{2} \mathrm{I}_{2}$ could play an important role. The Calvert and Lindberg (2004a,b) studies found that, per molecule, $\mathrm{CH}_{2} \mathrm{I}_{2}$ and other iodine compounds added to a $\mathrm{Br}_{2}$ and $\mathrm{BrCl}$ mixture have a significantly greater ozone depletion effect than additional $\mathrm{Br}_{2}$ and $\mathrm{BrCl}$ molecules. Observed total organic reactive iodine mixing ratios of up to $5 \mathrm{pmol} / \mathrm{mol}$ (sum of $\mathrm{CH}_{2} \mathrm{I}_{2}+\mathrm{CH}_{2} \mathrm{IBr}+\mathrm{CH}_{2} \mathrm{ICl}$ ) in Arctic air (Carpenter et al., 2005a) could produce reactive I species that may either couple into bromine explosion chemistry or participate through cross reaction cycles (e.g. $\mathrm{IO}+\mathrm{BrO}$ ). However, these reactive iodine species mixing ratios are significantly smaller than the observed $\mathrm{BrCl}$ and $\mathrm{Br}_{2}$ mixing ratios of $0-35 \mathrm{pmol} / \mathrm{mol}$ and $0-25 \mathrm{pmol} / \mathrm{mol}$, respectively, observed during polar sunrise at Alert, Canada (Foster et al., 2001; Spicer et al., 2002).

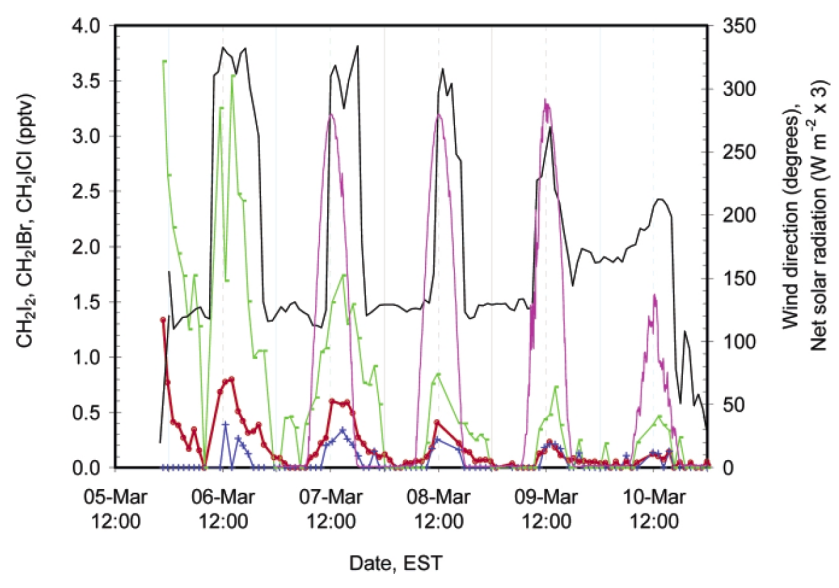

Fig. 17. Organoiodines observed at Hudson Bay, Canada during 5-10 March 2004. Shown are the mixing ratios of $\mathrm{CH}_{2} \mathrm{I}_{2}$ (red), $\mathrm{CH}_{2} \mathrm{IBr}$ (green), $\mathrm{CH}_{2} \mathrm{ICl}$ (blue), net solar radiation (pink) and wind direction (black). Adapted from Carpenter et al. (2005a), reproduced with permission from Environmental Science and Technology 2005, 39, 8812-8816. Copyright 2005 American Chemical Society.

\section{Impacts of ODEs on polar chemistry}

\subsection{Effects on halogen - mercury interactions}

Mercury $(\mathrm{Hg})$ is a global pollutant emitted from both natural and anthropogenic sources. Anthropogenic contributions are suggested to have increased the atmospheric mercury loading significantly in comparison to pre-industrial times (Mason et al., 1994). Some natural sources of mercury include: forest fires, volcanoes, and emissions from oceans. Anthropogenic mercury sources are: coal-fired power plants, chloralkali plants, medical activities, and products such as fluorescent light bulbs, thermometers, and switches. The high vapor pressure of this metal enables mercury to be transported in the atmosphere, primarily in the form of gaseous elemental mercury. Recent data from the developing world (e.g., China) indicates that a large fraction of the observed atmospheric mercury is emitted in the form of mercury particles. The particulate fraction deposits locally near point sources, but the gas $\left(\mathrm{Hg}^{0}\right)$ transports over long ranges. $\mathrm{Hg}^{0}$ is then oxidized to reactive gaseous mercury (RGM) that is rapidly scavenged. The unique chemistry of the Arctic region appears very efficient in oxidizing $\mathrm{Hg}^{0}$ and depositing the products. Following deposition, mercury can, in part, re-enter the atmosphere through volatalization and (photo)reduction processes. The remaining deposited mercury can ultimately reach deep sediments and/or bioaccumulate into wildlife (primarily in the marine environment) and eventually into humans as well. All forms of $\mathrm{Hg}$ that have been detected in the atmosphere have been established as toxic (Hylander and Goodsite, 2006), however the level of toxicity of mercury 


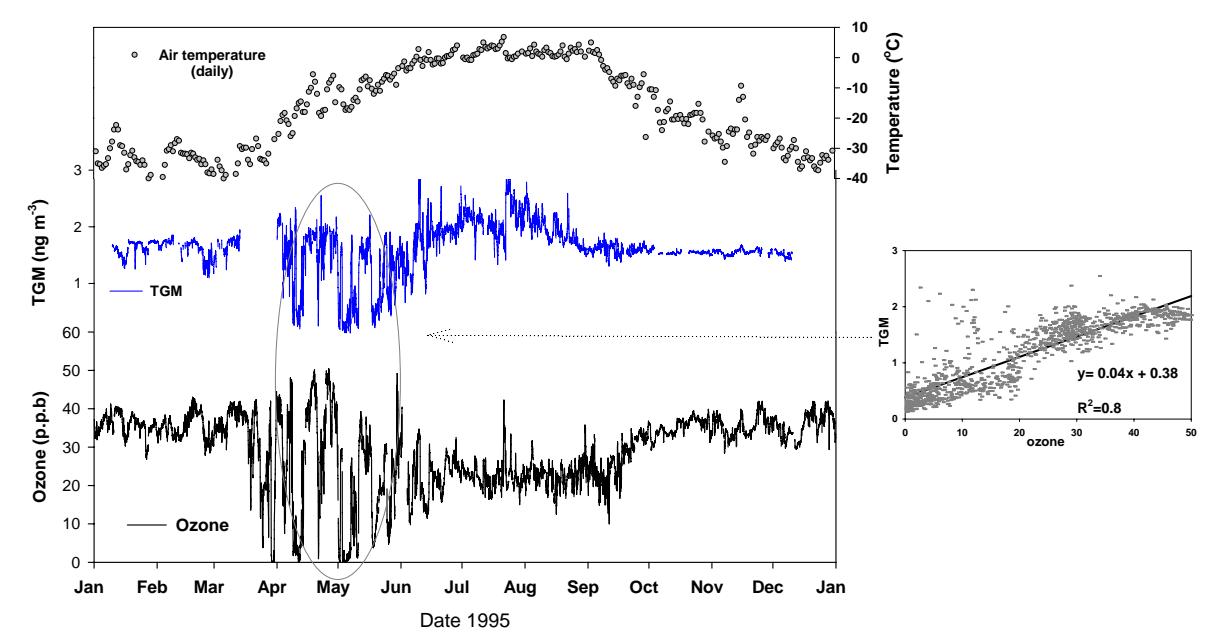

Fig. 18. Time series of air temperature, total gaseous mercury (TGM), and ozone concentrations at Alert, Canada, in 1995. The inset shows concentrations of TGM versus ozone at Alert for the period from 9 April 1995 to 29 May 1995. Note that $R^{2}=0.8$ for the correlation between TGM and ozone concentrations during this period. From Alexandra Steffen based upon data of Schroeder et al. (1998). Reprinted by permission from Macmillan Publishers LTD: Nature, copyright 1998.

compounds varies significantly, with organomercury complexes being particularly neurotoxic compounds.

Schroeder et al. (1998) were the first to report rapid depletion of measured gaseous elemental mercury (GEM) in the marine boundary layer during the springtime in the Arctic (see Fig. 18). It was found that within hours GEM decreased from its average background air concentration $\left(\sim 1.7 \mathrm{ng} \mathrm{m}^{-3}\right)$, in the Northern Hemisphere (Slemr et al., 2003) to values lower than $0.5 \mathrm{ng} \mathrm{m}^{-3}$. This finding was contrary to the typical GEM atmospheric residence time of 6-24 months (Schroeder and Munthe, 1998). It was also found that the depletion of $\mathrm{Hg}$ occurred concurrently with tropospheric ozone depletion. The occurrence and mechanisms of these "atmospheric mercury depletion events (AMDEs)" are reviewed by Steffen et al. (2007). The observations of Schroeder et al. (1998), have led to many field campaigns where observations of AMDEs were made throughout polar regions (e.g. Schroeder et al., 2003; Ebinghaus et al., 2004) and has engendered a new field of mercury research. Halogens appear to play a key role in these AMDEs but a complete understanding of these reaction processes has yet to be achieved (e.g. Ariya et al., 2004).

Considerable research has been undertaken in the last several years to elucidate the mechanisms behind these AMDEs and to include this knowledge into numerical models using both experimental and calculated kinetic data in regards to mercury and halogen interactions (e.g. Ariya et al., 2002, 2004; Shepler and Peterson, 2003; Khalizov et al., 2003; Calvert and Lindberg, 2003; Goodsite et al., 2004; Raofie and Ariya, 2004, 2006). This research proposes that, through a series of photochemically initiated interactions, reactive bromine plays the key role in oxidizing mercury in the Arc- tic and marine boundary layer (and possibly the free troposphere) to convert gas-phase elemental mercury (GEM, or equivalently $\mathrm{Hg}^{0}$ ) as shown below:

$$
\begin{aligned}
\mathrm{Br}+\mathrm{Hg}^{0} & \rightarrow \mathrm{HgBr} \\
\mathrm{BrO}+\mathrm{Hg}^{0} & \rightarrow \mathrm{HgO}+\mathrm{Br} \\
\mathrm{BrO}+\mathrm{Hg}^{0} & \rightarrow \mathrm{HgBrO} \\
\mathrm{BrO}+\mathrm{Hg}^{0} & \rightarrow \mathrm{HgBr}+\mathrm{O}
\end{aligned}
$$

These oxidized inorganic $\mathrm{Hg}$ species, currently operationally defined as reactive gaseous mercury (RGM), are more reactive than GEM and may directly deposit to snow/ice or associate with particles in the air that can subsequently deposit onto the snow and ice surfaces (Lu et al., 2001; Lindberg et al., 2002). Increases in both RGM and particulate adsorbed mercury $(\mathrm{p}-\mathrm{Hg})$ have been reported in conjunction with decreases of GEM (Lu et al., 2001; Lindberg et al., 2002; Aspmo et al., 2005). High levels of mercury are found in snow and ice in regions influenced by ODEs/AMDEs (Lindberg et al., 2002; Douglas et al., 2005; Bargagli et al., 2005). Estimates have calculated that these spring-time mercury depletion events deposit between 50 and 300 additional tons of mercury to the Arctic over a period of one year (Schroeder et al., 1998; Banic et al., 2002; Ariya et al., 2004). It has been proposed that this input to the polar environment may have consequences for the health of the aboriginal population and the Arctic ecosystems following flushing of mercury in the melt water during springtime and summer (Schroeder et al., 1998; Lu et al., 2001; Lindberg et al., 2002; Hylander and Goodsite, 2006; Poulain et al., 2006). Hg exposure was assessed in two communities in Nunavut at two Arctic sites of Igloolik and Repulse Bay (Chan, 2005). In this study, 33\% of participants from Igloolik and $60 \%$ of participants from 
Repulse Bay had exposure estimates above the minimal risk level.

Atomic bromine and bromine oxide are thought to play essential roles in AMDEs, however, atomic bromine is suspected to be a more important oxidant in these reactions. Reactions of $\mathrm{Cl}, \mathrm{Cl}_{2}$, and $\mathrm{Br}_{2}$ are reportedly too slow to be responsible for AMDEs (e.g. Ariya et al., 2002, 2004; Goodsite et al., 2004). Recent laboratory studies of I, $I_{2}, I O$, and $\mathrm{ClO}$ initiated reactions of GEM indicate that these reactions are unlikely to compete with $\mathrm{Br}$-atom oxidation mechanism in the destruction of elemental mercury in the Arctic (Raofie and Ariya, 2006).

The remaining open questions include the identification of the exact chemical structure of so-called RGM and $\mathrm{p}-\mathrm{Hg}$, as the existing analytical techniques are inadequate to determine the detailed chemical speciation of mercury. Further kinetic, theoretical, and product studies to determine primary and secondary reactions leading to oxidized mercury are required. Further studies on redox mechanisms (including photo-redox) in snow, at the air-snow interface, in clouds and fogs, and in molten snow are needed, as they are amongst several factors that dictate the accumulation of mercury in polar environments.

\subsection{Effects on hydrocarbons and aldehydes}

Ozone depletion and halogen chemistry has a significant impact on VOC and OVOC photochemistry. Jobson et al. (1994) and Yokouchi et al. (1994) first observed that light hydrocarbons are rapidly consumed (mostly by $\mathrm{Cl}$ atoms) during ODEs. The lifetime of propane under normal conditions for example is $\left(k_{\mathrm{OH}} \times[\mathrm{OH}]\right)^{-1} \approx 14$ days (at $\mathrm{T}=245 \mathrm{~K}$ and with a global average of $\left.[\mathrm{OH}]=1.0 \times 10^{6} \mathrm{~cm}^{-3}\right)$. However, during ozone depletion events, the $[\mathrm{Cl}]$ concentrations may be as high as $7.5 \times 10^{4} \mathrm{~cm}^{-3}$ (Boudries and Bottenheim, 2000). The high rate constant of $\mathrm{Cl}$ with propane $(8800$ times larger with $\mathrm{Cl}$ than $\mathrm{OH}$ ) results in a propane lifetime of $\sim 8 \mathrm{~h}$. Jobson et al. (1994) and Yokouchi et al. (1994) showed that reactive alkanes, such as butane and n- and isopentane are nearly completely removed during ODEs. Usually they would decay slowly through the spring season, due to reduced $\mathrm{OH}$ radical chemistry at large solar zenith angles and low absolute $\left[\mathrm{H}_{2} \mathrm{O}\right]$. Jobson et al. (1994) used the ratio [isobutane]/[n-butane] as an indicator of chlorine atom oxidation to show that during ozone depletion events there is extensive chlorine-atom processing of VOCs (see Fig. 19). Possibly more important than the rapid destruction of alkanes, alkenes and most aromatics is the production of OVOC oxidation products in the stable polar marine boundary layer. For example, during ozone depletion events, there is a substantial consumption of propane, and a concomitant increase in acetone (Guimbaud et al., 2002). It is important to note, however, that alkane oxidation alone cannot account for the increase in gas phase OVOCs during ODEs (Sumner et al., 2002; Guimbaud et al., 2002).

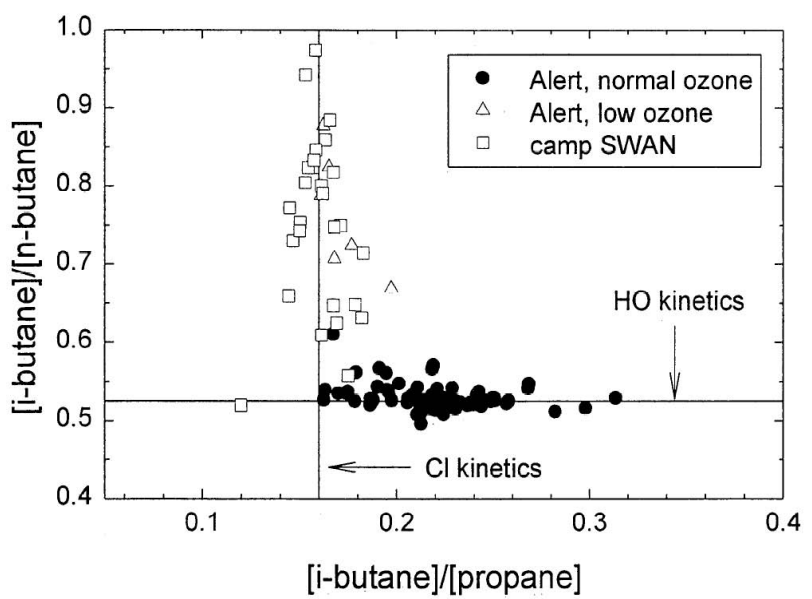

Fig. 19. Observed ratios of hydrocarbons during normal and low ozone condition. Reprinted from Jobson et al. (1994) with permission from the American Geophysical Union (AGU).

As discussed by Sumner et al. (2002), $\mathrm{HO}_{2}$ is produced in significant part by $\mathrm{Cl}$ atom reaction with VOCs (e.g. methane and ethane), to produce $\mathrm{HO}_{2}$ directly, or through photolysis of the product HCHO. Therefore, of particular importance is the production of $\mathrm{HCHO}$, as this species ties together halogens, VOCs, and ODEs and AMDEs. HCHO can be produced from the following reaction sequence.

$$
\begin{aligned}
\mathrm{Cl}+\mathrm{CH}_{4}\left(+\mathrm{O}_{2}\right) & \rightarrow \mathrm{HCl}+\mathrm{CH}_{3} \mathrm{OO} \\
\mathrm{CH}_{3} \mathrm{OO}+\mathrm{NO} & \rightarrow \mathrm{CH}_{3} \mathrm{O}+\mathrm{NO}_{2} \\
\mathrm{CH}_{3} \mathrm{OO}+\mathrm{CH}_{3} \mathrm{OO} & \rightarrow 2 \mathrm{CH}_{3} \mathrm{O}+\mathrm{O}_{2} \\
\mathrm{CH}_{3} \mathrm{OO}+\mathrm{CH}_{3} \mathrm{OO} & \rightarrow \mathrm{CH}_{3} \mathrm{OH}+\mathrm{HCHO}+\mathrm{O}_{2} \\
\mathrm{CH}_{3} \mathrm{O}+\mathrm{O}_{2} & \rightarrow \mathrm{HCHO}+\mathrm{HO}_{2} \\
\mathrm{HCHO}+h v\left(+\mathrm{O}_{2}\right) & \rightarrow 2 \mathrm{HO}_{2}+\mathrm{CO}
\end{aligned}
$$

Hydroperoxy radicals $\left(\mathrm{HO}_{2}\right)$, produced in the reactions above, can then react with $\mathrm{BrO}$ as in Reaction (R5) to produce $\mathrm{HOBr}$, a central reactant involved in the "bromine explosion" (see Sect. 1.3) and thus accelerating the halogen, ODE and AMDE chemistry.

Gas phase oxidation cannot account for the observed HCHO. Shown in Fig. 20 is the measured HCHO at Alert above the snow pack, as a function of ozone concentration. Also shown is the concentration calculated from oxidation of $\mathrm{CH}_{4}$ by $\mathrm{Cl}$ atoms, which can account for only $\sim 100 \mathrm{pmol} / \mathrm{mol} \mathrm{HCHO}$. However, as much as $300 \mathrm{pmol} / \mathrm{mol}$ in the near-surface boundary layer have been observed during partial ODEs. Production in and emission from the snow pack is discussed in the companion paper on snow photochemistry (see also Fuhrer et al., 1996; Hutterli et al., 1999; Sumner and Shepson, 1999; Sumner et al., 2002; Perrier et al., 2002; Grannas et al., 2002; Hutterli et al., 2004; Riedel et al., 2005). 
Table 3. Some literature calculations of radiative forcing (mostly longwave) by tropospheric ozone, linearly interpolated or extrapolated to a change of +3 DU. Most papers report radiative forcing rather than the change in surface temperature, and we have used a climate sensitivity of $2.5 \mathrm{~W} \mathrm{~m}^{-2} \mathrm{~K}^{-1}$ to relate them. Although the model comparison by Gauss et al. (2003) examines results from 11 different CTMs, the ozone change from each is fed into the radiative model of Berntsen and Isaksen (1997), so does not produce independent calculations for a given ozone change.

\begin{tabular}{lccccc}
\hline Citation & Model type & Height of $\mathrm{O}_{3}$ change & location & Forcing $\left(\mathrm{W} \mathrm{m}{ }^{-2}\right.$ ) & Change in surface $T$ \\
\hline Lacis et al. (1990) & rad.-convect & tropopause & mid-latitudes & 0.14 & $0.055 \mathrm{~K}$ \\
Berntsen and Isaksen (1997) & radiative & mixed & $30^{\circ} \mathrm{S}$ annual & 0.10 & $\sim 0.04 \mathrm{~K}$ \\
Brasseur et al. (1998) & CTM & mixed & SH winter & 0.14 & $\sim 0.06 \mathrm{~K}$ \\
Kiehl (1999) & radiative & mixed & & 0.11 & $\sim 0.04 \mathrm{~K}$ \\
Mickley et al. (2001) & GCM & mixed & global annual & 0.09 & $\sim 0.04 \mathrm{~K}$ \\
\hline
\end{tabular}

A problem with sustaining high concentrations of $\mathrm{HCHO}$ during ODEs is that $\mathrm{HCHO}$ reacts rapidly with $\mathrm{Br}$ atoms, thus as $\left[\mathrm{O}_{3}\right]$ gets low, $\mathrm{BrO}_{\mathrm{x}}$ repartitions to a higher fraction of $\mathrm{Br}$ and $\mathrm{HCHO}$ destruction increases via the reaction:

$\mathrm{HCHO}+\mathrm{Br} \rightarrow \mathrm{HBr}+\mathrm{CHO}$.

Although reactive bromine chemistry may also produce $\mathrm{HCHO}$ via the reaction (Wagner et al., 2002):

$\mathrm{BrO}+\mathrm{CH}_{3} \mathrm{OO} \rightarrow \mathrm{Br}+\mathrm{HO}_{2}+\mathrm{HCHO}$.

The aircraft vertical profiles obtained during the TOPSE campaign over the Arctic Ocean showed elevated HCHO in the near surface layer, consistent with a snow pack/sea ice source (Ridley et al., 2003). The snow pack chlorine chemistry may also contribute to production of $\mathrm{CH}_{3} \mathrm{CHO}$ (Grannas et al., 2002), which is important sink for $\mathrm{NO}_{\mathrm{x}}$. At low temperatures, oxidation of $\mathrm{CH}_{3} \mathrm{CHO}$ by $\mathrm{Br}$ leads to the production of PAN (Dassau et al., 2004). Michalowski et al. (2000) suggested that the reaction $\mathrm{BrO}+\mathrm{HCHO}$ might be important in the timing of on ODE as it shifts the speciation from $\mathrm{BrO}$ to $\mathrm{HOBr}$ and could therefore speed up the depletion for $\mathrm{O}_{3}$ as more $\mathrm{HOBr}$ is available for heterogeneous reactions and $\mathrm{BrO}$ is part of odd-oxygen so by destroying $\mathrm{BrO}$, ozone is being destroyed.

Other OVOCs, such as acetone, are produced during ozone depletion events. Yokouchi et al. (2002) were the first to show the dramatic inverse correlation between acetone and ozone during ODEs. However, the work of Guimbaud et al. (2002) showed, through measurements and models, that the large (often as much as $500 \mathrm{pmol} / \mathrm{mol}$ ) increase in acetone concentrations during ODEs cannot be accounted for on the basis of gas phase oxidation of the measured VOCs (e.g. propane). Again, a contribution from the snow pack was invoked to explain the high concentrations during ODEs (see the companion paper of snow photochemistry, Grannas et al., 2007).

It is also known that halogen-VOC chemistry can be detected through measurements of halogenated VOC oxidation products. A number of halogen-containing species have been detected, including products of chlorine and bromine reaction with ethene and propene (Keil and Shepson, 2006), halogenated carboxylic acids in particulate matter (Narukawa et al., 2003), and diiodomethane and bromo-iodo-methane, suggested to be produced from $\mathrm{HOBr}$ and $\mathrm{HOI}$ reaction with organic matter in the sea ice/snow pack (Carpenter et al., 2005a). It is thus clear that halogen chemistry has an impact on atmospheric composition that goes well beyond ozone and $\mathrm{Hg}$ depletion.

\subsection{Effects on radiation and of radiation}

Tropospheric ozone depletion events change both short-wave UV and long-wave IR radiation balance at the surface. They increase the UV radiation reaching the lower atmosphere, but the typical amount of ozone depletion is $30 \mathrm{nmol} / \mathrm{mol}$ in a thickness of $0.5 \mathrm{~km}$, which is only $1 \%$ of the total column abundance. Together with the small incident UV at the high solar zenith angles of the early spring, this decrease results in little extra UV to cause damage either to organisms or humans. Similarly, there is a negligible increase in actinic fluxes: at $10^{\circ}$ solar elevation $\left(80^{\circ} \mathrm{SZA}\right)$, a decrease in ozone from 300 to 297 Dobson units increases $j\left(\mathrm{O}^{1} \mathrm{D}\right)$ by $1.5 \%$, and $j\left(\mathrm{NO}_{2}\right)$ by $0.01 \%$ (calculated by the TUV model: http://cprm.acd.ucar.edu/Models/TUV/).

Ozone interacts with IR radiation and can be powerful greenhouse gas. The size of the effect, however, is dependent on the height of the concentration change. A change in ozone mixing ratio at the surface has negligible effects on IR radiation, while an increase in ozone in the Upper Troposphere will cause a surface warming (Lacis et al., 1990). Hence, ozone-poor air mixed to the free troposphere may induce a regional cooling. The predicted radiative forcing of a 3 DU change in tropospheric ozone is small (see Table 3). A change in the intensity of ODEs could alter the tropospheric ozone column, and thus give rise to a small climate feedback, which might be coupled to sea-ice conditions and thus feedback into further changes in ODEs. In this feedback, ozonepoor air from depletion events, when mixed to the free troposphere, is currently causing a small regional cooling. If a 
reduction in sea ice occurred in a warming world, there might then be an altered frequency of depletion events which could then affect the surface energy balance. Mixing of ozonepoor air to the lower free troposphere in Antarctica was observed by Wessel et al. (1998) and Roscoe et al. (2001). This ozone-poor air probably mixes to the upper troposphere because the ozone replacement time is long in air containing very little $\mathrm{NO}_{\mathrm{x}}$, such as that above the Southern Ocean. In these remote regions, the ozone production rate is less than $0.5 \mathrm{nmol} / \mathrm{mol} /$ day in summer and even less in the reduced UV of spring (Ayers et al., 1997). At a production rate of $0.5 \mathrm{nmol} / \mathrm{mol} / \mathrm{day}$ it takes over 30 days to recover to normal southern-hemisphere ozone values of $15-20 \mathrm{nmol} / \mathrm{mol}$.

As well as the effects of ODEs on radiation, there is also an effect of UV radiation intensity on ODEs. Stratospheric ozone depletion in polar regions causes enhanced UV radiation flux at the surface. This radiation in the wavelength region of $280-315 \mathrm{~nm}$ strongly affects the photochemistry in the troposphere. It increases photodissociation rates of tropospheric ozone and other trace gases. As a consequence, ODEs might occur more frequently or with greater extent or depth. However, this effect remains to be quantified.

\subsection{Effects on bromine export to the free troposphere}

Outside the polar regions, satellite observations show the widespread presence of $\mathrm{BrO}$ in the troposphere with global background tropospheric vertical columns of about 1$3 \times 10^{13} \mathrm{molec}^{-2}$. These VCDs correspond to $\mathrm{BrO}$ mixing ratios of $0.5-2 \mathrm{pmol} / \mathrm{mol}$, if uniformly mixed in the troposphere (e.g. Van Roozendael et al., 2002; Pundt et al., 2002). Comparisons with balloon and ground based measurements in mid and high northern latitudes, the diurnal variation of ground based $\mathrm{BrO}$ column measurements as well as two direct measurements of $\mathrm{BrO}$ indicated that the tropospheric $\mathrm{BrO}$ was mainly located within the free troposphere (Pundt et al., 2002; Van Roozendael et al., 2002), see also discussion and references in von Glasow et al. (2004). Model calculations show that these amounts of $\mathrm{BrO}$ would lead to significant decreases in global zonal mean $\mathrm{O}_{3}$ concentrations of 5-20\% (von Glasow et al., 2004; Yang et al., 2005).

The polar regions may be a source of $\mathrm{BrO}$ to the free troposphere. There are two main transport pathways for $\mathrm{BrO}$ from the polar boundary layer to the free troposphere: 1) Rapid vertical transport in association with convection from open leads. 2) "Spill-out" and frontal uplifting. McElroy et al. (1999) have observed BrO in the Arctic free troposphere and argue that this is due to strong convection from open leads caused by the very large temperature differences of open sea water and the surrounding air. "Spill-out" of $\mathrm{BrO}$ clouds to lower latitudes is a feature that can commonly be observed in satellite images (Hollwedel et al., 2004; Hollwedel, 2005). One such event was probably identified in the north Pacific in $\mathrm{O}_{3}$ measurements aboard a commercial ship (Watanabe et al., 2005) where very low $\mathrm{O}_{3}$ was measured in airmasses

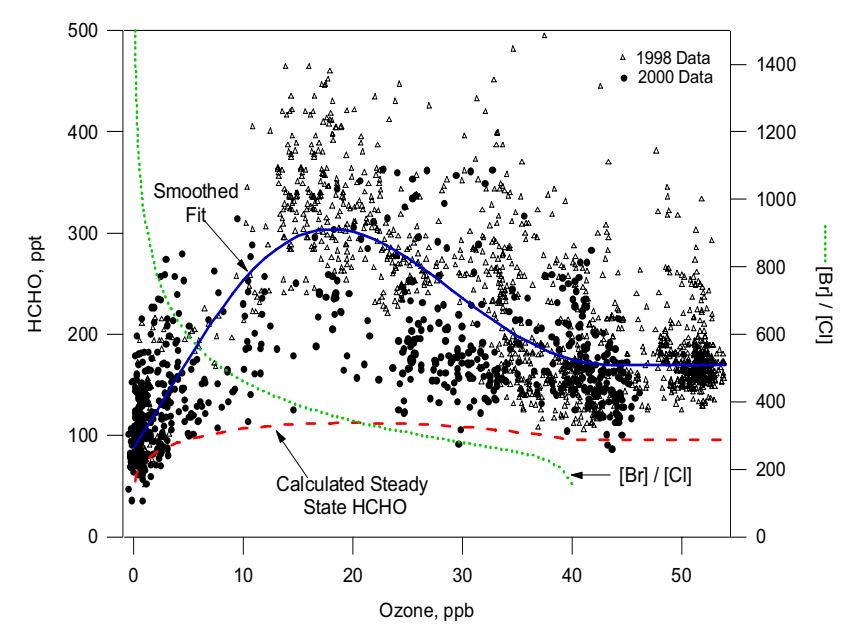

Fig. 20. Formaldehyde measurements and modeling during partial ODEs at Alert. Reprinted from Sumner et al. (2002), copyright 2002, with permission from Elsevier.

originating from an area with increased $\mathrm{BrO}$ as detected by GOME. The combination of "spill-out" of $\mathrm{BrO}$ to lower latitudes with frontal uplifting can lead to the transport of BrOrich air into the FT as indicated by the analysis of satellite images in combination with back trajectories (Hollwedel, 2005) and ground based measurements combined with backtrajectory calculations (Frieß et al., 2004).

\subsection{Effects on the sulfur cycle}

The sulfur cycle in the clean marine boundary layer is dominated by the emission of dimethylsulfide (DMS) from the ocean. Usually, $\mathrm{OH}$ and $\mathrm{NO}_{3}$ are assumed to be the main oxidants for DMS, where $\mathrm{OH}$ both adds oxygen to and abstracts hydrogen from $\mathrm{DMS}$ and $\mathrm{NO}_{3}$ only abstracts hydrogen. The importance of the different initial products lies in the final products and the fact that only $\mathrm{H}_{2} \mathrm{SO}_{4}$, which is mainly produced in the abstraction pathway, can lead to the production of new aerosol particles whereas all other DMS products can only grow existing particles. As discussed in von Glasow and Crutzen (2004), the dominance of the addition pathway can result in cloud feedbacks that counter the increase of cloud albedo caused by DMS emission as proposed in the so-called CLAW hypothesis (Charlson et al., 1987) as fewer new particles are formed. The chlorine atom also adds to DMS but under ODE conditions this effect is probably less important compared to the reaction of $\mathrm{BrO}$ with DMS. Based on measurements by Barnes et al. (1991), Toumi (1994) suggested $\mathrm{BrO}$ to be a potentially important additional oxidant for DMS. The rapid reaction of $\mathrm{BrO}$ with DMS leads to the addition of oxygen to DMS and therefore to the above discussed shifts in the final oxidation products of DMS

$\mathrm{BrO}+\mathrm{DMS} \rightarrow \mathrm{DMSO}+\mathrm{Br}$ 
Global model studies have shown that $\mathrm{BrO}$ mixing ratios down to $0.5 \mathrm{pmol} / \mathrm{mol}$ in the marine boundary layer can significantly affect DMS on the global scale (Boucher et al., 2003; von Glasow et al., 2004). Very high BrO mixing ratios as present during ODEs would imply that DMS oxidation is dominated by $\mathrm{BrO}$. This would both speed up the oxidation of DMS especially when $\mathrm{OH}$ and $\mathrm{NO}_{3}$ concentrations are low and result in the above mentioned shifts in reaction pathways and final products. It might result in increased growth rates of pre-existing aerosol particles but probably not in an increase in new particle formation as the yield of sulfuric acid is relatively small and this acid is the only sulfur species that can nucleate new particles(for more details see, e.g., von Glasow and Crutzen, 2004) .

\subsection{Effects on aerosol production}

The change in oxidants during ODEs could lead to an increase of aerosol production, as long as there are appropriate organic (e.g. aromatics, DMS) or inorganic (e.g. $\mathrm{SO}_{2}$ ) precursors present which can be oxidized by $\mathrm{Cl}, \mathrm{Br}$, or $\mathrm{BrO}$. An intriguing question is if the coupling between ODE chemistry and long range transported anthropogenic pollutants contributes to Arctic Haze and cloud cover, because radiative impacts are very dependent on the aerosol type (Hu et al., 2005). Aerosols have been studied in the Arctic, starting with the AGASP studies of the early 1980s (Radke et al., 1984, also see Sect. 1.2). During the Polar Sunrise Experiment 1992, Staebler et al. (1994) examined relationships between aerosol size and number distributions and ozone, including during ODEs. They found that accumulation mode aerosol concentration was weakly negatively correlated with ozone in the dark period, but was less correlated after sunrise at Alert. The dark period is characterized by long range transport of haze aerosols to the Arctic region, e.g. from Eurasia. Under these conditions, aerosols correlate well with $\mathrm{CO}_{2}$, PAN and other indicators of anthropogenic pollution. In contrast, during April when ozone was periodically depleted (with air mass origins from the Arctic Ocean), the small particles were in fact well positively correlated with ozone, i.e. when ozone was depleted, accumulation mode (0.07$0.2 \mu \mathrm{m})$ particle numbers decreased. In contrast, larger particles $(0.7-12 \mu \mathrm{m})$ correlated negatively with ozone. Indeed, very large particles, most likely sea salt, were only observed during ozone depletion events. The close positive correlation of ozone with accumulation mode particles at Alert is most likely due to long range transport of haze aerosols (i.e. sulfate) in air masses aloft of the marine boundary layer. During ozone depletion events at Alert, the air sampled represents relatively clean marine boundary layer air, with some associated sea salt particles, explaining the negative correlation between large particles and ozone. Unlike iodine, bromine is not known to produce new particles, but it might contribute to particle mass. The peak in the surface area distribution is at $\sim 0.2 \mu \mathrm{m}$ diameter, and thus $\mathrm{HBr}$ adsorption could cause growth of these particles. Indeed, during ozone depletion events, there is a reasonable negative correlation between ozone and aerosols in the $0.7 \mu \mathrm{m}$ range $(R=0.5)$, consistent not with production of new particles, but growth onto existing small sulfate aerosol. This particle growth would be also consistent with DMS oxidation by $\mathrm{BrO}$ and related particle growth (see Sect. 4.5) if DMS concentrations are high enough.

In the Arctic, so far, no new particle formation events have been observed during ODEs, so it appears that most of the products of chlorine atom reaction with VOCs remain in the gas phase, or undergo uptake into existing particles (or surface deposition). Studies at mid-latitude sites have shown (e.g. O'Dowd and Hoffmann, 2005) that new particles can be produced very efficiently under iodine-rich conditions so that there might indeed be halogen-induced particle bursts in polar regions under some conditions. The presence of high IO concentrations in coastal Antarctica (Saiz-Lopez et al., 2007b) might explain the observation of Davison et al. (1996) of ultrafine particle events in the Antarctic.

\subsection{Effects on ice core chemistry}

Ice cores play a very powerful role in the study of the Earth System because not only do they contain records of changing climate, but also of changing atmospheric composition (e.g. Wolff, 2005). These records include both stable trace gases such as $\mathrm{CH}_{4}$ and $\mathrm{CO}_{2}$, (e.g. Etheridge et al., 1996; Siegenthaler et al., 2005; Spahni et al., 2005) and aerosol compounds including sea salt ions (Wagenbach et al., 1998; Rankin et al., 2002; Wolff et al., 2003; Röthlisberger et al., 2003; Wolff et al., 2006).

Sea-salt ions such as $\mathrm{Na}^{+}$are routinely measured in ice cores, and indicate, to first order, the amount of sea-salt aerosol in the atmosphere above the site. Recent interpretations suggest that the primary source of the sea salt in the polar regions may not be open water but instead saline sea ice surfaces (including frost flowers, see Sect. 3.1). This relationship might provide a possibility to study ODEs in the past. During the last glacial maximum, when there was certainly more sea ice and more sea salt in the atmosphere and snow (Wolff et al., 2003, 2006; Gersonde et al., 2005); it is interesting to ask how ODEs were affected. Bromide $\left(\mathrm{Br}^{-}\right)$ has rarely been measured in ice cores, but if it is strongly fractionated in some regions by halogen activation, then ice core studies in carefully chosen sites, could provide some additional information about the extent of ODE activity. On the other hand, effects of ODEs on ice cores are probably small, since these seasonal episodes of ozone losses are brief and mostly observed on the frozen ocean and at costal sites and not at the inland ice core sites that give the longest historical records. However, there are some secondary effects of elevated halogen species. For example, halogens play a role in determining hydrocarbon concentrations in coastal Arctic and Antarctic regions. Although there has been little 
work to date on organic compound concentrations in ice, this is clearly an issue to take into account if such studies become feasible. Another important area is the study of sulfur compounds in ice cores. The ratio of methane sulfonic acid (MSA) to non-sea-salt sulfate $\left(\mathrm{nssSO}_{4}^{2-}\right.$ ) derived from oxidation of DMS has been the subject of numerous ice core studies (e.g. Legrand and Pasteur, 1998). Though the mechanisms producing MSA seem to be more important at low temperatures (e.g. Bates et al., 1992), highest ratios in Antarctica are usually found in summer. As suggested by Toumi et al. (1995) and von Glasow and Crutzen (2004) reactions of halogens (especially $\mathrm{BrO}$ ) with DMS may be important, and lead to relatively greater production of MSA. If halogen concentrations really control sulfur chemistry, then ratios preserved in ice cores might be useful in diagnosing the extent of halogen activation in the past.

\section{Future scenarios of ozone depletion and open ques- tions}

\subsection{Anthropogenic influences and atmospheric change}

Tropospheric ODEs occur naturally and are not caused by anthropogenic pollution. However, there are anthropogenic influences that could change the frequency and intensity of ODEs. When ODEs were first discovered, they were thought to be related to anthropogenic pollution known as Arctic Haze (e.g. Barrie, 1986). Later studies began to shift their view more towards influences of the frozen Arctic Ocean. The finding that ODEs also occur in the much more pristine Antarctic soon showed that they could happen without anthropogenic pollution. For liquid systems, laboratory studies show a $\mathrm{pH}$ dependence requiring acidity for the release of halogens following $\mathrm{HOBr}$ uptake on salt solutions (Fickert et al., 1999). The freezing of these solutions appears to reduce or possibly eliminate the need for acidity (Huff and Abbatt, 2000, 2002; Adams et al., 2002), although the mechanism for this change is not well understood and needs more study. A recent chemical model study (Sander et al., 2006) indicates that an acidification of the snow or ice, allowed by carbonate precipitation, accelerates the activation of halogens (see Sects. 1.3, 2.1, and 3.1.2). If acidity speeds halogen activation, it could provide a role for acid pollution in affecting ODE intensity. In the Arctic, natural processes like forest fires and pollution outflow from the industrialized parts of the Northern Hemisphere provide humic material, acidic aerosols, precursors of inorganic acidity (e.g. $\mathrm{SO}_{2}$, and $\mathrm{NO}_{\mathrm{x}}$ ). Sulfate aerosols, for example, might play a role in the halogen liberation process by acting as surfaces for heterogeneous recycling and acid accelerated chemistry. Humic material in snow/ice is a likely source of many VOCs and NMHCs and therefore plays a role in the chemistry on the snow/ice surface and the boundary layer and therefore influences the development of ODEs. The production and world- wide use of CFCs lead to a drastic decrease in stratospheric ozone in polar regions. Connected with that is an enhanced UV radiation flux at the surface. This potentially impacts on the photochemistry involved in ODEs; however, this has not been investigated yet.

Another important influence is the effect of climate change and global warming on ODEs. Polar regions, especially the Northern Arctic, are more affected by climate change and have experienced a greater increase in temperatures than lower latitudes (Serreze and Francis, 2006, and references therein). Higher temperatures directly affect the chemical reaction cycles through their temperature-dependent rate coefficients. Significant changes in sea ice extent and thickness due to climate change are already being observed in the Northern Hemisphere (Johannessen et al., 1999; Overpeck et al., 2005; Serreze et al., 2003; Stroeve et al., 2005; Serreze and Francis, 2006; Holland et al., 2006, see also Fig. 21). This sea ice change is very likely to have an impact on ODEs; however, the sign is difficult to discern due to lack of mechanistic understanding of the role of sea ice on ODEs (see Sect. 3.1). Thinner winter ice may increase the probability for open leads and thus frost flower formation, which seems to be related to bromine explosions (Kaleschke et al., 2004). Also, thinner ice could enhance the availability of sea salts on the surface through increased capillary action. The extent of perennial sea ice, ice that has survived a summer melt season, has declined 20\% since the mid-1970s (Stroeve et al., 2005). In a warmer climate, an even larger fraction of ice would be first-year ice, which is likely to be involved in bromine activation (Wagner et al., 2001; Frieß et al., 2004; Simpson et al., 2007). These processes would imply an increase in the extent/frequency of ODEs. Warmer temperatures, however, may also decrease the probability of frost flower formation, which has been shown to be a strong function of temperature (Martin et al., 1995, 1996). Increasing temperatures could also interfere with the temperature-dependent precipitation of salts (see Sect. 3.1) affecting brine composition and possibly leading to reduced ODE probability. In order to assess the sign of the effect of polar warming on ODEs, we have to improve our mechanistic understanding of ODEs.

Sea-ice models recently showed that the Arctic Ocean may be ice-free during the summer as early as 2040 (Holland et al., 2006, see also Fig. 21). However, note that sea ice during the ODE season (winter/spring) should still fill most of the Arctic basin. This change could substantially benefit shipping, perhaps opening the Arctic Ocean as a major trade route during summer/fall. Shipping could occur both along the North West Passage and the Russian Northern Sea Route. Consequently, this increase in shipping in the Arctic Ocean could amplify the total burden of pollutants entering the Arctic environment from ports, ship operations, and accidents. If fossil fuel is still the main power source, then ships would deliver $\mathrm{NO}_{\mathrm{x}}$, aerosols, black carbon, and NMHC to the high Arctic, possibly affecting ODEs through an increase of acidic aerosols and pollutants. However, the seasonality 

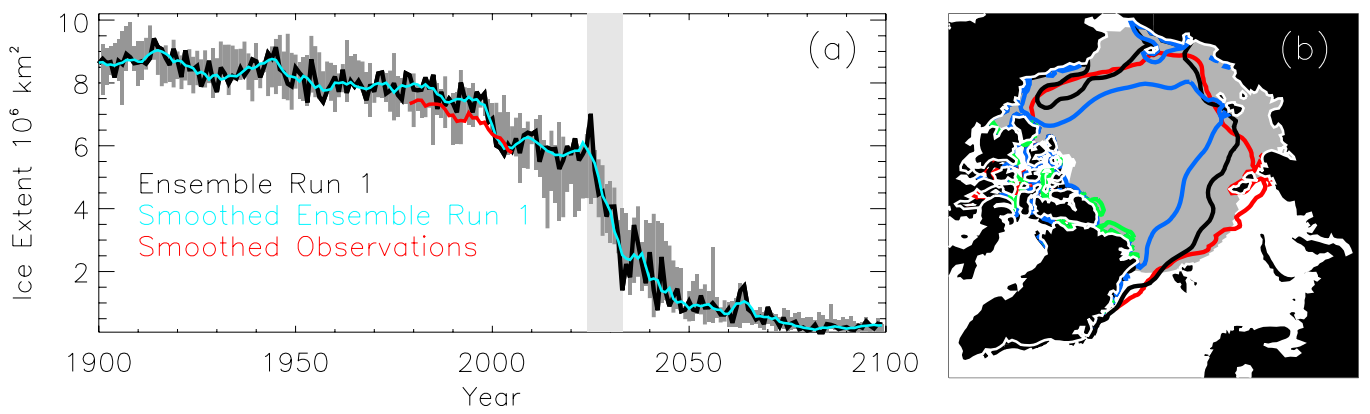

Fig. 21. (a) Northern Hemisphere September ice extent for a model (black), that model five-year running mean (blue), and the observed five-year running mean (red). The range from the ensemble members is in dark grey. Light grey indicates the abrupt event. (b) The model (black) and observed (red) 1990s averaged September ice edge (50\% concentration) and model conditions averaged over 2010-2019 (blue) and 2040-2049 (green). The arctic region used in this analysis is in grey. Reprinted from Holland et al. (2006) with permission from the American Geophysical Union (AGU).

of the shipping is nearly opposite from that of the ODEs, so mechanisms that store this pollution and re-deliver it during the ODE season, such as storage in snow and ice, are necessary to have strong effects of this pollution on ODEs. Pollution of the Arctic through increased transportation, would have many additional effects, though, on biological systems, snow pack photochemistry (Grannas et al., 2007), and icealbedo climate feedbacks. A similar effect could result from long range transport of pollution from the rapidly expanding economies in Asia and possibly also Russia. Iziomon et al. (2006) showed that summertime pollution events in the Arctic are dominated by outflow from Russia (40\%) while South Asia, Europe and North America each contribute 6\% to the observed aerosol loading.

\subsection{Global relevance of ODEs}

While ODEs are episodic in nature when they have been observed at coastal locations on the fringe of the ice-pack, satellite images of $\mathrm{BrO}$ show that halogen activation is quite common in young ice areas across the Arctic (Wagner and Platt, 1998a; Richter et al., 1998c). The limited observations on the ice pack in the Arctic indicate that ozone concentrations are decreased on the majority of days during polar springtime (Hopper et al., 1994). Therefore, ODES have a significant impact on tropospheric chemistry in polar regions. The use of polar ice cores to study global atmospheric processes highlights the need to understand local polar processes. Sulfur oxidation products in ice cores, for example, are used to discuss global aerosol issues, but the presence of halogens in polar regions may influence the ratios of these oxidation products (see Sect. 4.5). The magnitude of ODE's influence on the larger global scale, however, remains to be determined. One possible impact could be long-range transport of $\mathrm{BrO}$ to lower latitudes and a contribution to the $\mathrm{BrO}$ background levels in the free troposphere (see Sect. 4.4). Transport to the free troposphere has been observed in some cases (McElroy et al., 1999) but needs to be quantified. If export of $\mathrm{BrO}$ does contribute to tropospheric $\mathrm{BrO}$, changes in polar regions could have more global consequences. Also the transport of $\mathrm{O}_{3}$ depleted air to lower latitudes is possible and would impact the local radiative balance there (see Sect. 4.3) as well as the chemistry, but has not yet been studied. Mercury deposition due to ODE-related halogen chemistry is of great concern for its ability to contaminate the Arctic ecosystems (see Sect. 4.1 and the accompanying mercury review, Steffen et al., 2007). Any possible changes in ODE frequency and strength resulting from climate change could therefore have a strong impact on the bioaccumulation of mercury in the environment. So far, a quantitative assessment of these points cannot be done, as we still lack important information regarding the factors controlling ODEs, as outlined in the following section.

\subsection{Open questions}

While a lot of progress in our understanding has been made since the first discovery of ODEs, many open questions remain. The autocatalytic reaction cycle for bromine explosions consists of an initiation step, propagation, and termination reactions (see Sect. 1.3). We currently believe that brine-derived salts on ice surfaces (frost flowers, aerosols, or snow) are key in controlling propagation, while meteorology is important in providing a somewhat "closed reaction chamber" through temperature inversions and affecting dispersion and termination of ODEs. However, the initiation step is less well understood. Some possible initiation reactions that can start the bromine explosion are summarized by Sander et al. (2003a). One possible example is the photolysis of organohalogen species (see Sect. 3.3.2), which could initiate bromine explosions that amplify the weak photolytic source. When considering propagation, an important 
question we have to ask is: Under what conditions is the bromine explosion cycle really "exploding", i.e. when is the production of new $\mathrm{BrO}_{\mathrm{x}}$ fast enough to compensate for termination reactions? This question is difficult to answer and the maintenance of the autocatalytic bromine release cycle will depend on the availability of bromide, acidity, temperature, and other factors.

Another open question is that of the role of ice and snow surfaces in halogen activation (see Sect. 3.1). Salts, originally derived from sea water underlying the ice, are clearly the source of the majority of the atmospheric bromine loading, although many important aspects of the mechanism by which this transport and chemical transformation occurs are still lacking. Specifically, how these salts are transported from the water to the atmosphere is still being discussed. The site of halogen activation (on frost flowers, aerosol particles, or in snow pack) is still an area of active research. Acidity, a key prerequisite of ODE chemistry is also an issue. Both $\mathrm{H}^{+}$and $\mathrm{HO}_{\mathrm{x}}$ are consumed during bromine explosion reactions, so there must be sources to maintain halogen activation and ozone depletion conditions. An important question in this respect is: What is the effective $\mathrm{pH}$ of surfaces of snow, ice and frost flowers, and how is it affected by the temperature dependent precipitation of alkaline salts like $\mathrm{CaCO}_{3}$ (see Sect. 3.1.2)?

The roles of chlorine and iodine in ODEs still pose many open questions. For example, how can the release of chlorine be explained quantitatively and how important is chlorine (photo)chemistry (e.g. affecting the fate of hydrocarbons during ODEs)? Most of the earlier studies have focused on bromine chemistry, but chlorine and iodine could also contribute and in some situations even be the dominant halogens. In the Antarctic, high concentrations of IO were observed (see Sect. 2.3). In the Arctic, however, a link between iodine and bromine has not been observed. These findings lead to the question of the iodine sources and release mechanisms and if this link between $\mathrm{I}$ and $\mathrm{Cl}$ has been overlooked in the Arctic or if important differences exist between halogen interactions in the Arctic and Antarctic.

Due to its large ecological impacts, the fate of mercury in the polar environment is important. However, the speciation of mercury at the snow-air interface is not well understood. The chemical speciation of mercury may affect (photo)reduction processes and its bioavailability.

\subsection{Future needs and plans}

Future research to address the open questions listed above have several components. One important aspect is the need to perform in-situ measurements during ODEs to improve understanding of chemical mechanisms and constrain model simulations. As discussed in Sect. 2, only a small fraction of the halogen compounds thought to be involved in the chain reactions has been detected in field measurements to date. Direct measurements of halogen activation at locations on the ice, particularly near leads and frost flowers, are needed to determine the origin of reactive halogens. Better understanding of these sources is critical for meaningful prediction of how halogen activation may be enhanced or reduced by changes in sea ice and temperature in the polar regions. Continued exploitation of satellite remote sensing data combined with coordinated field campaigns using multiple platforms and long-duration measurements can provide key big-picture constraints on the role of sea ice on halogen activation. Towers or tethered balloons could be used to get more information on the vertical distribution of chemicals. Airships could provide vertical information in addition to being able to conduct Lagrangian experiments, where the life cycle of an ODE within the air mass might be studied. Both techniques, of course, are very challenging to be employed in polar regions.

Satellite remote sensing data provides direct observations of halogen activation (e.g. measurements of $\mathrm{BrO}$ and $\mathrm{IO}$ ). These measurements continue to improve in data quality, spatial and temporal resolution, and availability of ancillary data sets. Clever combinations of multiple remote sensing data sets have begun to probe relationships between $\mathrm{BrO}$ and controlling influences (e.g. sea ice, temperature, open leads/polynyas), however more work is needed to identify frost flowers, new sea ice, and open water areas. Future work is likely to improve understanding of halogen activation events and prediction of events. Also, satellite-observed measurements should assist in making maps of the effects of ODEs (e.g. ozone depletion and/or mercury deposition).

Model studies are currently limited by both a lack of measurement data for evaluation and missing data on reaction kinetics, in particular the temperature dependence of some key reactions. Important areas of possible improvements in current models are the representation of aerosols which still is oversimplified in some models and the representation of the very shallow polar boundary layer. The eventual aim for models should be to reproduce individual ODEs including knowledge of sea ice forms (e.g. frost flowers, snow), boundary layer inversions without constraining gas phase halogens or the need for external start and end of the ODE.

Laboratory studies are needed to understand chemistry above frost flowers and other ice surfaces as well as the microstructural distribution of impurities on ice surfaces. Many of the rate constants used in modeling of the halogen chemistry need better measurements and better definition of their temperature dependence. Also, methods need to be developed to determine in-situ properties of ice surfaces, such as the effective $\mathrm{pH}$ of ice surfaces.

It is also vital to understand the transport and fate of atmospheric mercury. Field campaigns as well as laboratory and theoretical calculations must continue to elucidate the halogen-mercury interaction and its potential global impact on the transformation of GEM to oxidized mercury with subsequent deposition and ultimate potential bioaccumulation of mercury in the environment. 
The importance of targeted field campaigns both in the Artic and Antarctic cannot be overemphasised for the study of ODEs. The International Polar Year (IPY 2007/08) will be an exceptional occasion to bring together expertise and logistical resources to perform large simultaneous field campaigns that can provide answers to the most critical questions.

\section{Summary}

After the initial discovery of the phenomenon in the Arctic in the late $1980 \mathrm{~s}$, the research on polar boundary-layer ozone depletions has made major progress. The key reactions have been identified, with the self reaction of $\mathrm{BrO}$ as rate determining step. Later, the importance of heterogeneous reactions was recognized, which explained the bromine explosion and the efficient recycling of $\mathrm{BrO}_{\mathrm{x}}$ in the troposphere. Satellites allowed the first world-wide coverage of halogen oxide measurements and confirmed that $\mathrm{BrO}$ enriched air masses existed not only in the Arctic but also in the Antarctic. Though most of the research reviewed in this paper concentrates on bromine, chlorine and iodine chemistry is strongly coupled with bromine chemistry. Interhalogen reactions play an important role in halogen activation. However, the precise source of halogens remains an open question and further research is needed to close this gap. Suggestions have included sea salt deposits on snow, young sea-ice surfaces, sea-salt aerosol, concentrated brines on new sea-ice, and frost flowers. This question is one of the most debated ones in the community today. Though ODEs are spatially restricted, they can influence the chemistry in the polar troposphere significantly. The main consequence of halogen activation is chemical destruction of ozone, which leads to a shift in oxidants and oxidation products. No measurements of $\mathrm{OH}$ during ODE conditions have yet been reported (but see discussion of $\mathrm{HO}_{\mathrm{x}}$ chemistry and influence of snow photochemistry in the accompanying paper, Grannas et al., 2007) so it is not established yet whether or not other $\mathrm{OH}$ production pathways can maintain $\mathrm{OH}$ conditions at levels comparable to non-ODE conditions. What is established is that very strong oxidation processes do occur, one of the most dramatic examples is the oxidation of mercury leading to its almost complete removal from the gas phase and deposition with impacts on polar ecosystems. Also, the oxidation of VOC is dominated by chlorine chemistry under ODE conditions, which may cause feedbacks through the production of $\mathrm{HO}_{\mathrm{x}}$. In coastal regions, the oxidation of DMS by $\mathrm{BrO}$ and $\mathrm{Cl}$ is dramatically increased but also the products are changed compared to "background" chemistry. The production of aldehydes and major effects on the sulfur cycle affect the interpretation of ice cores. A major question for the future will be: How do climate changes and anthropogenic influences affect ODEs? Specifically, models predict scenarios of a seasonally ice-free Arctic Ocean, possible increases in pollution due to shipping, and a very different winter ice pack. How will higher tem- peratures affect the formation of young sea-ice and the occurrence of ODEs? We need to develop models, laboratory methods, and field measurement techniques that will help us to answer these questions to understand fully the role of halogens in tropospheric ozone depletion in the polar regions.

Acknowledgements. Each of the three first authors on this work contributed equally to this review article, and the subsequent alphabetic list of co-authors includes contributors of major material and review of the manuscript. We thank the International Global Atmospheric Chemistry (IGAC) project and the Atmosphere-Ice Chemical Interactions (AICI) task for organizing the workshop that led to this review article. We acknowledge the financial support of funding agencies (e.g. NSF in the U.S. under grant OPP-0435922, New Zealand, and EU sources) and our research institutions. This paper is a contribution to the IGAC/SOLAS task "Halogens in the Troposphere" (HitT). We would like to thank the following people for helpful discussions, for making unpublished material available to us and/or for very helpful comments on this and/or earlier drafts of this review: J. McConnell, J. Dibb, G. Carver, M. Piot, J. Savarino, and S. Morin.

Edited by: W. T. Sturges

\section{References}

Abbatt, J. P. D.: Heterogeneous reaction of $\mathrm{HOBr}$ with $\mathrm{HBr}$ and $\mathrm{HCl}$ on ice surfaces at $228 \mathrm{~K}$, Geophys. Res. Lett., 21, 665-668, 1994.

Abbatt, J. P. D.: Interactions of Atmospheric Trace Gases with Ice Surfaces, Chem. Rev., 103, 4783 - 4800, 2003.

Abbatt, J. P. D. and Nowak, J. B.: Heterogeneous interactions of $\mathrm{HBr}$ and $\mathrm{HOCl}$ with cold sulfuric acid solutions: Implications for Arctic boundary layer bromine chemistry, J. Phys. Chem. A, 101, 2131-2137, 1997.

Adams, J. W., Holmes, N. S., and Crowley, J. N.: Uptake and Reaction of HOBr on Frozen and dry Salt Surfaces, Atmos. Chem. Phys., 2, 79-91, 2002,

http://www.atmos-chem-phys.net/2/79/2002/.

Alam, A. and Curry, J.: Lead-Induced Atmospheric Circulations, J. Geophys. Res., 100, 4643-4651, 1995.

Anderson, P. and Neff, W.: Boundary Layer Physics over Snow and Ice, Atmos. Chem. Phys. Discuss., 7, 7625-7677, 2007, http://www.atmos-chem-phys-discuss.net/7/7625/2007/.

Anlauf, K. G., Mickle, R. E., and Trivett, N. B. A.: Measurement of ozone during Polar Sunrise Experiment 1992, J. Geophys. Res., 99, 25 345-25 353, 1994.

Aranda, A., Le Bras, G., La Verdet, G., and Poulet, G.: The BrO $+\mathrm{CH}_{3} \mathrm{O}_{2}$ reaction: Kinetics and role in the atmospheric ozone budget, Geophys. Res. Lett., 24, 2745-2748, 1997.

Ariya, P., Dastoor, A. P., Amyot, M., Schroeder, W. H., Barrie, L., Anlauf, K., Raofie, F., Ryzhkov, A., Davignon, D., Lalonde, J., and Steffen, A.: The Arctic: a sink for mercury, Tellus, 56B, 397-403, 2004.

Ariya, P. A., Jobson, B. T., Sander, R., Niki, H., Harris, G. W., Hopper, J. F., and Anlauf, K. G.: Measurements of $\mathrm{C}_{2}-\mathrm{C}_{7}$ hydrocarbons during the Polar Sunrise Experiment 1994: Further 
evidence for halogen chemistry in the troposphere, J. Geophys. Res., 103, 13 169-13 180, 1998.

Ariya, P. A., Khalizov, A., and Gidas, A.: Reactions of Gaseous Mercury with Atomic and Molecular Halogens: Kinetics, Product Studies, and Atmospheric Implications, J. Phys. Chem. A, 106, 7310-7320, 2002.

Ashworth, S. H., Allan, B. J., and Plane, J. M. C.: High resolution spectroscopy of the OIO radical: implications for the ozonedepletion potential of iodine in the marine boundary layer, Geophys. Res. Lett., 29, 1456, doi:10.1029/2001GL013851, 2002.

Aspmo, K., Gauchard, P.-A., Steffen, A., Temme, C., Berg, T., Bahlmann, E., Banic, C., Dommergue, A., Ebinghaus, R., Ferrari, C., Pirrone, N., Sproviere, F., and Wibetoe, G.: Measurements of atmospheric mercury species during an international study of mercury depletion events at $\mathrm{Ny}$-Ålesund, Svalbard, spring 2003. How reproducible are our present methods?, Atmos. Environ., 39, 7607-7619, 2005.

Atkinson, R., Baulch, D. L., Cox, R. A., Crowley, J. N., Hampson, R. F., Hynes, R. G., Jenkin, M. E., Rossi, M. J., and Troe, J.: Evaluated kinetic and photochemical data for atmospheric chemistry: Volume II - reactions of organic species, Atmos. Chem. Phys., 6, 3625-4055, 2006,

http://www.atmos-chem-phys.net/6/3625/2006/.

Atlas, E. L., Ridley, B. A., and Cantrell, C. A.: The Tropospheric Ozone Production about the Spring Equinox (TOPSE) Experiment: Introduction, J. Geophys. Res., 108, 8353, doi:10.1029/2002JD003172, 2003.

Avallone, L. M., Toohey, D. W., Fortin, T. J., McKinney, K. A., and Fuentes, J. D.: In situ measurements of bromine oxide at two high-latitude boundary layer sites: Implications of variability, J. Geophys. Res., 108, 4089, doi:10.1029/2002JD002843, 2003.

Ayers, G. P., Granek, H., and Boers, R.: Ozone in the Marine Boundary Layer at Cape Grim: Model Simulation, J. Atmos. Chem., 27, 179-195, 1997.

Banic, C., Beauchamp, S. T., Tordon, R. J., Schroeder, W. H., Steffen, A., and Anlauf, K. A.: Vertical distribution of gaseous elemental mercury in Canada, J. Geoph. Res., 108, 4264-4278, 2002.

Bargagli, R., Agnorelli, C., Borghini, F., and Monaci, F.: Enhanced deposition and bioaccumulation of mercury in Antarctic terrestrial ecosystems facing a coastal polynya, Environ. Sci. Technol., 39, 8150-8155, 2005.

Barnes, I., Becker, K. H., and Starcke, J.: Fourier-transform IR spectroscopic observation of gaseous nitrosyl iodine, nitryl iodine, and iodine nitrate, J. Phys. Chem., 95, 9736-9740, 1991.

Barrie, L. and Platt, U.: Arctic tropospheric chemistry: an overview, Tellus, 49B, 450-454, 1997.

Barrie, L. A.: Arctic air pollution: an overview of current knowledge, Atmos. Environ., 20, 643-663, 1986.

Barrie, L. A., Bottenheim, J. W., Schnell, R. C., Crutzen, P. J., and Rasmussen, R. A.: Ozone destruction and photochemical reactions at polar sunrise in the lower Arctic atmosphere, Nature, 334, 138-141, 1988.

Barrie, L. A., den Hartog, G., Bottenheim, J. W., and Landsberger, S.: Anthropogenic aerosols and gases in the lower troposphere at Alert, Canada in April 1986, J. Atmos. Chem., 9, 101-127, 1989.

Barrie, L. A., Bottenheim, J. W., and Hart, W. R.: Polar Sunrise Experiment 1992 (PSE 1992): Preface, J. Geophys. Res., 99, $25313-25314,1994$.
Bates, T. S., Calhoun, J. A., and Quinn, P. K.: Variations in the methanesulfonate to sulfate molar ratio in submicrometer marine aerosol particles over the Southern Pacific Ocean, J. Geophys. Res., 97, 9859-9865, 1992.

Beine, H. J., Dominé, F., Ianniello, A., Nardino, M., Allegrini, I., Teinilä, K., and Hillamo, R.: Fluxes of nitrates between snow surfaces and the atmosphere in the European high Arctic, Atmos. Chem. Phys., 3, 335-346, 2003, http://www.atmos-chem-phys.net/3/335/2003/.

Berg, W. W., Sperry, P. D., Rahn, A., and Gladney, E. S.: Atmospheric Bromine in the Arctic, J. Geophys. Res., 88, 6719-6736, 1983.

Berntsen, T. K. and Isaksen, I. S. A.: A global three-dimensional chemical transport model for the troposphere.1. Model description and CO and ozone results, J. Geophys. Res., 102, 21239 $21280,1997$.

Bottenheim, J. W. and Chan, E.: A trajectory study into the origin of spring time Arctic boundary layer ozone depletion, J. Geophys. Res., 111, D19301, doi:10.1029/2006JD007055, 2006.

Bottenheim, J. W., Gallant, A. J., and Brice, K. A.: Measurements of $\mathrm{NO}_{\mathrm{y}}$ species and $\mathrm{O}_{3}$ at $82^{\circ} \mathrm{N}$ latitude, Geophys. Res. Lett., 13, 113-116, 1986.

Bottenheim, J. W., Dibb, J. E., Honrath, R. E., and Shepson, P. B.: An introduction to the ALERT 2000 and SUMMIT 2000 Arctic research studies, Atmos. Environ., 36, 2467-2469, 2002.

Bottenheim, W., Barrie, L. A., Atlas, E., Heidt, L. E., Niki, H., Rasmussen, R. A., and Shepson, P. B.: Depletion of lower tropospheric ozone during Arctic spring: The polar sunrise experiment 1988, J. Geophys. Res., 95, 18 555-18 568, 1990.

Boucher, O., Moulin, C., Belviso, S., Aumont, O., Bopp, L., Cosme, E., von Kuhlmann, R., Lawrence, M. G., Pham, M., Redyy, M. S., Sciare, J., and Venkataraman, C.: Sensitivity study of dimethylsulfide (DMS) atmospheric concentrations and sulphate aerosol indirect radiative forcing to the DMS source representation and oxidation, Atmos. Chem. Phys., 3, 49-65, 2003, http://www.atmos-chem-phys.net/3/49/2003/.

Boudries, H. and Bottenheim, J. W.: $\mathrm{Cl}$ and $\mathrm{Br}$ Atom Concentrations During a Surface Boundary Layer Ozone Depletion Event in the Canadian High Arctic, Geophys. Res. Lett., 27, 517-520, 2000.

Boudries, H., Canagaratna, M. R., Jayne, J. T., Alfarra, M. R., Allan, J., Bower, K. N., Coe, H., Pryor, S. C., Jimenez, J. L., Brook, J. R., Li, S., and Worsnop, D. R.: Chemical and physical processes controlling the distribution of aerosols in the Lower Fraser Valley, Canada, during the Pacific 2001 field campaign, Atmos. Environ., 38, 5759-5774, 2004.

Brasseur, G. P., Cox, R. A., Hauglustaine, D., Isaksen, I., Lelieveld, J., Lister, D. H., Sausen, R., Schumann, U., Wahner, A., and Wiesen, P.: European Scientific Assessment of the Atmospheric Effects of Aircraft Emissions, Atmos. Environ., 32, 2329-2418, 1998.

Burrows, J. P., Weber, M., Buchwitz, M., Rozanov, V., LadstätterWeißenmayer, A., Richter, A., DeBeek, R., Hoogen, R., Bramstedt, K., Eichmann, K.-U., Eisinger, M., and Perner, D.: The Global Ozone Monitoring Experiment (GOME): Mission Concept and First Scientific Results, J. Atmos. Sci., 56, 151-175, 1999.

Calvert, J. G. and Lindberg, S. E.: A modeling study of the mechanism of the halogen-ozone-mercury homogeneous reactions in 
the troposphere during the polar spring, Atmos. Environ., 37, 4467-4481, 2003.

Calvert, J. G. and Lindberg, S. E.: Potential influence of iodinecontaining compounds on the chemistry of the troposphere in the polar spring. I. Ozone depletion, Atmos. Environ., 39, 50875104, doi:10.1016/j.atmosenv.2004.05.049, 2004a.

Calvert, J. G. and Lindberg, S. E.: Potential influence of iodinecontaining compounds on the chemistry of the troposphere in the polar spring. II. Mercury depletion, Atmos. Environ., 38, 51055116, doi:10.1016/j.atmosenv.2004.05.050, 2004 b.

Carpenter, L. J., Hopkins, J. R., Jones, C. E., Lewis, A. C., Parthipan, R., Wevill, D. J., Poissant, L., Pilote, M., and Constant, P.: Abiotic Source of Reactive Organic Halogens in the Sub-Arctic Atmosphere?, Environ. Sci. Technol., 39, 88128816, doi:10.1021/es050918w, 2005a.

Carpenter, L. J., Wevill, D. J., O’Doherty, S., Spain, G., and Simmonds, P. G.: Atmospheric bromoform at Mace Head, Ireland: Evidence for a peatland source, Atmos. Chem. Phys., 5, 29272934, 2005b.

Chan, H. M.: A database for environmental contaminants in traditional foods in northern and arctic Canada: Development and applications, Food Addit. Contam., 15, 127-134, 2005.

Chance, K.: Analysis of BrO Measurements from the Global Ozone Monitoring Experiment, Geophys. Res. Lett., 25, 3335-3338, 1998.

Charlson, R. J., Lovelock, J. E., Andreae, M. O., and Warren, S. G.: Oceanic phytoplankton, atmospheric sulphur, cloud albedo and climate, Nature, 326, 655-661, 1987.

Cleveland, W. S. and Devlin, S. J.: Regression by local fitting: Methods, prospectives and computational algorithms, J. Am. Stat. Assoc., 83, 596-610, 1988.

Couch, T. L., Sumner, A. L., Dassau, T. M., and Shepson, P.: An Investigation of the interaction of carbonyl compounds with the snowpack, Geophys. Res. Lett., 27, 2241-2244, 2000.

Dassau, T. M., Shepson, P. B., Bottenheim, J. W., and Ford, K. M.: Peroxyacetyl nitrate photochemistry and interactions with the Arctic surface, J. Geophys. Res., 109, D18302, doi:10.1029/2004JD004562, 2004.

Davidson, C. and Schnell, R.: Arctic air, snow and ice chemistry, Atmos. Environ., 27 A, 2695-3041, 1993.

Davison, B., Hewitt, C., O’Dowd, C., Lowe, J., Smith, M., Schwikowski, M., Baltensperger, U., and Harrison, R.: Dimethyl sulfide, methane sulfonic acid and physicochemical aerosol properties in Atlantic air from the United Kingdom to Halley Bay, J. Geophys. Res., 101, 22 855-22 867, 1996.

de Serves, C.: Gas phase formaldehyde and peroxide measurements in the Arctic atmosphere, J. Geophys. Res., 99, 25 391-25 398, 1994.

Dominé, F. and Shepson, P. B.: Air-Snow Interactions and Atmospheric Chemistry, Science, 297, 1506-1510, 2002.

Dominé, F., Sparapani, R., Ianniello, A., and Beine, H. J.: The origin of sea salt in snow on Arctic sea ice and in coastal regions, Atmos. Chem. Phys., 4, 2259-2271, 2004, http://www.atmos-chem-phys.net/4/2259/2004/.

Domine, F., Taillandier, A. S., Simpson, W. R., and Severin, K.: Specific surface area, density and microstructure of frost flowers, Geophys. Res. Lett., 32, L13502, doi:10.1029/2005GL023245, 2005.

Douglas, T. A., Sturm, M., Simpson, W. R., Brooks, S., Lindberg,
S., and Perovich, D.: Elevated mercury measured in snow and frost flowers near Arctic sea ice leads, Geophys. Res. Lett., 32, L04502, doi:10.1029/2004GL022132, 2005.

Ebinghaus, R., Kock, H. H., Temme, C., Einax, J. W., Löwe, A. G., Richter, A., Burrows, J. P., and Schroeder, W. H.: Antarctic Springtime Depletion of Atmospheric Mercury, Environ. Sci. Technol., 36, 1238-1244, 2002.

Ebinghaus, R., Temme, C., Lindberg, S. E., and Scott, K. J.: Springtime accumulation of atmospheric mercury in polar ecosystems, J. Phys. IV, 121, 195-208, 2004.

Eisinger, M., Burrows, J. P., Richter, A., and LadstätterWeißenmayer, A.: $\mathrm{SO}_{2}, \mathrm{OClO}, \mathrm{BrO}$, and other minor trace gases from the Global Ozone Monitoring Experiment (GOME), in: Proc. 3rd ERS symposium, Space at the service of our environment, Florence, Italy, 17-21 March 1997, 1997.

EPICA community members: Eight glacial cycles from an Antarctic ice core, Nature, 429, 623-628, 2004.

Etheridge, D. M., Steele, L. P., Langenfelds, R. L., Francey, R. J., Barnola, J. M., and Morgan, V. I.: Natural and anthropogenic changes in atmospheric $\mathrm{CO}_{2}$ over the last 1000 years from air in Antarctic ice and firn, J. Geophys. Res., 101, 4115-4128, 1996.

Evans, M. J., Jacob, D. J., Atlas, E., Cantrell, C. A., Eisele, F., Flocke, F., Fried, A., Mauldin, R. L., Ridley, B. A., Wert, B., Walega, J., Weinheimer, A., Blake, D., Heikes, B., Snow, J., Talbot, R., and Dibb, J.: Coupled evolution of $\mathrm{BrO}_{\mathrm{x}}-\mathrm{ClO}_{\mathrm{x}}-\mathrm{HO}_{\mathrm{x}}-\mathrm{NO}_{\mathrm{x}}$ chemistry during bromine-catalyzed ozone depletion events in the Arctic boundary layer, J. Geophys. Res., 108, 8368, doi:10.1029/2002JD002732, 2003.

Fan, S.-M. and Jacob, D. J.: Surface ozone depletion in Arctic spring sustained by bromine reactions on aerosols, Nature, 359, $522-524,1992$.

Farman, J. C., Gardiner, B. G., and Shanklin, J. D.: Large losses of total ozone in Antarctica reveal seasonal $\mathrm{ClO} \times \mathrm{x} / \mathrm{NO}_{\mathrm{x}}$ interaction, Nature, 315, 207-210, 1985.

Fickert, S., Adams, J. W., and Crowley, J. N.: Activation of $\mathrm{Br}_{2}$ and $\mathrm{BrCl}$ via uptake of $\mathrm{HOBr}$ onto aqueous salt solutions, J. Geophys. Res., 104, 23 719-23 727, 1999.

Finlayson-Pitts, B. J.: The tropospheric chemistry of sea salt: A molecular-level view of the chemistry of $\mathrm{NaCl}$ and $\mathrm{NaBr}$, Chem. Rev., 103, 4801 - 4822, 2003.

Finlayson-Pitts, B. J. and Pitts, Jr., J. N.: Chemistry of the Upper and Lower Atmosphere, Academic Press, San Diego, 2000.

Finlayson-Pitts, B. J., Livingston, F. E., and Berko, H. N.: Ozone destruction and bromine photochemistry at ground level in the Arctic spring, Nature, 343, 622-625, 1990.

Foster, K. L., Plastridge, R. A., Bottenheim, J. W., Shepson, P. B., Finlayson-Pitts, B. J., and Spicer, C. W.: The Role of $\mathrm{Br}_{2}$ and $\mathrm{BrCl}$ in Surface Ozone Destruction at Polar Sunrise, Science, 291, 471-474, 2001.

Frieß, U., Wagner, T., Pundt, I., Pfeilsticker, K., and Platt, U.: Spectroscopic Measurements of Tropospheric Iodine Oxide at Neumayer Station, Antarctica, Geophys. Res. Lett., 28, 1941-1944, 2001.

Frieß, U., Hollwedel, J., König-Langlo, G., Wagner, T., and Platt, U.: Dynamics and chemistry of tropospheric bromine explosion events in the Antarctic coastal region, J. Geophys. Res., 109, D06305, doi:10.1029/2003JD004133, 2004.

Fuhrer, K., Hutterli, M., and McConnell, J.: Overview of recent field experiments for the study of the air-snow transfer of $\mathrm{H}_{2} \mathrm{O}_{2}$ 
and $\mathrm{HCHO}$, in: Chemical Exchange Between the Atmosphere and Polar Snow, edited by: Wolff, E. W. and Bales, R. C., 43, 307-318, Springer-Verlag, 1996.

Gauss, M., Isaksen, I. S. A., Wong, S., and Wang, W. C.: Impact of $\mathrm{H}_{2} \mathrm{O}$ emissions from cryoplanes and kerosene aircraft on the atmosphere, J. Geophys. Res., 108, 4304, doi:10.1029/2002JD002623, 2003.

Gersonde, R., Crosta, X., Abelmann, A., and Armand, L.: Seasurface temperature and sea ice distribution of the Southern Ocean at the EPILOG Last Glacial Maximum - a circumAntarctic view based on siliceous microfossil records, Quat. Sci. Rev., 24, 869-896, 2005.

Ghosal, S., Shbeeb, A., and Hemminger, J. C.: Surface Segregation of Bromine doped $\mathrm{NaCl}$ : Implications for the Seasonal Variations in Arctic Ozone, Geophys. Res. Lett., 27, 1879-1882, 2000.

Ghosal, S., Verdaguer, A., Hemminger, J. C., and Salmeron, M.: In Situ Study of Water-Induced Segregation of Bromide in Bromide-Doped Sodium Chloride by Scanning Polarization Force Microscopy, J. Phys. Chem. A, 109, 4744-4749, 2005.

Gong, S. L., Barrie, L. A., and Blanchet, J.-P.: Modeling sea-salt aerosols in the atmosphere: 1. Model development, J. Geophys. Res., 102, 3805-3818, 1997.

Goodsite, M. E., Plane, J. M. C., and Skov, H.: A Theoretical Study of the Oxidation of $\mathrm{Hg}^{0}$ to $\mathrm{HgBr}_{2}$ in the Troposphere, Environ. Sci. Technol., 38, 1772-1776, 2004.

Grannas, A. M., Shepson, P. B., Guimbaud, C. G., Sumner, A. L., Albert, M., Simpson, W., Domine, F., Boudries, H., Bottenheim, J., Beine, H. J., Honrath, R., and Zhou, X.: A study of photochemical processes affecting carbonyl compounds in the Arctic atmospheric boundary layer, Atmos. Environ., 36, 2733-2742, 2002

Grannas, A. M., Jones, A. E., Dibb, J., Ammann, M., Anastasio, C., Ariya, P., Beine, H. J., Bergin, M., Bottenheim, J., Boxe, C. S., Carver, G., Chen, G., Crawford, J. H., Dominé, F., Frey, M. M., Guzmán, M. I., Heard, D. E., Helmig, D., Hoffmann, M. R., Honrath, R. E., Huey, L. G., Hutterli, M., Jacobi, H., Klán, P., McConnell, J., Sander, R., Savarino, J., Shepson, P. B., Simpson, W. R., Sodeau, J. R., von Glasow, R., Weller, R., Wolff, E., and Zhu, T.: An overview of snow photochemistry: Evidence, mechanisms and impacts, Atmos. Chem. Phys., 7, 4329-4373, 2007 ,

http://www.atmos-chem-phys.net/7/4329/2007/.

Guimbaud, C., Grannas, A. M., Shepson, P. B., Fuentes, J. D., Boudries, H., Bottenheim, J. W., Domine, F., Houdier, S., Perrier, S., Biesenthal, T. B., and Splawn, B. G.: Snowpack processing of acetaldehyde and acetone in the Arctic atmospheric boundary layer, Atmos. Environ., 36, 2743-2752, 2002.

Hara, K., Osada, K., Kido, M., Hayashi, M., Matsunaga, K., Iwasaka, Y., Yamanouchi, T., Hashida, G., and Fukatsu, T.: Chemistry of sea-salt particles and inorganic halogen species in Antarctic regions: Compositional differences between coastal and inland stations, J. Geophys. Res., 109, D20208, doi:10.1029/2004JD004713, 2004.

Hausmann, M. and Platt, U.: Spectroscopic measurement of bromine oxide and ozone in the high Arctic during Polar Sunrise Experiment 1992, J. Geophys. Res., 99, 25 399-25 413, 1994.

Hebestreit, K., Stutz, J., Rosen, D., Matveiv, V., Peleg, M., Luria, M., and Platt, U.: DOAS Measurements of Tropospheric Bromine Oxide in Mid-Latitudes, Science, 283, 55-57, 1999.
Hegels, E., Crutzen, P. J., Klüpfel, T., Perner, D., and Burrows, J. P.: Global distribution of atmospheric bromine-monoxide from GOME on earth observing satellite ERS-2, Geophys. Res. Lett., 25, 3127-3130, 1998a.

Hegels, E., Harder, H., Klüpfel, T., Crutzen, P. J., and Perner, D.: On the global distribution of the halogen oxides from observations by GOME (Global Ozone Monitoring Experiment) on ERS-2, in: Proceedings of the fourth European symposium, 2226 September 1997, Schliersee, Germany, Air Pollution Report 66, 343-346, 1998b.

Holland, M. M., Bitz, C. M., and Tremblay, B.: Future abrupt reductions in the summer Arctic sea ice, Geophys. Res. Lett., 33, L23503, doi:10.1029/2006GL028024, 2006.

Hollwedel, J., Wenig, M., Beirle, S., Kraus, S., Kühl, S., WilmsGrabe, W., Platt, U., and Wagner, T.: Year-to- Year Variability of Polar Tropospheric BrO as seen by GOME, Adv. Space Res., 34, 804-808, 2004.

Hollwedel, J. C.: Observations of Tropospheric and Stratospheric Bromine Monoxide from Satellite, Ph.D. thesis, University of Heidelberg, 2005.

Hönninger, G.: Halogen Oxide Studies in the Boundary Layer by Multi Axis Differential Optical Absorption Spectroscopy and Active Longpath-DOAS, Ph.D. thesis, University of Heidelberg, Germany, 2002.

Hönninger, G. and Platt, U.: Observations of $\mathrm{BrO}$ and its vertical distribution during surface ozone depletion at Alert, Atmos. Environ., 36, 2481-2489, 2002.

Hönninger, G., Bobrowski, N., Palenque, E. R., Torrez, R., and Platt, U.: Reactive bromine and sulfur emissions at Salar de Uyuni, Bolivia, Geophys. Res. Lett., 31, L04101, doi:10.1029/2003GL018818, 2004a.

Hönninger, G., Leser, H., Sebastián, O., and Platt, U.: Groundbased measurements of halogen oxides at the Hudson Bay by longpath DOAS and passive MAX-DOAS, Geophys. Res. Lett., 31, L04111, doi: 10.1029/2003GL018982, 2004b.

Hönninger, G., von Friedeburg, C., and Platt, U.: Multi axis differential optical absorption spectroscopy (MAX-DOAS), Atmos. Chem. Phys., 4, 231-254, 2004c.

Honrath, R. E., Peterson, M. C., Guo, S., Dibb, J. E., Shepson, P. B., and Campbell, B.: Evidence of $\mathrm{NO}_{\mathrm{x}}$ production within or upon ice particles in the Greenland snowpack, Geophys. Res. Lett., 26, 695-698, 1999.

Honrath, R. E., Peterson, M. C., Dziobak, M. P., Dibb, J. E., Arsenault, M. A., and Green, S. A.: Release of $\mathrm{NO}_{\mathrm{x}}$ from Sunlightirradiated Midlatitude Snow, Geophys. Res. Lett., 27, $2237-$ 2240, 2000.

Hopper, J. F., Peters, B., Yokouchi, Y., Niki, H., Jobson, B. T., Shepson, P. B., and Muthuramu, K.: Chemical and meteorological observations at ice camp SWAN during Polar Sunrise Experiment 1992, J. Geophys. Res., 99, 25 489-25 498, 1994.

Hopper, J. F., Barrie, L. A., Silis, A., Hart, W., Gallant, A. J., and Dryfhout, H.: Ozone and meteorology during the 1994 Polar Sunrise Experiment, J. Geophys. Res., 103, 1481-1492, 1998.

Hu, Y. Y., Tung, K. K., and Liu, J. P.: A closer comparison of early and late-winter atmospheric trends in the northern hemisphere, J. Climate, 18, 3204 - 3216, 2005.

Huff, A. K. and Abbatt, J. P. D.: Gas-Phase $\mathrm{Br}_{2}$ Production in Heterogeneous Reactions of $\mathrm{Cl}_{2}, \mathrm{HOCl}$, and $\mathrm{BrCl}$ with Halide-Ice Surfaces, J. Phys. Chem. A, 104, 7284-7293, 2000. 
Huff, A. K. and Abbatt, J. P. D.: Kinetics and Product Yields in the Heterogeneous Reactions of $\mathrm{HOBr}$ with Ice Surfaces Containing $\mathrm{NaBr}$ and $\mathrm{NaCl}$, J. Phys. Chem. A, 106, 5279-5287, 2002.

Huthwelker, T., Ammann, M., and Peter, T.: The Uptake of Acidic Gases on Ice, Chem. Rev., 106, 1375-1444, doi:10.1021/ cr020506v, 2006.

Hutterli, M., Rankin, A. M., Knox, K. J., Jones, A. E., and Wolff, E. W.: A laboratory study of ozone depletion over frost flowers, in: EGU Conference, vol. 7, p. 06593, Geophys. Res. Abs., Vienna, 2006.

Hutterli, M. A., Bales, R. C., and Röthlisberger, R.: Atmosphereto-snow-to-firn transfer studies of HCHO at Summit, Greenland, Geophys. Res. Lett., 26, 1691-1694, 1999.

Hutterli, M. A., , McConnell, J. R., Chen, G., Bales, R. C., Davis, D. D., and Lenschow, D. H.: Formaldehyde and hydrogen peroxide in air, snow and interstitial air at South Pole, Atmos. Environ., 38, 5439-5450, 2004.

Hylander, L. D. and Goodsite, M. E.: Environmental costs of mercury pollution, Sci. Total Environ., 368, 352-370 Sp. Iss. SI, 2006.

Ianniello, A., Beine, H. J., Sparapani, R., Di Bari, F., Allegrini, I., and Fuentes, J. D.: Denuder measurements of gas and aerosol species above Arctic snow surfaces at Alert 2000, Atmos. Environ., 36, 5299-5309, 2002.

Impey, G. A., Shepson, P. B., Hastie, D. R., and Barrie, L. A.: Measurement technique for the determination of photolyzable chlorine and bromine in the atmosphere, J. Geophys. Res., 102, 15 999-16 004, 1997a.

Impey, G. A., Shepson, P. B., Hastie, D. R., Barrie, L. A., and Anlauf, K. G.: Measurements of photolyzable chlorine and bromine during the Polar Sunrise Experiment 1995, J. Geophys. Res., 102, 16005-16010, 1997b.

Impey, G. A., Mihele, C. M., Anlauf, K. G., Barrie, L. A., Hastie, D. R., and Shepson, P. B.: Measurements of photolyzable halogen compounds and bromine radicals during the Polar Sunrise Experiment 1997, J. Atmos. Chem., 34, 21-37, 1999.

Ingham, T., Cameron, M., and Crowley, J. N.: Photodissociation of IO $(355 \mathrm{~nm})$ and OIO $(532 \mathrm{~nm})$ : Quantum Yields for $\mathrm{O}\left({ }^{3} \mathrm{P}\right) / \mathrm{I}$ Production, J. Phys. Chem. A, 104, 8001-8010, 2000.

Iziomon, M. G., Lohmann, U., and Quinn, P. K.: Summertime pollution events in the Arctic and potential implications, J. Geophys. Res., 111, D12206, doi:10.1029/2005JD006223, 2006.

Jacobi, H. W. and Hilker, B.: A mechanism for the photochemical transformation of nitrate in snow, J. Photochem. Photobiol. A, 185, 371-382, 2007.

Jacobi, H.-W., Kaleschke, L., Richter, A., Rozanov, A., and Burrows, J. P.: Observation of a fast ozone loss over frost flowers in the marginal ice zone of the Arctic Ocean, J. Geophys. Res., 111, D15309, doi:10.1029/2005JD006715, 2006.

Jobson, B. T., Niki, H., Yokouchi, Y., Bottenheim, J., Hopper, F., and Leaitch, R.: Measurements of $\mathrm{C}_{2}-\mathrm{C}_{6}$ hydrocarbons during the Polar Sunrise 1992 Experiment: Evidence for $\mathrm{Cl}$ atom and Br atom chemistry, J. Geophys. Res., 99, 25 355-25 368, 1994.

Johannessen, O. M., Shalina, E. V., and Miles, M. W.: Satellite Evidence for an Arctic Sea Ice Cover in Transformation, Science, 286, 1937-1939, 1999.

Jones, A. E., Weller, R., Wolff, E. W., and Jacobi, H.-W.: Speciation and Rate of Photochemical $\mathrm{NO}$ and $\mathrm{NO}_{2}$ Production in Antarctic Snow, Geophys. Res. Lett., 27, 345-348, 2000.
Jones, A. E., Anderson, P. S., Wolff, E. W., Turner, J., Rankin, A. M., and Colwell, S. R.: A role for newly forming sea ice in springtime polar tropospheric ozone loss? Observational evidence from Halley Station, Antarctica, J. Geophys. Res., 111, D08306, doi:10.1029/2005JD006566, 2006.

Jones, P. D., New, M., Parker, D. E., Martin, S., and Rigor, I. G.: Surface air temperature and its changes over the past 150 years, Rev. Geophys., 37, 173-199, 1999.

Joseph, D. M., Ashworth, S. H., and Plane, J. M. C.: The absorption cross-section and photochemistry of OIO, J. Photochem. Photobiol. A: Chem., 176, 68-77, 2005.

Jungwirth, P. and Tobias, D. J.: Molecular Structure of Salt Solutions: A New View of the Interface with Implications for Heterogeneous Atmospheric Chemistry, J. Phys. Chem. B, 105, $10468-$ $10472,2001$.

Jungwirth, P. and Tobias, D. J.: Chloride Anion on Aqueous Clusters, at the Air-Water Interface, and in Liquid Water: Solvent Effects on $\mathrm{Cl}^{-}$Polarizability, J. Phys. Chem. A, 106, 379-383, 2002.

Kaleschke, L., Lüpkes, C., Vihma, T., Haarpaintner, J., Bochert, A., Hartmann, J., and Heygster, G.: SSM/I Sea Ice Remote Sensing for Mesoscale Ocean-Atmosphere Interaction Analysis, Can, J. of Remote Sens., 27, 526-537, 2001.

Kaleschke, L., Richter, A., Burrows, J., Afe, O., Heygster, G., Notholt, J., Rankin, A. M., Roscoe, H. K., Hollwedel, J., Wagner, T., and Jacobi, H.-W.: Frost flowers on sea ice as a source of sea salt and their influence on tropospheric halogen chemistry, Geophys. Res. Lett., 31, L16114, doi:10.1029/2004GL020655, 2004.

Kaleschke, L., Hollwedel, J., Richter, A., Burrows, J., Afe, O., Heygster, G., Notholt, J., Roscoe, H., Wolff, E. W., and Yang, $\mathrm{X}$.: Boundary-layer ozone loss near the poles - why spring and not autumn?, Geophys. Res. Abs., 7, 04916, 2005.

Kalnajs, L. E. and Avallone, L. M.: Frost flower influence on springtime boundary-layer ozone depletion events and atmospheric bromine levels, Geophys. Res. Lett., 33, L10810, doi:10.1029/2006GL025809, 2006.

Keil, A. D. and Shepson, P. B.: Chlorine and bromine atom ratios in the springtimes Arctic troposphere as determined from measurements of halogenated volatile organic compounds, J. Geophys. Res., 111, D17303, doi:10.1029/2006JD007119, 2006.

Khalizov, A. F., Viswanathan, B., Larregaray, P., and Ariya, P. A.: A Theoretical Study on the Reactions of $\mathrm{Hg}$ with Halogens: Atmospheric Implications, J. Phys. Chem. A, 107, 6360-6365, 2003.

Kiehl, J. T.: Solving the Aerosol Puzzle, Science, 283, 1273-1275, 1999.

Kieser, B. N., Bottenheim, J. W., Sideris, T., and Niki, H.: Spring 1989 Observations Of Lower Tropospheric Chemistry In The Canadian High Arctic, Atmos. Environ., 27, 2979-2988, 1993.

Kirchner, U., Benter, T., and Schindler, R. N.: Experimental verification of gas phase bromine enrichment in reactions of $\mathrm{HOBr}$ with sea salt doped ice surfaces, Ber. Bunsenges. Phys. Chem., 101, 975-977, 1997.

Knight, G. P. and Crowley, J. N.: The reactions of IO with $\mathrm{HO}_{2}$, $\mathrm{NO}$ and $\mathrm{CH}_{3} \mathrm{SCH}_{3}$ : Flow tube studies of kinetics and product formation, Phys. Chem. Chem. Phys., 3, 393-401, 2001.

Knipping, E. M., Lakin, M. J., Foster, K. L., Jungwirth, P., Tobias, D. J., Gerber, R. B., Dabdub, D., and Finlayson-Pitts, B. J.: Experiments and Molecular/Kinetics Simulations of Ion-Enhanced 
Interfacial Chemistry on Aqueous $\mathrm{NaCl}$ Aerosols, Science, 288, 301-306, 2000

Koop, T., Kapilashrami, A., Molina, L. T., and Molina, M. J.: Phase transitions of sea-salt/water mixtures at low temperatures: Implications for ozone chemistry in the polar marine boundary layer, J. Geophys. Res., 105, 26 393-26 402, 2000.

Kreher, K., Keys, J. G., Johnston, P. V., Platt, U., and Lui, X.: Ground based measurements of $\mathrm{ClO}$ and $\mathrm{HCl}$ in austral spring 1993 at Arrival Heights, Antarctica, Geophys. Res. Lett., 23, 1545-1548, 1996.

Kreher, K., Johnston, P. V., Wood, S. W., Nardi, B., and Platt, U.: Ground-based measurements of tropospheric and stratospheric $\mathrm{BrO}$ at Arrival Heights, Antarctica, Geophys. Res. Lett., 24, 3021-3024, 1997.

Lacis, A. A., Wuebbles, D. J., and Logan, J. A.: Radative forcing of climate by changes in the vertical distribution of ozone, J. Geophys. Res., 95, 9971-9981, 1990.

Laskin, A., Gaspar, D. J., Wang, W., Hunt, S. W., Cowin, J. P., Colson, S. D., and Finlayson-Pitts, B. J.: Reactions at Interfaces As a Source of Sulfate Formation in Sea-Salt Particles, Science, 301, 340-344, 2003.

Leaitch, W. R., Barrie, L. A., Bottenheim, J. W., Li, S. M., Shepson, P. B., Muthuramu, K., and Yokouchi, Y.: Airborne Observations Related To Ozone Depletion At Polar Sunrise, J. Geophys. Res., 99, 25 499-25 517, 1994.

LeBras, G. and Platt, U.: A Possible Mechanism For Combined Chlorine And Bromine Catalyzed Destruction Of Tropospheric Ozone In The Arctic, Geophys. Res. Lett., 22, 599-602, 1995.

Legendre, L., Ackley, S. F., Dieckmann, G. S., Gulliksen, B., Horner, R. A., Hoshiai, T., Melnikov, I. A., Reeburgh, W. S., Spindler, M., and Sullivan, C. W.: Ecology of sea ice biota. 2. Global significance, Pol. Biol., 12, 471-477, 1992.

Legrand, M.: Ice-Core Records of Atmospheric Sulphur, Phil. Trans. R. Soc. Lond. B, 352, 241-250, 1997.

Legrand, M. and Mayewski, P.: Glaciochemistry of polar ice cores: A review, Rev. Geophys., 35, 219-243, 1997.

Legrand, M. and Pasteur, E. C.: Methane sulfonic acid to non-seasalt sulfate ratio in coastal Antarctic aerosol and surface snow, J. Geophys. Res., 103, 10 991-11 006, 1998.

Lehrer, E., Hönninger, G., and Platt, U.: A one dimensional model study of the mechanism of halogen liberation and vertical transport in the polar troposphere, Atmos. Chem. Phys., 4, 24272440, 2004,

http://www.atmos-chem-phys.net/4/2427/2004/.

Li, S. M., Yokouchi, Y., Barrie, L. A., Muthuramu, K., Shepson, P. B., Bottenheim, J. W., Sturges, W. T., and Landsberger, S.: Organic And Inorganic Bromine Compounds And Their Composition In The Arctic Troposphere During Polar Sunrise, J. Geophys. Res., 99, 25 415-25 428, 1994.

Lindberg, S. E., Brooks, S., Lin, C.-J., Scott, K. J., Landis, M. S., Stevens, R. K., Goodsite, M., and Richter, A.: Dynamic Oxidation of Gaseous Mercury in the Arctic Troposphere at Polar Sunrise, Environ. Sci. Technol., 36, 1245-1256, 2002.

Lizotte, M. P.: The contributions of sea ice algae to Antarctic marine primary production, Am. Zool., 41, 57-73, 2001.

Longhurst, A., Sathyendranath, S., Platt, T., and Caverhill, C.: An estimate of global primary production in the ocean from satellite radiometer data, J. Plankton Res., 17, 1245-1271, 1995.

Lønne, O. J.: On productivity in ice-covered polar oceans, in: Ice
Physics and the Natural Environment, edited by Wettlaufer, J. S., Dash, J. G., and Untersteiner, N., vol. I 56 of NATO ASI Series, pp. 209-218, Springer-Verlag, Berlin, Heidelberg, 1999.

Lu, J. Y., Schroeder, W. H., Barrie, L. A., Steffen, A., Welch, H. E., Martin, K., Lockhart, L., Hunt, R. V., Boila, G., and Richter, A.: Magnification of atmospheric mercury deposition to polar regions in springtime: the link to tropospheric ozone depletion chemistry, Geophys. Res. Lett., 28, 3219-3222, 2001.

Marion, G. M.: Carbonate mineral solubility at low temperatures in the Na-K-Mg-Ca-H-Cl-SO $-\mathrm{OH}-\mathrm{HCO}_{3}-\mathrm{CO}_{3}-\mathrm{CO}_{2}-\mathrm{H}_{2} \mathrm{O}$ system, Geochim. Cosmochim. Acta, 65, 1883-1896, 2001.

Martin, S., Drucker, R., and Fort, M.: A laboratory study of frost flower growth on the surface of young sea-ice, J. Geophys. Res., 100, 7027-7036, 1995.

Martin, S., Yu, Y., and Drucker, R.: The temperature dependence of frost flower growth on laboratory sea ice and the effect of the flowers on infrared observations of the surface, J. Geophys. Res. 101, 12 111-12 125, 1996.

Martinez, M., Arnold, T., and Perner, D.: The role of bromine and chlorine chemistry for arctic ozone depletion events in $\mathrm{Ny}$ Alesund and comparison with model calculations, Ann. Geoph., 17, 941-956, 1999.

Mason, R. P., Fitzgerald, W. F., and Morel, F. M. M.: The Biogeochemical Cycling Of Elemental Mercury - Anthropogenic Influences, Geochim. Cosmochim. Acta, 58, 3191-3198, 1994.

Mauldin, R. L., Kosciuch, E., Henry, B., Eisele, F. L., Shetter, R., Lefer, B., Chen, G., Davis, D., Huey, G., and Tanner, D.: Measurements of $\mathrm{OH}, \mathrm{HO}_{2}+\mathrm{RO}_{2}, \mathrm{H}_{2} \mathrm{SO}_{4}$, and MSA at the South Pole during ISCAT 2000, Atmos. Environ., 38, 54235437, 2004.

McConnell, J. C., Henderson, G. S., Barrie, L., Bottenheim, J., Niki, H., Langford, C. H., and Templeton, E. M. J.: Photochemical bromine production implicated in Arctic boundary-layer ozone depletion, Nature, 355, 150-152, 1992.

McElroy, C. T., McLinden, C. A., and McConnell, J. C.: Evidence for bromine monoxide in the free troposphere during the Arctic polar sunrise, Nature, 397, 338-341, 1999.

McFiggans, G., Plane, J. M. C., Allan, B. J., Carpenter, L. J., Coe, H., and O'Dowd, C.: A Modelling Study of Iodine Chemistry in the Marine Boundary Layer, J. Geophys. Res., 105, 1437114377, 2000.

Michalowski, B. A., Francisco, J. S., Li, S.-M., Barrie, L. A., Bottenheim, J. W., and Shepson, P. B.: A computer model study of multiphase chemistry in the Arctic boundary layer during polar sunrise, J. Geophys. Res., 105, 15 131-15 145, 2000.

Mickle, R. E., Bottenheim, J. W., Leaitch, R. W., and Evans, W.: Boundary layer ozone depletion during AGASP-II, Atmos. Environ., 23, 2443-2449, 1989.

Mickley, L. J., Jacob, D. J., and Rind, D.: Uncertainty in preindustrial abundance of tropospheric ozone: implications for radiative forcing calculations, J. Geophys. Res., 106, 3389-3399, 2001.

Mihele, C. M. and Hastie, D. R.: The sensitivity of the radical amplifier to ambient water vapour, Geophys. Res. Lett., 25, 19111913, 1998.

Mitchell, J. M. J.: Visual range in the polar regions with particular reference to the alaskan Arctic, J. Atm. Terr. Phys., Spec. Suppl., 1, 195-211, 1957.

Molina, M. J. and Rowland, F. S.: Stratospheric sink for chlorofluoromethanes: Chlorine-atom catalysed destruction of ozone, $\mathrm{Na}$ - 
ture, 249, 810-812, 1974.

Moore, R. M., Groszko, W., and Niven, S. J.: Ocean-atmosphere exchange of methyl chloride: Results from NW Atlantic and Pacific Ocean studies, J. Geophys. Res., 101, 28 529-28 538, 1996.

Moortgat, G. K., Meller, R., and Schneider, W.: Temperature dependence (256-296K) of the absorption cross sections of bromoform in the wavelength range 285-360 nm, in: Tropospheric Chemistry of Ozone in Polar Regions, NATO ASI Ser, Subser 1: Global Environmental Change, edited by: Niki, H. and Becker, K. H., 359-370, Springer Verlag, New York, 1993.

Morin, S., Hoenninger, G., Staebler, R. M., and Bottenheim, J.: A high time resolution study of boundary layer ozone chemistry and dynamics over the Arctic Ocean near Alert, Nunavut, Geophys. Res. Lett., 32, L08809, doi:10.1029/2004GL022098, 2005.

Muthuramu, K., Shepson, P. B., Bottenheim, J. W., Jobson, B. T., Niki, H., and Anlauf, K. G.: Relationships between organic nitrates and surface ozone destruction during Polar Sunrise Experiment 1992, J. Geophys. Res., 99, 25 369-25 378, 1994.

Narukawa, M., Kawamura, K., Anlauf, K. G., and Barrie, L. A.: Fine and coarse modes of dicarboxylic acids in the Arctic aerosols collected during the Polar Sunrise Experiment 1997, J. Geophys. Res., 108, 4575, doi:10.1029/2003JD003646, 2003.

Neff, W., Helmig, D., Grachev, A., and Davis, D. D.: A study of boundary layer behavior associated with high NO concentrations at the South Pole using a minisodar, tethered balloon, and sonic anemometer, Atmos. Environ., in press, doi:10.1016/j.atmosenv.2007.01.033, 2007.

Nghiem, S. V., Martin, S., Perovich, D. K., Kwok, R., Drucker, R., and Gow, A. J.: A laboratory study of the effect of frost flowers on C band radar backscatter from sea ice, J. Geophys. Res., 102, 3357-3370, 1997.

O'Dowd, C. D. and Hoffmann, T.: Coastal New Particle Formation: A Review of the Current State-Of-The-Art, Env. Chem., 2, 245255, 2005.

O’Driscoll, P., Lang, K., Minogue, N., and Sodeau, J.: Freezing halide ion solutions and the release of interhalogens to the atmosphere, J. Chem. Phys. A, 110, 4615, 2006.

Oltmans, S. J.: Surface ozone measurements in clean air, J. Geophys. Res., 86, 1174-1180, 1981.

Oltmans, S. J. and Komhyr, W.: Surface ozone distributions and variations from 1973 - 1984 measurements at the NOAA Geophysical Monitoring for Climate Change Baseline observatories, J. Geophys. Res., 91, 5229-5236, 1986.

Oltmans, S. J., Schnell, R. C., Sheridan, P. J., Peterson, R. E., Li, S. M., Winchester, J. W., Tans, P. P., Sturges, W. T., Kahl, J. D., and Barrie, L. A.: Seasonal surface ozone and filterable bromine relationship in the high Arctic, Atmos. Environ., 23, 2431-2441, 1989.

Overpeck, J. T., Sturm, M., Francis, J. A., Perovich, D. K., Serreze, M. C., Benner, R., Carmack, E. C., III, S. C., Gerlach, S. C., Hamilton, L. C., Hinzman, L. D., Holland, M., Huntington, H. P., Key, J. R., Lloyd, A. H., MacDonald, G. M., McFadden, J., Noone, D., Prowse, T. D., Schlosser, P., and Vrsmarty, C.: Arctic System on Trajectory to New, Seasonally Ice-Free State, Eos Trans. AGU, 86, 309, 2005.

Papadimitriou, S., Kennedy, H., Kattner, G., Dieckmann, G. S., and Thomas, D. N.: Experimental evidence for carbonate precipitation and $\mathrm{CO}_{2}$ degassing during sea ice formation, Geochim. Cosmochim. Acta, 68, 1749-1761, 2003.
Peña, D., Tiao, G. C., and Tsay, R. S.: A Course in Time Series Analysis, John Wiley, Hoboken, N. J., 2000.

Perner, D., Harder, H., Martinez, M., Hegels, E., Grund, A., and Klüpfel, T.: Observation of $\mathrm{BrO}$ in the atmosphere by remote sensing and its significance for the global budget of bromine, in: Proceedings of the fourth European symposium, 22-26 September 1997, Schliersee, Germany, Air Pollution Report 66, 378 381, 1998.

Perner, D., Arnold, T., Crowley, J., Klüpfel, T., Martinez, M., and Seuwen, R.: The measurements of active chlorine in the atmosphere by chemical amplification, J. Atmos. Chem., 34, 9-20, 1999.

Perovich, D. K. and Richter-Menge, J. A.: Surface characteristics of lead ice, J. Geophys. Res., 99, 16341-16350, 1994.

Perrier, S., Houdier, S., Domine, F., Cabanes, A., Legagneux, L., Sumner, A. L., and Shepson, P. B.: Formaldehyde in Arctic snow. Incorporation into ice particles and evolution in the snowpack, Atmos. Environ., 36, 2695-2705, 2002.

Peterson, M. C. and Honrath, R. E.: Observations of Rapid Photochemical Destruction of Ozone in Snowpack Interstitial Air, Geophys. Res. Lett., 28, 511-514, 2001.

Piot, M. and von Glasow, R.: The potential importance of frost flowers, recycling on snow, and open leads for Ozone Depletion Events, Atmos. Chem. Phys. Discuss., 7, 4521-4595, 2007, http://www.atmos-chem-phys-discuss.net/7/4521/2007/.

Platt, U. and Hönninger, G.: The role of halogen species in the troposphere, Chemosphere, 52, 325-338, 2003.

Platt, U. and Janssen, C.: Observation and Role of the Free Radicals $\mathrm{NO}_{3}, \mathrm{ClO}, \mathrm{BrO}$ and $\mathrm{IO}$ in the Troposphere, Faraday Discuss., 100, 175-198, 1995.

Platt, U. and Lehrer, E.: Arctic Tropospheric Ozone Chemistry, ARCTOC, Final Report of the EU-Project NO. EV5V-CT930318, 1996.

Platt, U. and Moortgat, G. K.: Heterogeneous and Homogeneous Chemistry of Reactive Halogen Compounds in the Lower Troposphere, J. Atmos. Chem., 34, 1-8, 1999.

Poulain, A. J., Orihel, D. M., Amyot, M., Paterson, M. J., Hintelmann, H., and Southworth, G. R.: Relationship to aquatic between the loading rate of inorganic mercury ecosystems and dissolved gaseous mercury production and evasion, Chemosphere, 65, 2199-2207, 2006

Pundt, I., Pommereau, J.-P., Chipperfield, M. P., Roozendael, M. V., and Goutail, F.: Climatology of the stratospheric $\mathrm{BrO}$ vertical distribution by balloon-borne UV-visible spectrometry, J. Geophys. Res., 107, 4806, doi:10.1029/2002JD002 230, 2002.

Radke, L. F., Lyons, J. H., Hegg, D. A., Hobbs, P. V., and Bailey, I. H.: Airborne observations of Arctic aerosols. I: Characteristics of Arctic haze, Geophys. Res. Lett., 11, 393-396, 1984.

Ramacher, B., Rudolph, J., and Koppmann, R.: Hydrocarbon measurements during tropospheric ozone depletion events: Evidence for halogen atom chemistry, J. Geophys. Res., 104, 3633-3653, 1999.

Rankin, A. M. and Wolff, E. W.: A year-long record of sizesegregated aerosol composition at Halley, Antarctica, J. Geophys. Res., 108, 4775, doi:10.1029/2003JD003993, 2003.

Rankin, A. M., Wolff, E. W., and Martin, S.: Frost flowers: Implications for tropospheric chemistry and ice core interpretation, J. Geophys. Res., 107, 4683, doi:10.1029/2002JD002492, 2002.

Raofie, F. and Ariya, P.: Reaction of gaseous mercury with molecu- 
lar iodine and iodine radicals: Kinetics, product states, and atmospheric implications, in: AGU Fall meeting 2006, San Francisco, 2006.

Raofie, F. and Ariya, P. A.: Product study of the gas-phase BrOinitiated oxidation of $\mathrm{Hg}-0$ : evidence for stable $\mathrm{Hg} 1+\mathrm{com}-$ pounds, Environ. Sci. Tech., 38, 4319-4326, 2004.

Reifenhäuser, W. and Heumann, K. G.: Bromo- and Bromochloromethanes in the Antarctic atmosphere and the South Polar Sea, Chemosphere, 24, 1293 - 1300, 1992a.

Reifenhäuser, W. and Heumann, K. G.: Determinations of methyl iodide in the Antarctic atmosphere and the South Polar Sea, Atmos. Environ., 26A, 2905-2912, 1992 b.

Richardson, C.: Phase relationships in sea ice as a function of temperature, J. Glaciol., 17, 507-519, 1976.

Richter, A., Eisinger, M., Wittrock, F., and Burrows, J. P.: Measurements of halogen oxides by GOME, Earth Observation Quarterly, 58, 19-20, 1998a.

Richter, A., Eisinger, M., Wittrock, F., Schlieter, S., LadstätterWeißenmayer, A., and Burrows, J.: Zenith Sky and GOME DOAS measurements of atmospheric trace gases above Bremen, $53^{\circ} \mathrm{N}, 1994-1997$, in: Proceedings of the fourth European symposium, 22-26 September 1997, Schliersee, Germany, Air Pollution Report 66, 482-485, 1998b.

Richter, A., Wittrock, F., Eisinger, M., and Burrows, J. P.: GOME Observations of Tropospheric BrO in Northern Hemispheric Spring and Summer 1997, Geophys. Res. Lett., 25, 2683-2686, 1998c.

Richter, A., Wittrock, F., Ladstätter-Weißenmayer, A., and Burrows, J. P.: GOME measurements of stratospheric and tropospheric BrO, Adv. Space Res., 29, 1667-1672, 2002.

Ridley, B. A., Atlas, E. L., Montzka, D. D., Browell, E. V., Cantrell, C. A., Blake, D. R., Blake, N. J., Cinquini, L., Coffey, M. T., Emmons, L. K., Cohen, R. C., DeYoung, R. J., Dibb, J. E., Eisele, F. L., Flocke, F. M., Fried, A., Grahek, F. E., Grant, W. B., Hair, J. W., Hannigan, J., Heikes, B. J., Lefer, B. L., Mauldin, R. L., Moody, J. L., Shetter, R. E., Snow, J. A., Talbot, R. W., Thornton, J. A., Walega, J. G., Weinheimer, A. J., Wert, B. P., and Wimmers, A. J.: Ozone Depletion Events Observed in the High Latitude Surface Layer During the TOPSE Aircraft Program, J. Geophys. Res., 108, 8356, doi:10.1029/2001JD001507, 2003.

Riedel, K., Allan, W., Weller, R., and Schrems, O.: Discrepancies between formaldehyde measurements and methane oxidation model predictions in the Antarctic troposphere: An assessment of other possible formaldehyde sources, J. Geophys. Res., 110, D15308, doi:10.1029/2005JD005859, 2005.

Roscoe, H. K. and Roscoe, J.: Polar tropospheric ozone depletion events observed in the International Geophysical Year of 1958, Atmos. Chem. Phys., 6, 3303-3314, 2006, http://www.atmos-chem-phys.net/6/3303/2006/.

Roscoe, H. K., Kreher, K., and Friess, U.: Ozone loss episodes in the free Antarctic troposphere, suggesting a possible climate feedback, Geophys. Res. Lett., 28, 2911-2914, 2001.

Röthlisberger, R., Mulvaney, R., Wolff, E. W., Hutterli, M. A., Bigler, M., Angelis, M. D., Hansson, M. E., Steffensen, J. P., and Udisti, R.: Limited dechlorination of sea-salt aerosols during the last glacial period: Evidence from the European Project for Ice Coring in Antarctica (EPICA) Dome C ice core, J. Geophys. Res., 108, 4526, doi:4510.1029/2003JD003604, 2003.

Rudolph, J., Fu, B., Thompson, A., Anlauf, K., and Bottenheim,
J.: Halogen atom concentrations in the Arctic trophosphere derived from hydrocarbon measurements: impact on the budget of formaldehyde, Geophys. Res. Lett., 26, 2941-2944, 1999.

Saiz-Lopez, A. and Plane, J. M. C.: Novel iodine chemistry in the marine boundary layer, Geophys. Res. Lett., 31, L04112, doi:10.1029/2003GL019215, 2004.

Saiz-Lopez, A., Chance, K., Liu, X., Kurosu, T. P., and Sander, S. P.: First observations of iodine oxide from space, Geophys. Res. Lett., 34, L12812, doi:10.1029/2007GL030111, 2007a.

Saiz-Lopez, A., Mahajan, A. S., Salmon, R. A., Bauguitte, S. J.B., Jones, A. E., Roscoe, H. K., and Plane, J. M. C.: Boundary layer halogens in coastal Antarctica, Science, 317, 348, doi:10.1126/science.1141408, 2007b.

Saiz-Lopez, A., Plane, J. M. C., Mahajan, A. S., Anderson, P. S., Bauguitte, S. J.-B., Jones, A. E., Roscoe, H. K., Salmon, R. A., Bloss, W. J., Lee, J. D., and Heard, D. E.: On the vertical distribution of boundary layer halogens over coastal Antarctica: implications for $\mathrm{O}_{3}, \mathrm{HO}_{\mathrm{x}}, \mathrm{NO}_{\mathrm{x}}$ and the $\mathrm{Hg}$ lifetime, Atmos. Chem. Phys. Discuss., 7, 9385-9417, 2007c.

Salawitch, R.: Atmospheric Chemistry: Biogenic Bromine, Nature, 439, 275-277, doi:10.1038/439 275a, 2006.

Sander, R., Vogt, R., Harris, G. W., and Crutzen, P. J.: Modeling the chemistry of ozone, halogen compounds, and hydrocarbons in the arctic troposphere during spring, Tellus, 49B, 522-532, 1997.

Sander, R., Keene, W. C., Pszenny, A. A. P., Arimoto, R., Ayers, G. P., Baboukas, E., Cainey, J. M., Crutzen, P. J., Duce, R. A., Hönninger, G., Huebert, B. J., Maenhaut, W., Mihalopoulos, N., Turekian, V. C., and Dingenen, R. V.: Inorganic bromine compounds in the marine boundary layer: A critical review, Atmos. Chem. Phys., 3, 1301-1336, 2003a.

Sander, R., Burrows, J., and Kaleschke, L.: Carbonate precipitation in brine - the trigger for tropospheric ozone depletion events, Atmos. Chem. Phys., 6, 4653-4658, 2006, http://www.atmos-chem-phys.net/6/4653/2006/.

Sander, S. P., Friedl, R. R., Golden, D. M., Kurylo, M. J., Huie, R. E., Orkin, V. L., Moortgat, G. K., Ravishankara, A. R., Kolb, C. E., Molina, M. J., and Finlayson-Pitts, B. J.: Chemical Kinetics and Photochemical Data for Use in Stratospheric Modeling, Tech. Rep. JPL Publication 02-25, Jet Propulsion Laboratory, Pasadena, CA, 2003b.

Schall, C. and Heumann, K. G.: GC determination of volatile organoiodine and organobromine compounds in Arctic seawater and air samples, Fresenius J. Anal. Chem., 346, 717-722, 1993.

Schall, C., Laturnus, F., and Heumann, K. G.: Biogenic volatile organoiodine and organobromine compounds released from polar macroalgae, Chemosphere, 28, 1315-1324, 1994.

Schnell, R. C.: Arctic haze and the Arctic Gas and Aerosol Sampling Program (AGASP), Geophys. Res. Lett., 11, 361-364, 1983.

Schönhardt, A., Richter, A., Wittrock, F., and Burrows, J. P.: First observations of atmospheric iodine oxide columns from satellite, Geophys. Res. Abs., 9, 00 592, 2007.

Schroeder, W. H. and Munthe, J.: Atmospheric Mercury - An Overview, Atmos. Environ., 32, 809-822, 1998.

Schroeder, W. H., Anlauf, K. G., Barrie, L. A., Lu, J. Y., Steffen, A., Schneeberger, D. R., and Berg, T.: Arctic springtime depletion of mercury, Nature, 394, 331-332, 1998.

Schroeder, W. H., Steffen, A., Scott, K., bender, T., Prestbo, E., 
Ebinghas, R., Lu, J. Y., and Lindberg, S. E.: Summary report: first international Arctic atmospheric mercury research workshop, Atmos. Environ., 37, 2551-2555, 2003.

Serreze, M. C. and Francis, J. A.: The Arctic amplification debate, Clim. Chang., 76, 241-264, doi:10.1007/s10584-005-9017-y, 2006.

Serreze, M. C., Maslanik, J. A., Rehder, M. C., Schnell, R. C., Kahl, J. D., and Andreas, E. L.: Theoretical Heights Of Buoyant Convection Above Open Leads In The Winter Arctic Pack Ice Cover, J. Geophys. Res., 97, 9411-9422, 1992.

Serreze, M. C., Maslanik, J. A., Scambos, T. A., Fetterer, F., Stroeve, J., Knowles, K., Fowler, C., Drobot, S., Barry, R. G., and Haran, T. M.: A record minimum arctic sea ice extent and area in 2002, Geophys. Res. Lett., 30, 1110, doi:10.1029/2002GL016406, 2003.

Shaw, G. E.: The arctic haze phenomenon, Bull. Am. Meteorol. Soc., 76, 2403-2413, 1995.

Shepler, B. C. and Peterson, K. A.: Mercury monoxide: A systematic investigation of its ground electronic state, J. Phys. Chem. A, 107, 1783-1787, 2003.

Shepson, P., Matrai, P., Barrie, L., and Bottenheim, J.: OceanAtmosphere-Sea Ice-Snowpack Interactions in the Arctic and Global Change, EOS Transactions, 84, 349, 2003.

Shepson, P. B., Mackay, E., and Muthuramu, K.: Henry's Law Constants and Removal Processes for Several Atmospheric $\beta$ Hydroxy Alkyl Nitrates, Environ. Sci. Technol., 30, 3618-3623, 1996.

Sheridan, P. J., Schnell, R. C., Zoller, W. H., Carlson, N. D., Rasmussen, R. A., Harris, J. M., and Sievering, H.: Composition of Br-containing aerosols and gases related to boundary layer ozone destruction in the Arctic, Atmos. Environ., 27 A, 2839-2849, 1993.

Siegenthaler, U., Stocker, T. F., Monnin, E., Luthi, D., Schwander, J., Stauffer, B., Raynaud, D., Barnola, J. M., Fischer, H., MassonDelmotte, V., and Jouzel, J.: Stable carbon cycle-climate relationship during the late Pleistocene, Science, 310, 1313-1317, 2005.

Simpson, W. R., King, M. D., Beine, H. J., Honrath, R. E., and Peterson, M. C.: Atmospheric photolysis rate coefficients during the Polar Sunrise Experimeny ALERT2000, Atmos. Environ., 36, 2471-2480, 2002.

Simpson, W. R., Alvarez-Aviles, L., Douglas, T. A., Sturm, M., and Domine, F.: Halogens in the coastal snow pack near Barrow, Alaska: Evidence for active bromine air-snow chemistry during springtime, Geophys. Res. Lett., 32, L04811, doi:10.1029/2004GL021748, 2005.

Simpson, W. R., Carlson, D., Hönninger, G., Douglas, T. A., Sturm, M., Perovich, D., and Platt, U.: First-year sea-ice contact predicts bromine monoxide $(\mathrm{BrO})$ levels at Barrow, Alaska better than potential frost flower contact, Atmos. Chem. Phys., 7, 621-627, 2007 ,

http://www.atmos-chem-phys.net/7/621/2007/.

Sjostedt, S. J., Huey, L. G., Tanner, D. J., Peischl, J., Chen, G., Dibb, J. E., Lefer, B., Hutterli, M. A., Beyersdorf, A. J., Blake, N. J., Blake, D. R., Sueper, D., Ryerson, T., Burkhart, J., and Stohl, A.: Observations of hydroxyl and the sum of peroxy radicals at Summit, Greenland during summer 2003, Atmos. Environ., 41, 5122-5137, doi:10.1016/j.atmosenv.2006.06.065, 2007.

Slemr, F., Brunke, E., Ebinghaus, R., Temme, C., Munthe, J., Wang- berg, I., Schroeder, W. H., Steffen, A., and Berg, T.: Worldwide Trend of Atmospheric Mercury since 1977, Geophys. Res. Lett., 30, 1516, doi:10.1029/2003GL016954, 2003.

Solberg, S., Schmidbauer, N., Semb, A., and Stordal, F.: Boundarylayer ozone depletion as seen in the Norwegian arctic in spring, J. Atmos. Chem., 23, 301-332, 1996.

Solomon, S., Garcia, R. R., Rowland, F. S., and Wuebbles, D. J.: On the depletion of Antarctic ozone, Nature, 321, 755-758, 1986.

Solomon, S., Garcia, R. R., and Ravishankara, A. R.: On the role of iodine in ozone depletion, J. Geophys. Res., 99, 20 491-20 499, 1994.

Sommar, J., Wängberg, I., Berg, T., Grdfeldt, K., Munthe, J., Richter, A., Urba, A., Wittrock, F., and Schroeder, W. H.: Circumpolar transport and air-surface exchange of atmospheric mercury at NyÅlesund (79 N), Svalbard, spring 2002, Atmos. Chem. Phys., 7, 151-166, 2007, http://www.atmos-chem-phys.net/7/151/2007/.

Spahni, R., Chappellaz, J., Stocker, T. F., Loulergue, L., Hausammann, G., Kawamura, K., Flückiger, J., Schwander, J., Raynaud, D., Masson-Delmotte, V., and Jouzel, J.: Atmospheric Methane and Nitrous Oxide of the Late Pleistocene from Antarctic Ice Cores, Science, 310, 1317-1321, 2005.

Spicer, C. W., Plastridge, R. A., Foster, K. L., Finlayson-Pitts, B. J., Bottenheim, J. W., Grannas, A. M., and Shepson, P. B.: Molecular halogens before and during ozone depletion events in the Arctic at polar sunrise: concentrations and sources, Atmos. Environ., 36, 2721-2731, 2002.

Staebler, R. M., Denhartog, G., Georgi, B., and Dusterdiek, T.: Aerosol-Size Distributions In Arctic Haze During The Polar Sunrise Experiment 1992, J. Geophys. Res., 99, 25 429-25 437, 1994.

Steffen, A., Douglas, T., Amyot, M., Ariya, P., Aspmo, K., Berg, T., Bottenheim, J., Brooks, S., Cobbett, F., Dastoor, A., Dommergue, A., Ebinghaus, R., Ferrari, C., Gardfeldt, K., Goodsite, M. E., Lean, D., Poulain, A., Scherz, C., Skov, H., Sommar, J., and Temme, C.: A synthesis of atmospheric mercury depletion event chemistry linking atmosphere, snow and water, Atmos. Chem. Phys. Discus., 7, 10 837-10 931, 2007.

Stohl, A.: Characteristics of atmospheric transport into the Arctic troposphere, J. Geophys. Res., 111, D11306, doi:10.1029/2005JD006888, 2006.

Stroeve, J. C., Serreze, M. C., Fetterer, F., Arbetter, T., Meier, W., Maslanik, J., and Knowles, K.: Tracking the Arctic's shrinking ice cover: Another extreme September minimum in 2004, Geophys. Res. Lett., 32, L04501, doi: 10.1029/2004GL021810, 2005.

Strong, C., Fuentes, J. D., Davis, R. E., and Bottenheim, J. W.: Thermodynamic attributes of Arctic boundary layer ozone depletion, Atmos. Environ., 36, 2641-2652, 2002.

Sturges, W. T.: Excess particulate and gaseous bromine at a remote coastal location, Atmos. Environ., 24, 167-171, 1990.

Sturges, W. T. and Shaw, G. E.: Halogens in aerosols in central Alaska, Atmos. Environ., 27A, 2969-2977, 1993.

Sturges, W. T., Cota, G. F., and Buckley, P. T.: Bromoform emission form Arctic ice algae, Nature, 358, 660-662, 1992.

Sturges, W. T., Schnell, R. C., Dutton, G. S., Garcia, S. R., and Lind, J. A.: Spring measurements of tropospheric bromine at Barrow, Alaska, Geophys. Res. Lett., 20, 201-204, 1993.

Stutz, J., Ackermann, R., Fast, J. D., and Barrie, L.: Atmospheric 
Reactive Chlorine and Bromine at the Great Salt Lake, Utah, Geophys. Res. Lett., 29, 1380, doi:10.1029/2002GL014812, 2002.

Sumner, A. L. and Shepson, P. B.: Snowpack production of formaldehyde and its effect on the Arctic troposphere, Nature, 398, $230-233,1999$.

Sumner, A. L., Shepson, P. B., Grannas, A. M., Bottenheim, J. W., Anlauf, K. G., Worthy, D., Schroeder, W. H., Steffen, A., Domine, F., Perrier, S., and Houdier, S.: Atmospheric chemistry of formaldehyde in the Arctic troposphere at polar sunrise, and the influence of the snowpack, Atmos. Environ., 36, 2553-2562, 2002.

Swanson, A. L., Blake, N. J., Dibb, J. E., Albert, M. R., Blake, D. R., and Rowland, F. S.: Photochemically induced production of $\mathrm{CH}_{3} \mathrm{Br}, \mathrm{CH}_{3} \mathrm{I}, \mathrm{C}_{2} \mathrm{H}_{5} \mathrm{I}$, ethene, and propene within surface snow at Summit, Greenland, Atmos. Environ., 36, 2671-2682, 2002.

Tackett, P. J., Cavender, A., Shepson, P. B., Bottenheim, J. W., Morin, S., Deary, J., Steffen, A., and Doerge, C.: A Study of the vertical scale of halogen chemistry in the Arctic troposphere during polar sunrise at Barrow, AK, J. Geophys. Res., 112, D07306, doi:10.1029/2006JD007785, 2007.

Tang, T. and McConnell, J. C.: Autocatalytic release of bromine from Arctic snow pack during polar sunrise, Geophys. Res. Lett., 23, 2633-2636, 1996.

Tarasick, D. W. and Bottenheim, J. W.: Surface ozone depletion episodes in the Arctic and Antarctic from historical ozonesonde records, Atmos. Chem. Phys., 2, 197-205, 2002,

http://www.atmos-chem-phys.net/2/197/2002/.

Theys, N., Smedt, I. D., Roozendael, M. V., Fayt, C., Chabrillat, S., Chipperfield, M., Post, P., and van der A, R.: Total and tropospheric BrO derived from GOME and SCIAMACHY as part of the TEMIS project, in: Proc. Envisat/ERS Symposium, Salzburg, 6-10 September 2004, 2004.

Toom-Sauntry, D. and Barrie, L. A.: Chemical composition of snowfall in the high Arctic: 1990-1994, Atmos. Environ., 36, 2683-2693, 2002.

Toumi, R.: BrO as a sink for dimethylsulphide in the marine atmosphere, Geophys. Res. Lett., 21, 117-120, 1994.

Toumi, R., Bekki, S., and Law, K.: Climate And CCN - Reply, Nature, 375, 111-111, 1995.

Tucceri, M. E., Hólscher, D., Rodriguez, A., Dillon, T. J., and Crowley, J. N.: Absorption cross section and photolysis of OIO, Phys. Chem. Chem. Phys., 8, 834-846, 2006.

Tuckermann, M., Ackermann, R., Golz, C., Lorenzen-Schmidt, H., Senne, T., Stutz, J., Trost, B., Unold, W., and Platt, U.: DOAS-observation of halogen radical-catalysed Arctic boundary layer ozone destruction during the ARCTOC-campaigns 1995 and 1996 in Ny-Ålesund, Spitsbergen, Tellus, 49B, 533-555, 1997.

Van Roozendael, M., Fayt, C., Lambert, J.-C., Pundt, I., Wagner, T., Richter, A., and Chance, K.: Development of a bromine oxide product from GOME, in: Proc. ESAMS'99-European Symposium on Atmospheric Measurements from Space, ESTEC, Noordwijk, The Netherlands, 18-22 January 1999, ESA WPP-161, 543-547, 1999.

Van Roozendael, M., Wagner, T., Richter, A., Pundt, I., Arlander, D. W., Burrows, J. P., Chipperfield, M., Fayt, C., Johnston, P. V., Lambert, J. C., Kreher, K., Pfeilsticker, K., Platt, U., Pom- mereau, J. P., Sinnhuber, B. M., Tornkvist, K. K., and Wittrock, F.: Intercomparison of $\mathrm{BrO}$ measurements from ERS-2 GOME, ground-based and balloon platforms, in: Remote Sensing Of Trace Constituents In The Lower Stratosphere, Troposphere And The Earth's Surface: Global Observations, Air Pollution And The Atmospheric Correction, vol. 29 of Advances Space Res., 11, 1661-1666, 2002.

Vogt, R., Crutzen, P. J., and Sander, R.: A mechanism for halogen release from sea-salt aerosol in the remote marine boundary layer, Nature, 383, 327-330, 1996.

Vogt, R., Sander, R., von Glasow, R., and Crutzen, P.: Iodine Chemistry and its Role in Halogen Activation and Ozone Loss in the Marine Boundary Layer: A Model Study, J. Atmos. Chem., 32, 375-395, 1999.

von Glasow, R. and Crutzen, P. J.: Tropospheric halogen chemistry, in: The Atmosphere, edited by: Keeling, R. F., vol. 4, Treatise on Geochemistry, edited by: Holland, H. D. and Turekian, K. K., 21-64, Elsevier-Pergamon, Oxford, 2003.

von Glasow, R. and Crutzen, P. J.: Model study of multiphase DMS oxidation with a focus on halogens, Atmos. Chem. Phys., 4, 589608, 2004,

http://www.atmos-chem-phys.net/4/589/2004/.

von Glasow, R. and Crutzen, P. J.: Tropospheric halogen chemistry, in: The Atmosphere (ed. R. F. Keeling), Vol. 4 Treatise on Geochemistry (eds. H. D. Holland and K. K. Turekian), p. in press, Elsevier-Pergamon, Oxford, 2007.

von Glasow, R., von Kuhlmann, R., Lawrence, M. G., Platt, U., and Crutzen, P. J.: Impact of reactive bromine chemistry in the troposphere, Atmos. Chem. Phys., 4, 2481-2497, 2004, http://www.atmos-chem-phys.net/4/2481/2004/.

Wagenbach, D., Ducroz, F., Mulvaney, R., Keck, L., Minikin, A., Legrand, M., Hall, J. S., and Wolff, E. W.: Sea-salt aerosol in coastal Antarctic regions, J. Geophys. Res., 103, 10 961-10974, 1998.

Wagner, T.: Observations of Atmospheric Halogen Species, Ph.D. thesis, Univ. of Heidelberg, 1999.

Wagner, T. and Platt, U.: Satellite mapping of enhanced BrO concentrations in the troposphere, Nature, 395, 486-490, 1998a.

Wagner, T. and Platt, U.: Mapping of tropospheric BrO by GOME, Earth Observation Quarterly, ESA, March, 1998b.

Wagner, T., Pfeilsticker, K., and Platt, U.: GOME global BrO observations, validation with ground based and balloon measurements, in: Proceedings of the fourth European symposium, 22 26 September 1997, Schliersee, Germany, Air Pollution Report 66, 397-400, 1998a.

Wagner, T., Pfeilsticker, K., and Platt, U.: GOME observations of enhanced tropospheric $\mathrm{BrO}$ concentrations in the polar spring, in: Proceedings of the fourth European symposium, 22-26 September 1997, Schliersee, Germany, Air Pollution Report 66, 401404, 1998b.

Wagner, T., Leue, C., Wenig, M., Pfeilsticker, K., and Platt, U.: Spatial and temporal distribution of enhanced boundary layer $\mathrm{BrO}$ concentrations measured by the GOME instrument aboard ERS2, J. Geophys. Res., 106, 24 225-24 235, 2001.

Wagner, T., Ibrahim, O., Sinreich, R., Frieß, U., von Glasow, R., and Platt, U.: Enhanced tropospheric BrO concentrations over Antarctic sea ice in mid winter observed from MAX-DOAS on board the research vessel Polarstern, Atmos. Chem. Phys., 7, 3129-3142, 2007, 
http://www.atmos-chem-phys.net/7/3129/2007/.

Wagner, V., von Glasow, R., Fischer, H., and Crutzen, P. J.: Are $\mathrm{CH}_{2} \mathrm{O}$ Measurements in the Marine Boundary Layer Suitable for Testing the Current Understanding of $\mathrm{CH}_{4}$ Photooxidation?, J. Geophys. Res., 107, 4029, doi: 10.1029/2001JD000722, 2002.

Watanabe, A., Nojiria, Y., and Kariyab, S.: Measurement on a commercial vessel of the ozone concentration in the marine boundary layer over the northern North Pacific Ocean, J. Geophys. Res., 110, D11310, doi:10.1029/2004JD005514, 2005.

Wayne, R. P., Poulet, G., Biggs, P., Burrows, J. P., Cox, R. A., Crutzen, P. J., Hayman, G. D., Jenkin, M. E., le Bras, G., Moortgat, G. K., Platt, U., and Schindler, R. N.: Halogen oxides: Radicals, sources and reservoirs in the laboratory and in the atmosphere, Atmos. Environ., 29, 2677-2884, 1995.

Wennberg, P.: Bromine explosion, Nature, 397, 299-301, 1999.

Wessel, S., Aoki, S., Winkler, P., Weller, R., Herber, A., Gernandt, H., and Schrems, O.: Tropospheric ozone depletion in polar regions. A comparison of observations in the Arctic and Antarctic, Tellus, 50B, 34-50, 1998.

Wever, R., Tromp, M. G. M., Kronn, B. E., Marjani, A., and van Tol, M.: Brominating activity of the seaweed Ascophyllum nodosum: Impact on the Biosphere, Environ. Sci. Technol., 25, 446-449, 1991.

Wingenter, O., Sive, B. C., Blake, D. R., Rowland, F. S., and Ridley, B. A.: Unexplained enhancements of $\mathrm{CH}_{3} \mathrm{Br}$ in Artic and subArctic lower tyroposphere during TOPSE spring 2000, Geophys. Res. Lett., 30, 2160, doi:10.1029/2003GL018159, 2003.

Wittrock, F., Müller, R., Richter, A., H. Bovensmann, H., and Burrows, J. P.: Measurements of Iodine monoxide (IO) above Spitsbergen, Geophys. Res. Lett., 27, 1471-1474, 2000.

Wolff, E. W.: Understanding the past - climate history from Antarctica, Antarct. Sci., 17, 487-495, 2005.

Wolff, E. W., Rankin, A. M., and Roethlisberger, R.: An ice core indicator of Antarctic sea ice production?, Geophys. Res. Lett., 30, 2158-2161, 2003.

Wolff, E. W., Fischer, H., Fundel, F., Ruth, U., Twarloh, B., Littot, G. C., Mulvaney, R., Rothlisberger, R., de Angelis, M., Boutron, C. F., Hansson, M., Jonsell, U., Hutterli, M. A., Bigler, M., Lambeck, K., Kaufmann, P., Stauffer, B., Stocker, T. F., Steffensen, J. P., Siggaard-Andersen, M. L., Udisti, R., Becagli, S., Castellano, E., Severi, M., Wagenbach, D., Barbante, C., Gabrielli, P., and Gaspari, V.: Southern Ocean sea-ice extent, productivity and iron flux over the past eight glacial cycles, Nature, 440, 491-496, 2006.
Yang, J., Honrath, R. E., Peterson, M. C., Dibb, J. E., Sumner, A. L., Shepson, P. B., Frey, M., Jacobi, H. W., Swanson, A., and Blake, N.: Impacts of snowpack emissions on deduced levels of $\mathrm{OH}$ and peroxy radicals at Summit, Greenland, Atmos. Environ., 36, 2523-2534, 2002.

Yang, X., Cox, R. A., Warwick, N. J., Pyle, J. A., Carver, G. D., O'Connor, F. M., and Savage, N. H.: Tropospheric bromine chemistry and its impacts on ozone, J. Geophys. Res., 110, D23311, doi:10.1029/2005JD006244, 2005.

Yokouchi, Y., Akimoto, H., Barrie, L. A., Bottenheim, J. W., Anlauf, K., and Jobson, B. T.: Serial Gas-Chromatographic Mass-Spectrometric Measurements Of Some Volatile OrganicCompounds In The Arctic Atmosphere During The 1992 Polar Sunrise Experiment, J. Geophys. Res., 99, 25 379-25 389, 1994.

Yokouchi, Y., Barrie, L. A., Toom, D., and Akimoto, H.: The seasonal variation of selected natural and anthropogenic halocarbons in the Arctic troposphere, Atmos. Environ., 30, 1723-1727, 1996.

Yokouchi, Y., Ikeda, M., Inuzuka, Y., and Yukawa, T.: Strong emissions of methyl chloride from tropical plants, Nature, 416, 163$165,2002$.

Yung, Y. L., Pinto, J. P., Watson, R. T., and Sander, P.: Atmospheric bromine and ozone perturbations in the lower stratosphere, J. Atmos. Sci., 37, 339-353, 1980.

Zeng, T., Wang, Y., Chance, K., Browell, E. V., Ridley, B. A., and Atlas, E. L.: Widespread persistent near-surface ozone depletion at northern high latitudes in spring, Geophys. Res. Lett., 30, 2298, doi:10.1029/2003GL018 587, 2003.

Zeng, T., Wang, Y., Chance, K., Blake, N., Blake, D., and Ridley, B.: Halogen-driven low-altitude $\mathrm{O}_{3}$ and hydrocarbon losses in spring at northern high latitudes, J. Geophys. Res., 111, D17313, doi:10.029/2005JD006706, 2006.

Zhou, X., Beine, H. J., Honrath, R. E., Fuentes, J. D., Simpson, W., Shepson, P. B., and Bottenheim, J. W.: Snowpack Photochemical production of HONO: A Major Source of $\mathrm{OH}$ in the Arctic Boundary Layer in Springtime, Geophys. Res. Lett., 28, 40874090, 2001. 